\title{
MHC II and the endocytic pathway; Regulation by Invariant Chain
}

Thesis for the degree of Philosophiae Doctor

Ole Jørgen Bjarnason Landsverk
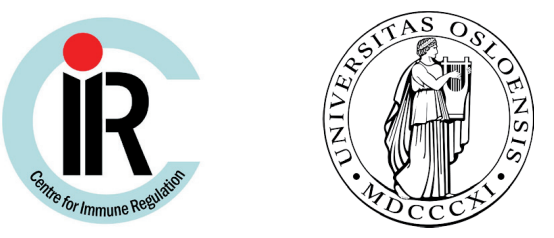

Centre for Immune Regulation

Department of Molecular Biosciences

Faculty of Mathematics and Natural Sciences

University of Oslo

2010 
(C) Ole Jørgen Bjarnason Landsverk, 2011

Series of dissertations submitted to the

Faculty of Mathematics and Natural Sciences, University of Oslo No. 1045

ISSN $1501-7710$

All rights reserved. No part of this publication may be reproduced or transmitted, in any form or by any means, without permission.

Cover: Inger Sandved Anfinsen.

Printed in Norway: AIT Oslo AS.

Produced in co-operation with Unipub.

The thesis is produced by Unipub merely in connection with the thesis defence. Kindly direct all inquiries regarding the thesis to the copyright holder or the unit which grants the doctorate. 


\section{CONTENTS}

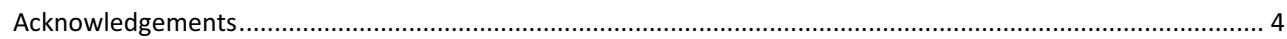

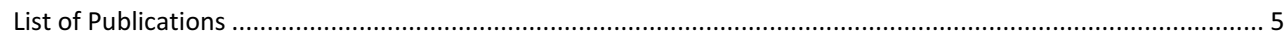

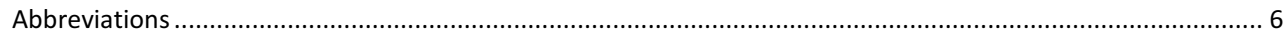

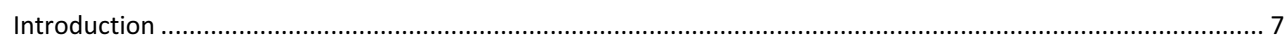

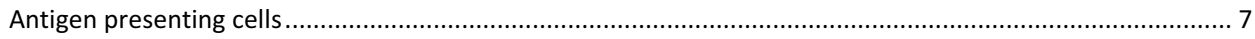

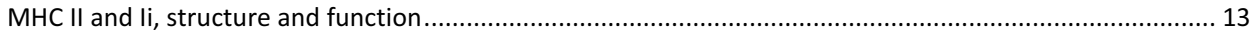

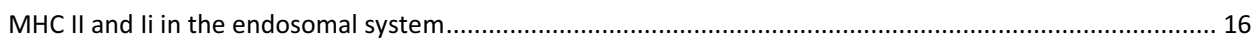

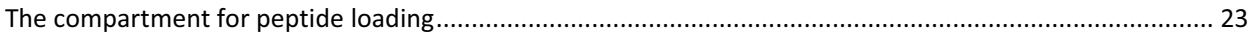

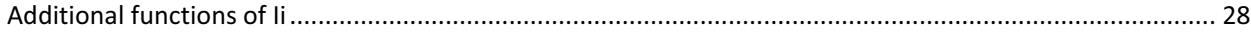

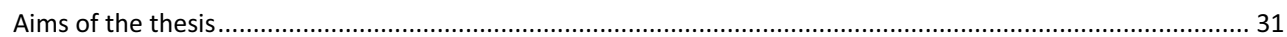

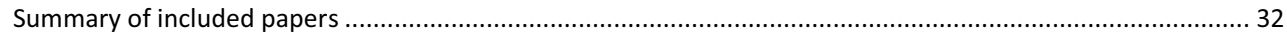

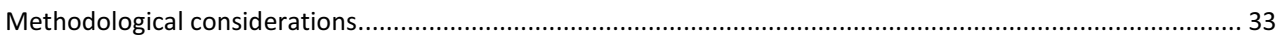

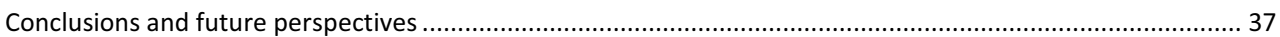

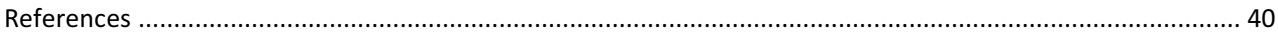

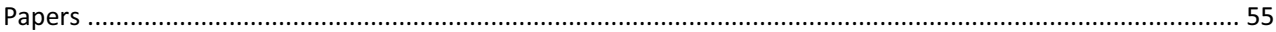




\section{ACKNOWLEDGEMENTS}

The work presented in this thesis was carried out in Professor Oddmund Bakke's laboratory in the Centre for Immune Regulation at the Department of Molecular Biosciences, Faculty of Mathematics and Natural Sciences, University of Oslo from 2005 to 2010 . This work was financially supported by a recruitment stipend with teaching responsibility from the University of Oslo.

I would like to thank professor Oddmund Bakke for giving me the opportunity to carry out the work presented in this thesis. His support, enthusiasm and confidence in my abilities have been invaluable in my development as a scientist. Furthermore, his efforts in establishing and maintaining the live imaging platform and recruiting and supporting the people who work here has provided a stimulating environment and excellent facilities in which to conduct this work.

I want to thank all my past and present colleagues and friends at the Department of Molecular Biosciences and the Centre for Immune Regulation for scientific discussions, technical advice and social activities. Many thanks to my co-supervisor Silke Appel for advise and critical review of my work and help with the moDCs and qRTPCR. Thanks to Inger $\varnothing$ ynebråten for comments on the text (and removing all the double-spaces) and help with the flow cytometry. Thanks to Frode Skjeldal and Trygve Bergeland for sharing their vast experience and passion for live cell microscopy and the endosomal system. Thanks to my ex-master student Anett $\mathrm{H}$. Ottesen for her work on paper II and the other co-authors for their contributions to the papers. A huge thanks to Tone Gregers for outstanding advice, persistent support and countless excellent scientific discussions.

A special thanks to my family for all their love and support, without you I would be lost. 


\section{LIST OF PUBLICATIONS}

Landsverk, O. J. B., Barois, N., Gregers, T. F., Bakke, O.

Invariant chain increases the half-life of $\mathrm{MHC}$ II by delaying endosomal maturation.

Immunol Cell Biol. 2010 Nov 30. [Epub ahead of print].

Landsverk, O. J. B., Ottesen, A. H., Berg-Larsen, A., Appel, S., Bakke, O.

Regulation of invariant chain through monocyte derived dendritic cell maturation.

Manuscript.

PARTS OF THE INTRODUCTION IS BASED ON

Landsverk O.J., Bakke O., Gregers T. F.

$\mathrm{MHC}$ II and the endocytic pathway: Regulation by invariant chain.

Scand J Immunol. 2009 Sep;70(3):184-93. Review

Landsverk O.J., Bakke O., Gregers T. F.

CD74 (Invariant chain).

UCSD-Nature Molecule Pages (in submission) Review

PUBLICATIONS NOT INCLUDED IN THE THESIS

Bergeland T., Haugen L., Landsverk O. J., Stenmark H., Bakke O.

Cell-cycle-dependent binding kinetics for the early endosomal tethering factor EEA1.

EMBO Rep. 2008 Feb;9(2):171-8.

Landsverk, H. B., Mora-Bermúdez, F. Landsverk O. J. B., Hasvold, G., Naderi, S., Bakke, O., Ellenberg, J., Syljuåsen, R. G., Collas, P., Küntziger, T.

The protein phosphatase 1 regulator PNUTS is a novel component of the DNA damage response.

EMBO Rep. 2010 Nov;11(11):868-75.

Marstad, A., Landsverk O. J., Otterlei, M., Bakke, O., Collas, P., Brede, G.

AKAP95 is a novel activator of ribosomal RNA transcription - a comparative examination of AKAP95 and HA95. Manuscript submitted. 


\section{ABBREVIATIONS}

\begin{tabular}{|c|c|c|c|}
\hline$A P$ & Adaptor protein & MDCK & Madin Darby canine kidney \\
\hline APC & Antigen presenting cell & $\mathrm{MHC}$ & Major histocompatibility complex \\
\hline ARF & ADP ribosylation factor & MIF & Macrophage migration inhibitory factor \\
\hline $\mathrm{BcR}$ & B cell receptor & MIIC & MHC class II compartment \\
\hline BMDC & Bone-marrow derived dendritic cell & $\operatorname{moDC}$ & Monocyte derived dendritic cell \\
\hline BSA & Bovine serum albumin & MR & Mannose receptor \\
\hline$C C D$ & Charge-coupled device & mRNA & Messenger ribonucleic acid \\
\hline $\mathrm{CCL}$ & $\mathrm{C}-\mathrm{C}$ motif chemokine ligand & MVB & Multi-vesicular body \\
\hline CCR & $\mathrm{C}-\mathrm{C}$ motif chemokine receptor & $\mathrm{M} \theta$ & Macrophage \\
\hline$C D$ & Cluster of differentiation & NF-KB & Nuclear factor-кВ \\
\hline CIITA & MHC class II trans-activator & NK & Natural killer \\
\hline CIIV & MHC class II vesicle & NOS2 & Nitric-oxide Synthase 2 \\
\hline CLIP & Class II associated Invariant chain peptide & NOX2 & Nicotinamide adenine dinucleotide phosphate \\
\hline COPII & Coat protein complex II & & (NADPH) oxidase \\
\hline DC & Dendritic cell & PAGFP & Photo-activable green fluorescent protein \\
\hline DNA & Deoxyribonucleic acid & $\mathrm{pDC}$ & Plasmacytoid dendritic cell \\
\hline EEA1 & Early endosomal antigen 1 & $\mathrm{PI}-\mathrm{K}$ & Phosphatidylinositol kinase \\
\hline EGFP & Enhanced green fluorescent protein & PKC & Protein kinase $\mathrm{C}$ \\
\hline ER & Endoplasmatic reticulum & PMT & Photo-multiplier tube \\
\hline \multirow[t]{2}{*}{ ESCRT } & \multirow{2}{*}{$\begin{array}{l}\text { Endosomal sorting complex required for trans- } \\
\text { port }\end{array}$} & PRR & Pattern recognition receptor \\
\hline & & Ptdlns & Phosphatidylinositol \\
\hline FcRn & Neonatal Fc receptor & qRT-PCR & Quantitative real time polymerase chain reac- \\
\hline FRET & Fluorescence resonance energy transfe & & tion \\
\hline FYVE & Ptdlns(3)P binding motif named after its 4 & RNA & Ribonucleic acid \\
\hline & founding members: Fab1, YOTB, Vac1 and EEA1 & SNARE & Soluble N-ethylmalemide-sensitive factor (NSF) \\
\hline GAP & GTPase activating protein & & attachment protein receptors \\
\hline GAPDH & Glyceraldehyde 3-phosphate dehydrogenase & SR & Scavenger receptor \\
\hline GEF & Guanine nucleotide exchange factor & TAP & Transporter associated with antigen processing \\
\hline GFP & Green fluorescent protein & TcR & T cell receptor \\
\hline \multirow[t]{2}{*}{ GM-CSF } & \multirow{2}{*}{$\begin{array}{l}\text { Granulocyte-macrophage colony-stimulating } \\
\text { factor }\end{array}$} & TEC & Thymic epithelial cell \\
\hline & & TGN & Trans-golgi network \\
\hline GTP & Guanosine triphosphate & $\mathrm{TH}$ & T helper cell \\
\hline GTPase & Guanosine triphosphatase & TLR & Toll-like receptor \\
\hline HLA & Human leukocyte antigen & TM & Trans-membrane \\
\hline HOPS & Homotypic vacuole fusion and protein sorting & TNF & Tumour necrosis factor \\
\hline Hrs & $\begin{array}{l}\text { Hepatocyte-growth-factor-regulated tyrosine- } \\
\text { kinase substrate }\end{array}$ & VAMP & Vesicle associated membrane protein \\
\hline IFN & Interferon & & \\
\hline $\lg$ & Immunoglobulin & & \\
\hline li & Invariant chain, also called CD74 & & \\
\hline $\mathrm{IL}$ & Interleukin & & \\
\hline iNOS & Inducible nitric oxide synthase & & \\
\hline LAMP & Lysosome associated membrane protein & & \\
\hline LC & Langerhans cell & & \\
\hline LIMP & Lysosome integral membrane protein & & \\
\hline LPS & Lipopolysaccharide & & \\
\hline M6PR & Mannose 6-phosphate receptor & & \\
\hline
\end{tabular}

MARCH-1 Membrane-associated RING-CH 1 


\section{INTRODUCTION}

The immune system serves to protect us against infectious agents (virus, bacteria, fungi and parasites) which manage to penetrate the epithelial surfaces of the body. It is generally divided into two parts, where the innate immune system recognizes foreign entities based on features common to groups of pathogens with invariant pattern recognition receptors (PRRs), and the adaptive immune system targets individual pathogens through the random generation and specific selection of antigen targeting modules ( $T$ cell receptors and antibodies). The adaptive immune response can be divided further into cell-mediatedand humoral immunity, characterized by activation and proliferation of $\mathrm{T}$ cells, and production of antibodies by $B$ cells, respectively. Both branches of the adaptive immune system require the licensing of pathogen specific $T$ cell clones by antigen presenting cells (APCs). APCs presenting pieces of antigen (peptides) on major histocompatibility complex (MHC) class I molecules activate $\mathrm{CD}^{+} \mathrm{T}$ cells and induce their differentiation into cytotoxic $T$ cells which eliminate infected cells presenting the same antigen on their MHC I. APCs presenting antigenic fragments on MHC class II molecules activate helper $\left(\mathrm{CD}^{+}\right) \mathrm{T}$ cells, which in turn activate $\mathrm{B}$ cells presenting the same antigen on their own MHC II. Activated B cells differentiate into plasma cells that produce antibodies which are released into the extracellular fluids where they attach to their antigens, neutralizing them and marking them for destruction by phagocytes and the complement system. Activated $\mathrm{CD}^{+}{ }^{+} \mathrm{T}$ cells can also contribute to cell-mediated immunity by stimulating APCs to become more efficient stimulators of $\mathrm{CD}^{+} \mathrm{T}$ cells, and on innate immunity by delivering activating signals to phagocytic cells. The presentation of antigenic peptides on MHC II is thereby important for both adaptive and innate immunity against infectious agents. MHC $\|$ assembly in the endoplasmic reticulum (ER) and trafficking to endosomes for peptide loading is guided by a specialized chaperone termed the invariant chain (Ii). li self-associates into a trimer in the ER, this provides a scaffold for the assembly of three MHC II heterodimers and blocks their peptide binding grooves to avoid premature binding of endogenous peptides in the ER and Golgi apparatus. Ii then transports MHC II to endocytic compartments where they encounter internalized pathogens and modulates the endocytic environment to facilitate the generation of diverse arrays of pathogenic peptides. Thus, in the absence of li the assembly of MHC II is impaired and the repertoire of antigenic peptides displayed is significantly compromised. Ii is therefore crucial to achieve the efficient antigen presentation on MHC II and consequently for APC function in innate and adaptive immune responses. The aim of this thesis was to investigate the molecular mechanisms involved in the loading of diverse repertoires of antigenic fragments on $\mathrm{MHC} \mathrm{II}$ with a special focus on the roles played by the versatile li molecule.

\section{ANTIGEN PRESENTING CELLS}

Whereas MHC I is ubiquitously expressed on all nucleated cells, the expression of MHC II is generally restricted to a limited set of cells, which include $B$ lymphocytes, cells of the monocyte-macrophage lineage (MOs) and dendritic cells (DCs). These three constitute the so-called professional antigen presenting cells (APCs), and are more or less specialized to acquire, process and present antigens 
(Trombetta and Mellman, 2005). In humans (but not in mice) activated T cells can also express MHC II, and thymic epithelial cells (TECs), presenting endogenous peptides on $\mathrm{MHC} \mathrm{II}$, play an vital role in the development of CD4+ T cells. Through positive and negative selection TECs direct the development of the $T$ cell receptor (TcR) repertoire in the thymus (Derbinski and Kyewski, 2010; Starr et al., 2003). Finally MHC II expression can be induced in a number of other cell types by interferon (IFN)- $\gamma$ (Harton and Ting, 2000; Pattenden et al., 2002; Pober et al., 1983).

\section{B LYMPHOCYTES}

The principal function of $B$ cells is to make antibodies to identify and neutralize foreign objects. As such, they primarily present fragments of antigens recognized and internalized via their clonally specific, cell surface expressed, immunoglobulin, the $B$ cell receptors $(B c R)$. Although antigen recognition and uptake via the $B c R$ can in some cases enable $B$ cells to activate naïve $T$ cells (Rodriguez-Pinto, 2005; Rodriguez-Pinto and Moreno, 2005), the relative low frequency of naïve $B$ cell clones with a BcR specific for any particular antigen and their absence from mucosa and skin make them inadequate as antigen presenters to initiate adaptive immune responses. Nevertheless, the presentation of antigen by $B$ cells to activated, antigen specific, helper $T$ cells is essential for their development into antibody producing plasma cells (Parker, 1993), and the class of antibody produced depends on the type of helper $\mathrm{T}$ cell involved and the cytokines released (King et al., 2008).

\section{MACROPHAGES}

$\mathrm{M} \theta \mathrm{s}$ are a diverse population of phagocytes which in the steady state scavenge cellular debris and facilitate tissue remodeling (Geissmann et al., 2010b; Mosser and Edwards, 2008). During infection they are particularly adept at the destruction of pathogens due to the expression of a broad range of phagocytic receptors, and a particularly proteolytic endo-lysosomal system (Aderem and Underhill, 1999; Gordon, 2002). In response to interferon (IFN) $\gamma$ and PRR stimulation, the processing of intracellular pathogens is further enhanced as part of the microbial response (MacMicking et al., 2003; Santic et al., 2005; Xu et al., 2007). Conversely this feature which makes them so adept at destroying intracellular microbes eliminates many $T$ cell epitopes and thereby negatively impacts on their capacity to present diverse repertoires of antigenic fragments on MHC II. Alternative activation with interleukin (IL)-4 and/or IL-13 results in MOs with a lower production of toxic oxygen and nitrogen radicals, and decreased ability to kill intracellular bacteria, but these $\mathrm{M} \theta$ s express little or no costimulatory molecules and fail to stimulate naïve $T$ cells (Edwards et al., 2006). In keeping with their primary function in clearing the interstitial environment of extraneous cellular material, MOs are mostly tissue resident and do not efficiently migrate to lymphoid organs where the majority of naïve $\mathrm{T}$ lymphocytes are found. Consequently $\mathrm{M} \theta \mathrm{s}$ fail to present their acquired antigen to wide repertoires of $\mathrm{T}$ cell clones, and are therefore not considered sufficient to maintain adaptive immunity.

\section{DENDRITIC CELLS}

The by far most potent stimulators of naïve $T$ cells are the DCs. These cells can be found throughout the various tissues of the body where they act as sentinels to discover and alert the immune system to the presence of foreign entities (Figure 1). DCs continuously sample their environment via diverse endocytic mechanisms and they express a wide range of PRRs which upon ligation initiates a 


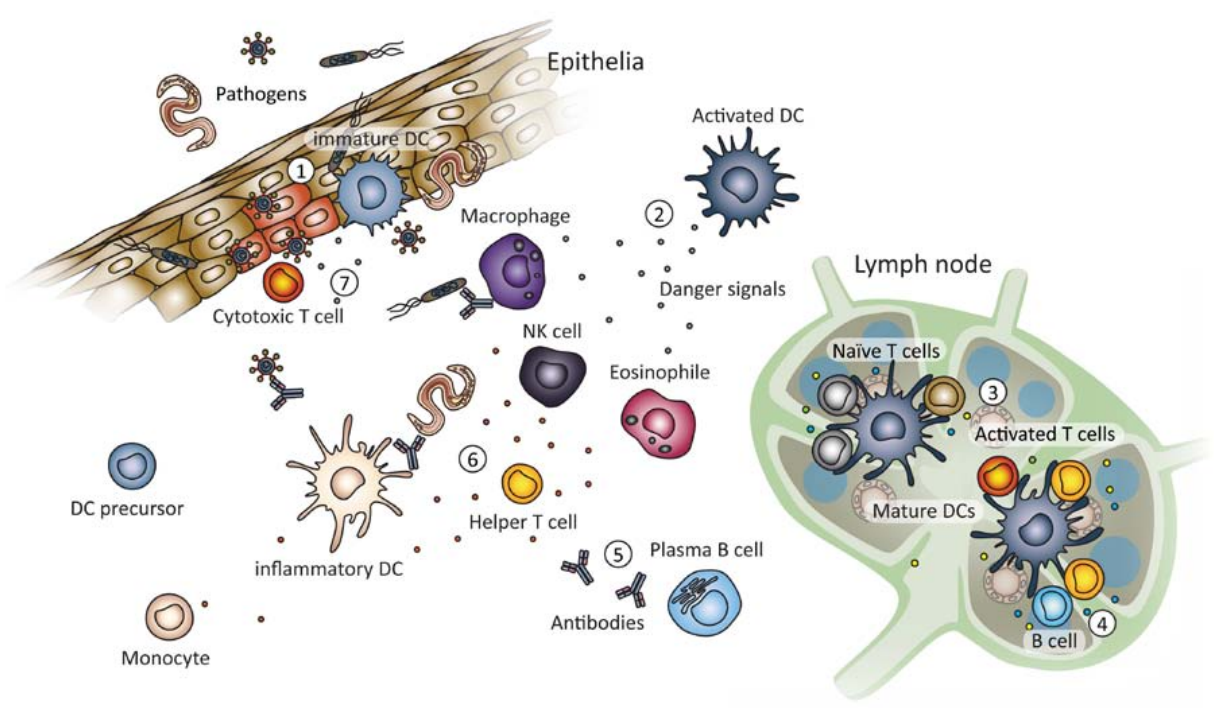

FIgURE 1 | FUnCTION OF DENDRITIC CELLS ACCORDING TO THE LANGERHANS CELL PARADIGME. DCs act as sentinels in tissues by sensing the local environment (1) and respond to pathogens (e.g. viruses and bacteria) or inflammatory stimuli (e.g. TNF- $\alpha$ or IL-1 $\beta$ ) by differentiating into mature DCs. Mature DCs act locally by secreting chemokines and cytokines which recruit and activate innate immune cells (e.g. NK cells, MOs and eosinophiles) (2), and they migrate to secondary lymphoid organs where they activate naïve antigen-specific T lymphocytes (3). Activated helper T cells can direct B cells to differentiate into plasma cells (4). Plasma B cells secrete antibodies which attach to antigens, neutralizing them and marking them for destruction by phagocytes and the complement system (5). T helper cells also produce cytokines locally for the recruitment and activation of innate immune cells (6). Activated cytotoxic T cells target infected cells directly by inducing their apoptosis or releasing lytic proteins (perforin, granulysins and granzymes) (7). Figure based on (Banchereau et al., 2000).

complex differentiation program termed "maturation". Mature DCs are characterized functionally by their ability to prime immune responses and phenotypically by the expression of high cell surface levels of MHC II and costimulatory molecules (discussed in (Reis e Sousa, 2006)). This is due to diverse intracellular events which influences: i) the uptake and processing of antigens, ii) the production, peptide loading and cell surface stability of $\mathrm{MHC}$ II, iii) the expression of cytokine receptors and adhesion molecules involved in migration, iv) the release of cytokines for recruitment and activation of innate immune cells and v) the expression of co-stimulatory molecules and secretion of cytokines for the activation and polarization of naïve $\mathrm{T}$ cells (Banchereau et al., 2000).

\section{DENDRitic CELls ORCHEStRATE IMMUNE RESPONSES}

Depending on the activating ligand, the extracellular milieu at the time and place of activation and the type of DC which is activated, mature DCs direct the polarization of antigen specific naïve $T$ cells to facilitate the appropriate responses (Dorhoi and Kaufmann, 2009). Thus, influenza virus dsRNA, binding TLR3, induces the secretion of IL-12 by human monocyte derived (mo-) DCs, $\mathrm{T}_{\mathrm{H}} 1$ development, and immunity against intracellular pathogens (Cella et al., 1999). Development of $\mathrm{T}_{\mathrm{H}} 2$ 
cells mediating host defense against parasitic infections can be induced in mice by bacterial peptidoglycan derived muramyl dipeptide binding the cytosolic PRR Nod2 in mouse bone marrow derived (BM-) DCs (Magalhaes et al., 2008), but also by the fungal cell wall component Zymosan, which triggers the release of IL-10 by mouse splenic $\mathrm{CD} 8 \alpha^{-}$ DCs (Manickasingham et al., 2003). Conversely, Zymosan binding the beta-glucan receptor Dectin 1 and Toll-like receptor (TLR) 2 on human moDCs triggers IL-23 secretion and the development of $T_{H} 17$ $\mathrm{T}$ helper cells crucial for defense against fungi and extracellular bacteria (Gerosa et al., 2008; McGeachy et al., 2009; Milner et al., 2008). In the absence of activating stimuli, or in the presence of immunosuppressive cytokines, DCs can also induce the development of regulatory $\mathrm{T}$ cells, induce $\mathrm{T}$ cell anergy or elimination (Pulendran et al., 2010;
Steinman et al., 2003; Yamazaki and Steinman, 2009) (Figure 2).

In addition to their potent effect on naïve T cells, DCs also influences the activity of other immune cells by releasing signals which recruit and activate innate immune cells. During inflammation, activated DCs release chemokines such as CCL4 (MIP-1 $\beta)$, CCL5 (RANTES), CX3CL1, CXCL8 (IL-8) and CXCL10 (IP-10) which recruits natural killer (NK) cells to sites of inflammation (Megjugorac et al., 2004; Papadopoulos et al., 1999). Type 1 IFNs released by activated plasmacytoid DCs preferentially augments protective NK cell cytotoxicity (Gerosa et al., 2005), whereas activated myeloid DCs secrete IL-12 and IL18 which induces IFNY production by NK cells (Andoniou et al., 2005; Ferlazzo et al., 2004). IFNY is an important inflammatory cytokine, which is also
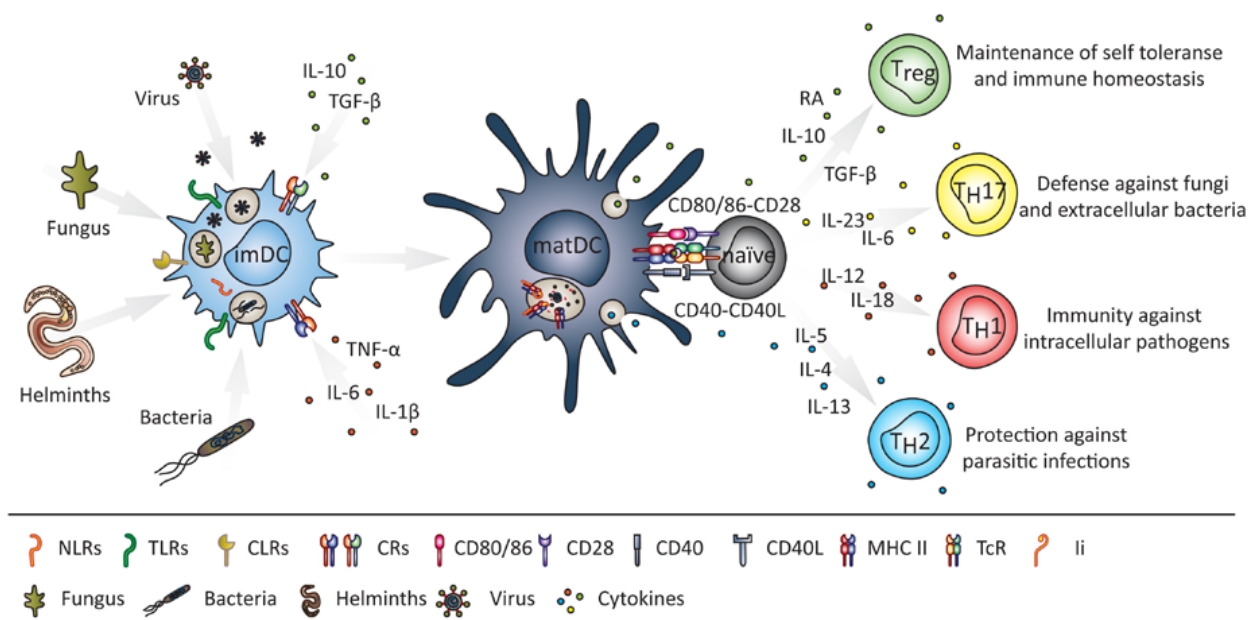

FIgURE 2 | DENDRITIC CELLS INTERPRETE ENVIRONMENTAL CUES AND DIRECT T CELL RESPONSES. DCs can sense pathogens directly through various invariant pattern recognition receptors but also indirectly, through factors secreted by other cells in the micro-environment. Stimulation of distinct signaling pathways mediates the production of different cytokines and factors that control TH polarization. Naïve CD4+ T cells recognizing a specific peptide-MHC II complex and activated through co-stimulatory ligands, develop into different lineages depending on the combination and level of cytokines present. Thus, IL-12 and IL-18 induce $\mathrm{T}_{\mathrm{H}} 1$ responses and IL-4 together with IL-5 and IL-13 favor $\mathrm{T}_{\mathrm{H}} 2$ differentiation. TGF- $\beta$ promotes either $\mathrm{T}_{\text {reg }}$ or $\mathrm{T}_{\mathrm{H}} 17$ polarization, depending on its abundance and on other cytokines. Based on (Dorhoi and Kaufmann, 2009; Pulendran et al., 2010). NLRs, Nod-like receptors; TLRs, Toll-like receptors; CLRs, C-type lectin receptors; CRs, cytokine receptors; TcR, T cell receptor; MHC II, major histocompatibility complex class II molecules; li, invariant chain. 
produced by antigen specific $T_{H} 1$ cells, that has multiple effects on the immune response, including activation of macrophage anti microbial activity, enhanced NK cell cytotoxicity and induction of MHC II and increased MHC I expression in diverse cell types. Importantly, IFNy also leads to the recruitment of monocytes to infected sites where they can differentiate into $M \theta s$ (Gordon and Taylor, 2005), TNF $\alpha$ and iNOS producing inflammatory DCS important for IgA production and clearance of gram positive bacteria (Kang et al., 2008; Serbina et al., 2003; Tezuka et al., 2007), dermal monocyte derived DCs producing IL-12 and $\mathrm{T}_{\mathrm{H}} 1$ responses (Leon et al., 2007) or DC-SIGN/CD209a positive DCs that actively home to lymph nodes in a L-selectin and CCR7 dependent manner and efficiently activate both $\mathrm{CD}^{+}$and $\mathrm{CD}^{+} \mathrm{T}$ cells (Cheong et al., 2010). Monocytes thereby contribute to the steady state DC network by differentiating into distinct mo-DC types at sites of inflammation.

\section{Heterogeneity in the Dendritic Cell network} The heterogeneity in the DC network is bewildering, and the relationship between DC subtypes, monocytes and $M \theta$ s is still debated (Geissmann et al., 2010a). This is due to the variable, often overlapping expression of the various cell surface markers used in their classification, their adaptability to the various tissues they inhabit and their plasticity in response to environmental cues. Also, the differences in DC biology between mice and humans makes extrapolation of findings in mice to the human DC systems complicated. Nevertheless, most DC biologists recognize two main categories of DCs in both species: plasmacytoid DCs (pDCs) and conventional DCs. The pDCs are long lived cells found in circulation which selectively express TLR7 and TLR9 and upon stimulation with viral compounds release large amounts of type । interferons important for anti-viral immunity (Colonna et al., 2004; Liu, 2005). In keeping with their anti-viral function, pDCs preferentially present endogenous viral antigens in a mature state, and maintain MHC II production and turnover in order to achieve this (Villadangos and Young, 2008; Young et al., 2008).

\section{Conventional Dendritic Cells. Conventional} DCs can be divided into multiple subpopulations based on their expression of surface markers, functional properties and the tissues they inhabit (Heath and Carbone, 2009; Shortman and Naik, 2007; Ueno et al., 2010b; Villadangos and Schnorrer, 2007). Mouse lymphoid organs contain at least three resident DC subsets distinguished by their expression of $\operatorname{CD} 8 \alpha$ and CD4. These cells develop from bone-marrow derived precursors within the lymphoid organs and remain there through a limited number of divisions before they die and are replaced (Liu et al., 2007; Naik et al., 2006). CD8 $\alpha$ positive DCs are particularly adept at cross-presenting exogenous antigens on MHC I (Villadangos and Schnorrer, 2007), they are the most efficient phagocytes of dead cells (lyoda et al., 2002) and the dominant producers of IL-12 (Hochrein et al., 2001; Reis e Sousa et al., 1997). This suggests that $C D 8 \alpha^{+}$DCs play a major role in directing $\mathrm{T}_{\mathrm{H}} 1$ development (Maldonado-Lopez et al., 1999) and activation of cytotoxic $\mathrm{CD}^{+} \mathrm{T}$ lymphocytes in response to cellassociated antigens (Shortman and Heath, 2010). In contrast, the $\operatorname{CD} 8 \alpha$ negative (CD4 positive/negative) DCs are more efficient at presenting antigens on MHC II and induction of $\mathrm{T}_{\mathrm{H}} 2$ responses (Dudziak et al., 2007; Maldonado-Lopez et al., 1999; Pulendran et al., 1999; Schnorrer et al., 2006). A third subset expressing neither CD8 $\alpha$ nor CD4 (double-negative) is generally included in the CD8 $\alpha^{-}$DC subset, they 
express the same PRRs (Luber et al., 2010) and have a similar cytokine profile in response to TLR agonists (Proietto et al., 2004). Lymphoid organ resident DCs acquire soluble antigens carried through the afferent lymph (Sixt et al., 2005), or antigen transported into lymph nodes by migratory DCs (Allan et al., 2006).

MIgRATORY DENDRITIC CELLS. At least three distinct migratory DCs enter the draining lymph nodes from the skin in the steady state, with related subsets present in the lymph nodes draining the gut, liver, kidneys and lungs (Heath and Carbone, 2009). The langerin (a C-type lectin receptor, also called CD207) expressing Langerhans cells (LCs) come from the epidermis (Schuler and Steinman, 1985), where they are capable of self renewal in the steady state, but are replenished by progenitor cells from the blood during inflammation (Merad et al., 2002). LCs were considered the prototypic DCs and are the origin of the so-called Langerhans cell paradigm of DC function presented in figure 1 (Girolomoni et al., 2002; Wilson and Villadangos, 2004). The central role of LCs in immunity to skin antigens became disputed when they were found to be incapable of priming $T$ cell responses to epidermal virus infection (Allan et al., 2003), and were dispensable for triggering hapten-specific $\mathrm{T}$ cell effectors by skin immunization (Kissenpfennig et al., 2005). However, other studies show competent cross-presenting capacity and potent induction of CD8+ T cell effector functions (Stoitzner et al., 2006), for reviews see (Kaplan et al., 2008; Romani et al., 2010). Recently a langerin positive DC subset expressing CD103 was identified in the dermis (Bursch et al., 2007; Ginhoux et al., 2007; Poulin et al., 2007), these DCs conform to the Langerhans cell paradigm, but are vastly superior to LCs at cross-presenting viral antigens to $\mathrm{CD}^{+}$T cells (Bedoui et al., 2009; Henri et al., 2010).
The third DC subset present in the skin in the steady state are the classical dermal $\mathrm{CD}_{11} \mathrm{~b}^{+} \mathrm{DCs}$. CD11b DCs efficiently migrate to draining lymph nodes and preferably present antigens in the context of $\mathrm{MHC} \mathrm{II}$ to $\mathrm{CD}^{+} \mathrm{T}$ cells (Bedoui et al., 2009; Zhao et al., 2003).

IN VITRO DENDRITIC CELLS. Studies on basic DC function in mice in many cases relies on in vitro differentiated DCs (Shortman and Naik, 2007), where bone marrow precursors cultured in granulocyte/macrophage colony-stimulating factor (GM-CSF) or FMS-related tyrosine kinase 3 ligand (FLT3L) give rise to DCs which resemble migratory and inflammatory $\mathrm{DCs}$ or $\mathrm{CD}^{-}, \mathrm{CD}^{+}$and $\mathrm{pDCs}$ respectively (Brasel et al., 2000; Inaba et al., 1992; Lutz et al., 1999; Naik et al., 2005).

\section{Dendritic Cells in Mice and Humans.}

Most of the DCs subsets have been identified and characterized in mice due to the obvious ethical and practical difficulties in conducting such research in humans. However, evidence exists that the DC network is maintained also in humans. Human skin contains LCs in the epidermis and two dermal subsets distinguished by the expression of CD1a and $\mathrm{CD} 14$. The $\mathrm{CD}_{14}{ }^{+} \mathrm{DCs}$ prime $\mathrm{CD} 4^{+} \mathrm{T}$ cells that direct plasma cell development but are poor at activating $\mathrm{CD} 8+\mathrm{T}$ cells, whereas the $\mathrm{CD}^{+} \mathrm{a}^{+} \mathrm{DCs}$ are intermediate at activating CD4 and CD8 positive T cells and LCs preferentially induce $T_{H} 2$ development and are superior at priming naïve $\mathrm{CD}^{+} \mathrm{T}$ cells (Klechevsky et al., 2008). Both pDCs and myeloid DCs are found in human blood, and human pDCs like their counterparts in mice, release large amounts of type I interferons upon viral exposure (Siegal et al., 1999). Recently, the human counterparts to mouse lymphoid organ resident $\mathrm{CD} 8 \alpha^{+} \mathrm{DCs}$ were identified, and these $\mathrm{CD}_{141^{+}} \mathrm{DCs}$ are also capable of 
phagocytosing dead cells and cross-presenting cellular and soluble antigens (Bachem et al., 2010; Crozat et al., 2010; Jongbloed et al., 2010; Poulin et al., 2010). In humans, as in mice, monocytes readily differentiate into DCs in response to appropriate stimuli, and such DCs readily stimulate $T$ cells in a mixed lymphocyte reaction (Sallusto and Lanzavecchia, 1994). This protocol for the rapid generation of large numbers of DCs from monocytes has been thoroughly exploited in research to study basic human DC function, and attempts have also been made to use these moDCs to combat cancer and infectious disease (Palucka et al., 2010). However, how these moDCs compare to their in vivo generated counterparts and steady state DC subsets is poorly investigated. In paper II we investigate the maturation induced effects in human moDCs on the molecules involved in presenting antigen to $C D 4+T$ cells.

\section{MHC II AND II, STRUCTURE AND FUNCTION}

MHC II is encoded by polymorphic genes and expressed as non-covalent heterodimers of two type

I (C-terminal in cytosol) transmembrane (TM) polypeptides. The $\alpha(35 \mathrm{kD})$ and the $ß(28 \mathrm{kD})$ chain differ in size mainly due to difference in $\mathrm{N}$-linked glycosylation (Kaufman et al., 1984). The luminal domains of the MHC II chains have an intrinsic ability to associate (Kjær-Nielsen et al., 1990; Wettstein et al., 1991), but interactions by the TM domains promote the formation of correctly assembled complexes (Cosson and Bonifacino, 1992). The extracellular part of the MHC II molecule forms a groove composed of two $\alpha$-helices supported by an eight-strand $\beta$-pleated sheet. The groove contains pockets into which anchoring peptide side chains
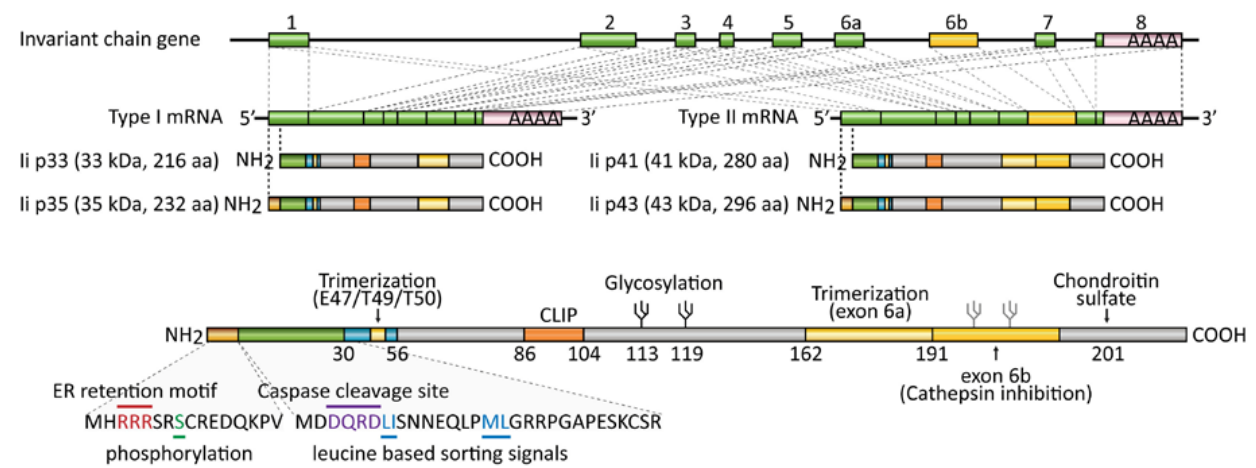

Figure 3 | MOdUlar StRUCtURE OF THE GENE ENCODING hUMAN INVARIANT CHAIN, ITS MRNAS AND PROTEIN PRODUCTS. The Ii gene yields two mRNA species differing in the $3^{\prime}$ region due to alternative splicing of exon 6 . Two alternative in-phase translation initiation codons give rise to four distinct protein isoforms distinguished by a 16 amino acid N-terminal extension (p35 and p43) and a 64 amino acid insertion in the C-terminal region (p41 and p43). The alternative splicing yielding p41 and p43 occurs on approximately 10\% of the transcripts and alternative translation from the first translation initiation start codon found in humans gives an estimated 20 -30\% li proteins containing this 16 amino acid extension. The predominant isoform is consequently p33, however, for simplicity p43 is shown. The 16 amino acid N-terminal extension in p35/p43 contains a prototypic ER retention motif (Lotteau et al., 1990) and a phosphorylation site targeted by protein kinase C (Kuwana et al., 1998). All isoforms contain the remainder of the cytoplasmic tail with a putative caspase cleavage site (DQRD) (Huang et al., 2008), two di-leucine based sorting motifs for adaptor protein interactions and a particular charge distribution which is essential for endosomal fusion and delayed maturation. Heterotypic trimerization is mediated by (at least) two domains contained in the transmembrane region and exon 6a, and MHC II association through CLIP (residues 86-104) which binds into the peptide binding groove of MHC II (Freisewinkel et al., 1993; Romagnoli and Germain, 1994; Stumptner and Benaroch, 1997), but also a region C-terminal to CLIP (residues 103-118) (Thayer et al., 1999) and the trans-membrane region (Castellino et al, 2001). All isoforms contain at least two $\mathrm{N}$-linked and two O-linked glycosylations (Machamer and Cresswell, 1984) and a tiny fraction may acquire a chondroitin sulphate moiety on S201. The figure is based on (Gregers et al., 2003b; Strubin et al., 1986a). 
can fit, and is open at the ends, allowing peptides of varying length to bind. In humans, there are three pairs of polymorphic MHC II genes, named human leukocyte antigen (HLA)-DR, -DP and -DQ (Trowsdale et al., 1991), and two pairs of non-classical MHC II genes, HLA-DM (Kelly et al., 1991) and HLA-DO (Karlsson et al., 1991). The genes are clustered on the short arm (q) of chromosome 6, one of the most gene-rich regions in mammalian genomes (1999). In the murine system, two major groups of the MHC II genes exist, I-A and I-E, as well as the non-classical genes encoding $\mathrm{H}-2 \mathrm{M}$ and $\mathrm{H}-2 \mathrm{O}$. The $\mathrm{li}$ gene is located on human chromosome 5 (q32), and was first identified in 1979 by Jones et al. (Jones et al., 1979), when the MHC II $\alpha$ chain and li could be separated by 2D-gels. However, it was not until 1989 that li was found to have a role in antigen presentation (Stockinger et al., 1989). In 1995 the Leukocyte Typing Workshop decided that li should be designated CD74 (Moller et al., 1995). li is a type II TM glycoprotein which exists in different isoforms defined by the primary amino acid sequence. There are four isoforms of $\mathrm{li}$ in humans, p33, p35, p41 and p43. li p33 and p41 are distinguished by alternative splicing of the li transcript where the p41 isoform contains an extra exon (exon 6b) (O'Sullivan et al., 1987; Strubin et al., 1986a). These two isoforms yield two additional protein products due to an $\mathrm{N}$ terminal cytoplasmic extension of 16 residues, which results from an alternative translation initiation site (O'Sullivan et al., 1987; Strubin et al., 1986b). Only the p33 and p41 isoforms are found in mice (the former as p31). The major human p33 isoform has an $\mathrm{N}$-terminal cytosolic tail of 30 amino acids, a TM domain consisting of amino acid 31-56 and a Cterminal 160 residue luminal domain (Claesson et al., 1983; Koch et al., 1987; Lipp et al., 1987) (Figure 3).
EXPRESSION AND REGULATION OF MHC II AND II In the APC lineages MHC II gene expression is modulated as a function of their developmental stage (Reith and Mach, 2001). Maturation of conventional DCs is accompanied by a transiently elevated transcription followed by more or less complete silencing to maintain the peptide-MHC II complexes formed at the time and place of activation (Landmann et al., 2001), whereas pDCs maintain MHC II production and turnover in order to continuously present endogenous viral antigens in an activated state (Young et al., 2008). MOs upregulate MHC II expression after IFN- $\gamma$ activation and B cells abolish MHC II expression completely upon differentiation to antibody producing plasma cells. MHC II expression is also tightly regulated in non-hematopoietic cells, TECs rapidly loose MHC II expression if they are removed from their thymic environment, and in IFN- $\gamma$ inducible cells, MHC II expression is subject to suppression by several cytokines (Reith et al., 2005). These tightly regulated expression patterns reflect a stringent control system with various cis- and trans-acting elements described (Benoist and Mathis, 1990; Glimcher and Kara, 1992). Subtle variations within the cis-acting elements in the genes give variable amounts of the individual gene products, with li being expressed at a significantly higher level than the MHC II isoforms (Landsverk et al. paper II). The expression of MHC II genes is dependent on a dedicated transcriptional co-activator called the MHC II trans-activator (CIITA) (Reith et al., 2005; Wright and Ting, 2006). CIITA controls the constitutive, maturation dependent expression of MHC II genes in APCs as well as the inducible expression in other cell types (Khalil et al., 2002; Nagarajan et al., 2002; Taxman et al., 2000; Westerheide et al., 1997). This regulator is uniquely devoted to regulating genes involved in antigen 
presentation, and apart from MHC I, MHC II, li and HLA-DM/-DO, only nine additional targets have been identified, most of which have, or are likely to have, a role in antigen presentation (Krawczyk et al., 2008). Three different isoforms of CIITA (pl, pllI and pIV) resulting from the use of four different promoters have been described (MuhlethalerMottet et al., 1997). These isoforms are surprisingly restricted in their expression, with $\mathrm{pl}$ being the principal CIITA in $\mathrm{M} \theta \mathrm{s}$, most DC subsets, including mouse $C D 8 \alpha^{+}$and $C D 8 \alpha^{-}$DCs, LCs, BMDCs, human CD11c+ DCs and LCs. pIII is the dominant isoform in $B$ cells, pDCs in human and mouse and is also expressed by human monocyte derived DCs, whereas pIV is expressed in IFN- $\gamma$ stimulated nonhematopoietic cells and $\mathrm{M} \theta$ s (reviewed in (Reith et al., 2005)).

\section{FOLDING AND ASSEMBLY OF MHC II AND II}

After translation and translocation into the ER, li and MHC II associate into a nonameric $(\alpha \beta l i)_{3}$ complex. The precise order of assembly is not clear, but it is likely that li initially self-associates into trimers prior to association with $\mathrm{MHC} \mathrm{II}$, either as preassembled $\alpha \beta$ complexes or with single $\alpha$ and $\beta$ chains (Anderson and Cresswell, 1994; Dixon et al., 2006; Lamb and Cresswell, 1992; Roche et al., 1991). Ii trimer formation is driven by luminal (Bijlmakers et al., 1994; Gedde-Dahl et al., 1997) and TM trimerization motifs (Ashman and Miller, 1999). The luminal trimerization domain, consisting of residues 163-183, has an intrinsic capacity to trimerize (Wakeham et al., 2003) and assumes a cylindrical shape (Jasanoff et al., 1998). The TM trimerization domain consists of a hydrophilic patch of polar amino acids (Ashman and Miller, 1999) forming an $\alpha$-helical structure which assembles into a lefthanded coiled-coil trimer (Kukol et al., 2002). The sequence of the TM domain is highly conserved across species (Bremnes et al., 2000) and mutations in this region can lead to failure in formation of mature MHC II complexes and consequent inefficient antigen presentation (Ashman and Miller, 1999; Frauwirth and Shastri, 2001). Thus, both the TM and luminal domains of li are able to make trimers, but both seem to be required for proper li structure and function. All four human li isoforms can be incorporated into mixed trimers, but as p33/41 is expressed 4-5 fold higher than p35/p43, and $\mathrm{p} 41 / 43$ significantly less than p33/35, p33 containing trimers will dominate (Arunachalam et al., 1994; Lamb and Cresswell, 1992; O'Sullivan et al., 1987). The luminal domain of li forms an extended structure which is important for the interaction between Ii and MHC II. Ii interacts with the MHC II $\alpha ß$ chains predominantly through a sequence comprising residues 86-104 (Freisewinkel et al., 1993; Romagnoli and Germain, 1994). This region (the MHC class II associated invariant chain peptide; CLIP) occupies the peptide-binding groove of $\mathrm{MHC}$ II and it is situated between the TM and luminal trimerization domains of li (Ghosh et al., 1995; Stumptner and Benaroch, 1997). The two independent trimerization domains in li may thus serve to impose some structure order onto the CLIP region that can facilitate the assembly of MHC II with li in the ER (Ashman and Miller, 1999). Ii thereby promotes the correct assembly of the MHC II heterodimers and prevents binding of peptides in the ER (Anderson and Miller, 1992; Lee and McConnell, 1995; Malcherek et al., 1995; Romagnoli and Germain, 1994; Schaiff et al., 1991; Sette et al., 1995). The CLIP peptide can be subdivided into two functional regions where the C-terminal segment (aa 92-105) occupies the peptide binding groove and a proline rich $\mathrm{N}$-terminal segment (residues 81-91) binds outside the groove and has been suggested to 
be important for the fast off-rate for CLIP after degradation of li (Kropshofer et al., 1995a; Kropshofer et al., 1995b). The removal of CLIP must necessarily precede binding of antigenic peptides, so CLIP should not have an overly high affinity for the peptide binding groove. However, the greatest variation in the polymorphic MHC II family is found in this domain, so the affinity of li for individual $\alpha \beta$ dimers naturally varies dramatically (Malcherek et al., 1995; Sette et al., 1995). In addition to the CLIP region, several additional MHC II interacting domains of li have been described. A proline $(P)$ rich region (aa 82-87) situated just outside CLIP mediates binding to the HLA-DR $\beta$ chain (Neumann and Koch, 2006; Siebenkotten et al., 1998; Stumptner and Benaroch, 1997), and also a region C-terminal to CLIP (aa 103-118) (Thayer et al., 1999) and the TM domain (Castellino et al., 2001) have been identified as MHC II interaction sites.

\section{MHC II AND II IN THE ENDOSOMAL SYSTEM}

After assembly in the ER, nonameric $(\alpha \beta \mathrm{li})_{3}$ complexes are transported to endosomal compartments for loading of peptides derived from internalized antigens (Figure 4). The exact route and traffic machinery involved in this transport has not been definitively established. Several reports suggest that the complex is transported directly from the trans-Golgi network (TGN) to the endocytic pathway (Bénaroch et al., 1995; Liu et al., 1998; Warmerdam et al., 1996), whereas other studies describe an indirect pathway via the plasma membrane (Bremnes et al., 1994; Henne et al., 1995; Ong et al., 1999; Roche et al., 1993; Wang et al., 1997). What is clear is that li plays an important role in this pathway. Mice lacking li exhibit impaired antigen presentation of intact protein antigen, but when fed antigenic peptides, they responded comparable or even superior to wt mice (Bikoff et al., 1993; Elliott et al., 1994; Viville et al., 1993; Zimmermann et al., 1999). Thus, li functions to bring nascent MHC II and internalized antigen together in an endocytic compartment containing proteolytic enzymes capable of processing both antigen and li itself.

\section{THE ENDOSOMAL SYSTEM}

The endosomal system consists of a dynamic network of membrane-enclosed organelles that differ in biochemical composition, cellular localization and morphology. The secretory pathway describes the outward flow of transmembrane and lumenal proteins from the ER, through the Golgi network to diverse intracellular organelles or the cell surface, whilst the endocytic pathway involves the inward flow of transmembrane proteins and cargo to lysosomes for degradation, or to early endosomes for recycling back to the cell surface (Behnia and Munro, 2005; Perret et al., 2005). Within this complex network proteins are continuously sorted in diverse directions, and the very nature of the compartments changes as organelles are formed, mature and consumed/dispersed.

Endocytosed cargo first enters early endosomes, which subsequently mature to late endosomes that finally fuse with lysosomes, generally considered the endpoint of the endocytic pathway (Luzio et al., 2007). In most cells this pathway is devoted to acquiring nutrients and building blocks (lipids, amino-acids and carbohydrates) for cellular metabolism and production of cellular components. The progression though this pathway is rapid, taking 5-15 minutes (Stoorvogel et al., 1991; Thilo et al., 1995), and entails the rapid acquisition of low $\mathrm{pH}$ and increasing amounts of active endocytic proteases (Honey and Rudensky, 2003). The identity 


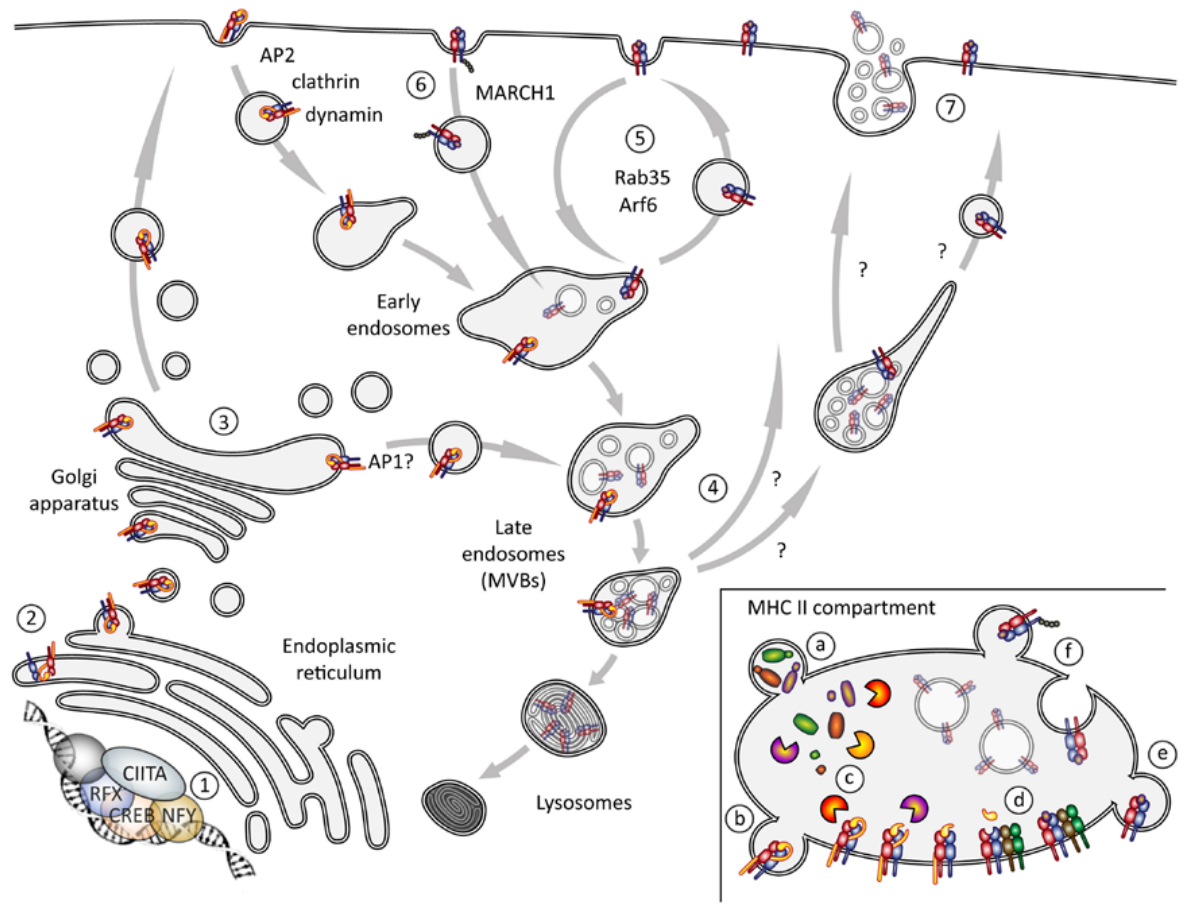

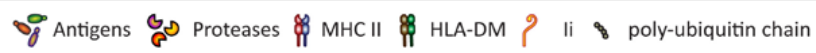

Figure 4 IMHC II AND II IN THE endosomal system. The endosomal system consists of morphologically, compositionally and functionally distinct compartments that are classified as early and late because they are sequentially accessed by endocytic cargo. As endosomes mature, they accumulate internal vesicles within them that are enriched in integral membrane proteins destined for lysosomal degradation. Late endosomes are also called multivesicular bodies (MVBs) and they receive newly synthesized lysosomal enzymes from the trans-Golgi network. Most MVBs fuse with lysosomes to degrade their contents, but in some cell types MVBs can also fuse with the plasma membrane and release their intralumenal vesicles as exosomes. MHC II and li genes are transcribed due to the action of the MHC II transactivator (1) and the translation products are inserted into the ER membrane where they assemble into nonameric complexes (2). From the trans-Golgi network li-MHC II can enter the endocytic pathway via the cell surface in an AP2 dependent manner, or possibly traffic directly to late endosomes (3). In endosomes li is degraded so that MHC II is freed to load peptides and traffic to the cell surface (4). Surface MHC II can recycle into Arf6 positive tubular recycling compartments (5) until they are ubiquitinated by specific ubiquitin E3 ligases (6) and sorted into intralumenal vesicles for degradation or release on exosomes (7). Endosomes accessed by MHC II are collectively termed MHC II compartments (MIICS). MIICS are accessible to endocytosed antigen (a) and new Ii-MHC II (b), and contain proteases which degrade both Ii and antigen (c). HLA-DM facilitates the exchange of CLIP for antigenic peptide (d) and peptide loaded MHC II can traffic to the cell surface (e). Mature MHC II is ubiquitinated by an ubiquitin E3 ligase and sorted into intra-lumenal vesicles for degradation (f).

of the different stages is maintained by specific lipid compositions and small GTP binding proteins (Behnia and Munro, 2005). Early endosomes have phosphatidylinositol 3-phosphate (PtdIns(3)P) in their membranes and are positive for Rab5, whereas recycling endosomes are positive for Rab4 and Rab11, and late endosomes contain domains enriched in Rab7a and Rab9 and the phosphoinositide Ptdlns $(3,5) \mathrm{P}_{2}$ (De Matteis and Godi, 2004; Stenmark, 2009). Lysosomes share several features with late endosomes, and the distinction between them is often unclear. Both compartments contain lysosome associated membrane proteins (LAMPs), lysosome integral membrane proteins (LIMPs) and endocytic proteases. But lysosomes lack the mannose 6- 
phosphate receptors (M6PRs) required for protease transport, contain more active proteases, are more acidic and are generally more electron dense due to their multi-lamellar morphology (Saftig and Klumperman, 2009). Lysosomes are, however, heterogeneous organelles with hybrid organelles appearing post fusion with late endosomes and specific cell types contain lysosome related organelles, such as the lytic granules of cytotoxic T cells and NK cells, the melanosomes of melanocytes and the secretory granules of mast-cells (Blott and Griffiths, 2002; Luzio et al., 2007).

Membrane proteins destined for degradation in lysosomes are recognized by the endosomal sorting complex required for transport (ESCRT) machinery which mediates the budding of vesicles into the lumen of endosomes (Hurley and Hanson, 2010). Components of ESCRT-I and -II recognize monoand/or Lys-63-poly-ubiquitinated cargo and cluster them into bud-like structures on the membrane, whilst ESCRT-III catalyses the scission of membrane necks and release of vesicles into the lumen (Duncan et al., 2006; Hurley, 2008; Wollert et al., 2009). The generation of intralumenal vesicles starts with the recruitment of Hrs to the endosomal membrane. Hrs has, in addition to its ubiquitin interacting motif, a FYVE domain (named after its 4 founding members: Fab1, YОTB, Vac1 and EEA1) which mediates binding to Ptdlns(3)P on early endosomal membranes (Gaullier et al., 1998; Raiborg et al., 2002). The number of internal vesicles increases as endosomes acquire late endosomal characteristics, and after fusion with lysosomes, the internal membranes become densely packed and are ultimately degraded by lysosomal phospholipases (Schulze et al., 2009).

As endosomes mature, membranes and cargo is continuously retrieved backwards in the pathway and new components introduced. This entails the sequential assembly and disassembly of factors mediating budding and fission of vesicles from donor membranes, and tethering, docking and fusion with acceptor membranes. Budding of vesicles is initiated by adaptor proteins (APs) binding sorting motifs in the cytoplasmic tails of transmembrane proteins. APs recruit factors which, through hydrophobic insertions and scaffolding, generate curvature on membranes to facilitate the scission of transport vesicles by the concerted action of constricting factors and motor proteins pulling membranes along the cytoskeleton (Conibear, 2010). Vesicles can reach their destinations by the directed transport along the cytoskeleton. Kinesins and cytoplasmic dynein, moving toward the plus and minus end of microtubules, respectively, and myosins moving on actin filaments have all been implicated in such transport (Akhmanova and Hammer, 2010; Hammer and $\mathrm{Wu}, 2002)$. Reaching their target membranes, vesicles initially loosely adhere (tether) to allow for the pairing of soluble $\mathrm{N}$-ethylmalemide-sensitive factor (NSF) attachment protein receptors (SNAREs) on opposing membranes (docking), which subsequently leads to membrane fusion (Cai et al., 2007; Jahn and Scheller, 2006). The fusion and fission of endosomes is regulated by Rab GTPases along with their cognate SNAREs. On early endosomes activated Rab5 recruits the phosphatidylinositol kinase Vps34 which generates Ptdlns(3)P. The early endosomal antigen-1 (EEA1) binds to Ptdlns(3)P and Rab5 on one membrane via its C-terminal FYVE and Rab5 interacting domains, and to incoming vesicles via a second $\mathrm{N}$-terminal Rab5 interacting domain, thereby tethering two Rab5-positive membranes (Callaghan et al., 1999a; Callaghan et al., 1999b; Gaullier et al., 1998). EEA1 also interacts directly with early endosomal SNAREs 
syntaxin- 6 and -13 and facilitates their assembly and fusion (McBride et al., 1999; Simonsen et al., 1999a). Similarly the fusion between late endosomes and lysosomes or phagosomes seems to depend on Rab7a which recruits components of the homotypic vacuole fusion and protein sorting (HOPS) complex to tether late endosomal/lysosomal membranes together, and the SNARES syntaxin 7, syntaxin 8 and vesicle associated membrane protein (VAMP)-7 to drive the fusion (reviewed in (Luzio et al., 2007)).

Rabs also function in vesicle budding and motility through the recruitment of diverse effector proteins. Late endosomal Rab9 interacts with the sorting adaptor TIP47 and stimulates the budding of M6PR vesicles for retrieval to the trans-Golgi network (TGN) (Carroll et al., 2001), the recycling Rab11 interacts via the Rab11 family-interacting protein 2 (Rab11FIP2) with the actin based motor myosin $\mathrm{Vb}$ for transport of vesicles from recycling endosomes to the cell surface (Hales et al., 2002; Lapierre et al., 2001), and Rab5 has been shown to stimulate the association of endosomes with microtubules and their minus end directed movement (Nielsen et al., 1999).

\section{TRAFFICKING OF II AND MHC II IN THE ENDOSOMAL SYSTEM}

In humans, li trimers containing p35/43 are retained in the ER due to an arginine based ER retention signal contained in the 16 amino acid extension to the $\mathrm{N}$-terminal cytosolic tail of these isoforms (Lotteau et al., 1990; Schutze et al., 1994). This retention can be bypassed through an interaction with the cytosolic tail of the HLA-DRß chain (Khalil et al., 2003) and/or protein kinase C mediated phosphorylation of serine 8 in the li p35/43 cytosolic tail (Anderson et al., 1999; Kuwana et al., 1998), leading to $14-3-3 \beta$ binding and blocking $\beta$-COP binding to the same site, thereby allowing for forward transport of p35/43 containing complexes (O'Kelly et al., 2002). Whether similar mechanisms exist in mice, which lack these isoforms, has not been determined. The cytoplasmic tail of all $\mathrm{li}$ isoforms from all species examined contain two dileucine based sorting motifs which are essential for sorting $M H C$ II heterodimers from the ER to endosomes (Bakke and Dobberstein, 1990; Bremnes et al., 1994). Both leucine signals can interact independently with AP-1 and AP-2, but not AP-3 in vitro (Hofmann et al., 1999; Rodionov and Bakke, 1998). AP-2 mediates transport between the plasma membrane and early endosomes, whereas AP-1 and AP-3 are involved in direct sorting from the TGN to late endosomes/lysosomes (Bonifacino and Traub, 2003; Sandoval and Bakke, 1994). In mice lacking the $\delta$ subunit of $\mathrm{AP}-3 \mathrm{MHC} \|$ trafficking in $\mathrm{M} \theta \mathrm{s}$, lymphoblasts and splenocytes is normal (Sevilla et al., 2001), and the same was found for human Blymphoblast cell-lines lacking AP-3 (Caplan et al., 2000). RNA interference targeting the various APs in model cells expressing MHC II, revealed that only depletion of $\mathrm{AP}-2$ results in defective $\mathrm{MHC} \|$ transport, with accumulation of MHC II-li complexes at the cell surface (Dugast et al., 2005; McCormick et al., 2005). This would indicate that the newly synthesized MHC II-li complexes are targeted to endosomes mainly via the plasma membrane, but whether this is the major pathway in APCs is still unclear. Silencing AP-1 in immature murine BM-DC does not compromise delivery of new MHC II-li to endosomes, but inhibition of AP-1 in mature BM-DCs results in accumulation of $\mathrm{li}$ at the cell surface (Santambrogio et al., 2005). This suggests that DCs differentially regulate the transport of new $\mathrm{MHC}$ II in response to pathogenic stimuli, with a shift toward more direct sorting to endosomes upon maturation. 
Alternative entry levels of $\mathrm{MHC}$ II-li complexes into the endocytic pathway could promote the presentation of a broader spectrum of antigenic peptides by early loading of peptides susceptible to terminal degradation in late compartments and later loading of protease resistant epitopes. Such dual routing has been described for LAMP 1 (Carlsson and Fukuda, 1992), the lysosomal membrane glycoprotein Igp120 (Harter and Mellman, 1992) and M6PR (Johnson and Kornfeld, 1992). Transport of new $\mathrm{MHC}$ II to compartments containing $\mathrm{BcR}$ internalized antigen has been shown to depend on li and the actin based motor myosin II. Whether this is due to a direct interaction or via some unknown adaptor, and whether these MHC II-li containing vesicles originated from the cell surface or the TGN was not determined in this study (Vascotto et al., 2007).

\section{PROTEOLYSIS AND MHC II PEPTIDE LOADING}

In endosomes proteolysis of li occurs through sequential cleavage from the lumenal (C-terminal) side, generating cleavage products of approximately $22 \mathrm{kDa}, 10 \mathrm{kDa}$, finally leaving only CLIP bound in the peptide binding groove of MHC II. The proteases involved in this processing have been the subject of intense studies for many years. It is now apparent that the endosomal proteases involved show somewhat overlapping specificities, a fact reflected by the divergent repertoires of these enzymes expressed by APCs (reviewed in (Hsing and Rudensky, 2005; Watts, 2004)). However, cathepsin $\mathrm{S}$ seems to play a central role as APCs from mice lacking this protease exhibit impaired MHC II transport with accumulated MHC II in endosomes and decreased motility due to defective li proteolysis (Driessen et al., 1999; Faure-Andre et al., 2008; Nakagawa et al., 1999). Intriguingly, li is itself able to modulate the activity of endocytic proteases. The Ii p41/43 isoforms contain a sequence in the alternatively spliced exon $6 \mathrm{~b}$ which inhibits the activity of several cysteine proteases (Bevec et al., 1996; Fineschi et al., 1996; Lennon-Dumenil et al., 2001; Mihelic et al., 2008; Ogrinc et al., 1993), suggesting that this fragment can reduce proteolytic activity in endosomes and thereby protect antigenic epitopes from excessive degradation. Conversely, activated DCs and MOs secrete cathepsin L complexed with a fragment of li p41/43 (exon 6b), and this enzyme is catalytically active in the extracellular milieu. Regulated secretion of the exon $6 \mathrm{~b}$ stabilized cathepsin $\mathrm{L}$ was therefore proposed to facilitate migration of APCs by degrading the extracellular matrix (Fiebiger et al., 2002). Mouse strains expressing either li p31 or p41 were, however, found equally competent with respect to $\mathrm{MHC}$ II function and $\mathrm{CD}^{+} \mathrm{T}$ cell development. These studies showed that li p41 could compensate for loss of p31 and converse, but whether the peptide repertoires expressed were similar was not determined (Takaesu et al., 1995; Takaesu et al., 1997). A somewhat surprising finding was that $p 41$ but not p33 could to some extent compensate for lack of HLA-DM (se below) with regard to MHC II peptide loading, suggesting that CLIP derived from p41/43 might be less tightly bound to MHC II (Bikoff et al., 1998).

Exchange of CLIP for antigenic peptides is facilitated through the action of HLA-DM, which binds to MHC II and induces an altered conformation in the peptide binding groove, resulting in the release of CLIP and binding of high-affinity peptides (Busch et al., 2005). In B cells HLA-DM activity can be regulated by HLA-DO, which seems to promotes HLA-DM activity at low $\mathrm{pH}$ and restrict its activity at neutral $\mathrm{pH}$. This has been proposed to promote the generation of high affinity antibodies by restricting 
peptide loading on $\mathrm{MHC}$ II to antigens carried through to low $\mathrm{pH}$ compartments by high affinity BcRs (Brocke et al., 2002). Expression of HLA-DO is generally restricted to $B$ cells and TECs, but certain DC subsets such as the LCs may express HLA-DO in an immature state, but down-regulate it in response to maturation stimuli (Hornell et al., 2006). HLA-DO expression correlates with increased levels of MHC II loaded with CLIP peptide at the cell surface in model cell lines and transduced moDCs (Bellemare-Pelletier et al., 2005; Denzin et al., 1997; van Ham et al., 1997).

\section{RETROGRADE TRANSPORT OF MATURE MHC II}

After proteolysis of $\mathrm{Ii}$ and peptide loading, mature MHC II (i.e. li disassociated, peptide loaded MHC II) traffic to the cell surface where their peptides can be sampled by $\mathrm{CD}^{+} \mathrm{T}$ lymphocytes. The sorting signals and machinery involved in this step has not been resolved, however, peptide loading promotes a conformational change in MHC II which is sufficient for transport of MHC II to the surface (Germain and Hendrix, 1991; Neefjes and Ploegh, 1992; SadeghNasseri and Germain, 1991; Thery et al., 1998; Wettstein et al., 1991). In a human melanoma cell line endosomes enriched in MHC II can move bidirectionally along microtubules, due to the opposing action of dynamin and kinesin, and these compartments were able to fuse directly with the cell surface (Wubbolts et al., 1999; Wubbolts et al., 1996). Fusion of endosomes with the cell surface has also been observed in human B lymphoblastoid cells and moDCs with the resulting release of lumenal vesicles, called exosomes, which contain both $\mathrm{MHC} \mathrm{II}$ and co-stimulatory molecules, and can activate $\mathrm{CD} 4^{+}$ T cells. However, this occurs rarely, and is probably not a major pathway for surface delivery of MHC II (Kleijmeer et al., 2001; Raposo et al., 1996). In activated mouse BMDCs, endosomes containing
MHC II can tubulate along microtubuli towards T cells in an antigen specific manner (Boes et al., 2003; Boes et al., 2002), and tubules or vesicles formed at their leading edge has been shown to fuse with the cell surface (Chow et al., 2002). Tubular extensions from multivesicular endosomes has also been observed upon activation of mouse spleen derived DCs and human moDCs (Barois et al., 2002; Kleijmeer et al., 2001), but as these tubules are absent from immature cells, the steady state transport of MHC II to the cell surface in immature DCs and other APCs probably occurs by vesicular transport involving some as yet unidentified components. In mice BMDCs and human B cells a compartment termed the class II vesicle (CIIV) has been proposed as a transport vesicle for peptide loaded MHC II. CIIVs contain MHC II loaded with peptides generated in late endosomal/lysosomal compartments, but lacks LAMP1, HLA-DM and li (Amigorena et al., 1994; Turley et al., 2000), however the relative large size, intralumenal vesicles and accessibility to immune complexes and the transferrin receptor is very suggestive of a recycling, early endosome.

\section{MHC II AT THE CELL SURFACE}

At the cell surface mature MHC II can recycle into recycling compartments and load, or exchange, peptides in a HLA-DM dependent or independent manner (Pathak et al., 2001; Pinet and Long, 1998). Recycling events may thereby contribute to the diversity of T cell epitopes presented. Recycling was originally proposed to be due to a leucine based sorting signal in the $\beta$-chain, thereby involving AP-2 and clathrin mediated endocytosis (Simonsen et al., 1999b; Zhong et al., 1997). However, the internalization of pMHC II was recently found to be independent of the cytosolic tails of $\mathrm{MHC} \mathrm{II}$, and depletion of AP-2, clathrin and dynamin had no 
effect on this recycling (Walseng et al., 2008). In this study PMHC II was found to enter tubular early endosomes containing the ADP ribosylation factor (ARF)-6 and Rab35, two small GTPases which are involved in protein recycling (Donaldson, 2003; Kouranti et al., 2006). Whether these GTPases were involved in the internalization or return to the cell surface, and whether these compartments were the same or distinct from conventional recycling endosomes was not addressed in this study.

Mature MHC II (but not li associated) is also subject to ubiquitination by specific ubiquitin ligases acting on a conserved lysine residue in the cytosolic tail of the $\beta$-chain. (Ohmura-Hoshino et al., 2006b; Shin et al., 2006; van Niel et al., 2006). The E3 ubiquitin ligase membrane-associated RING-CH 1 (MARCH1) attaches a poly-ubiquitin chain to MHC II which presumably leads to ESCRT mediated sorting into intralumenal vesicles and degradation in lysosomes. In conventional DCs in mice and in human moDCs this ubiquitination is developmentally regulated. In an immature state DCs continuously exchange their MHC II, but upon maturation ubiquitination of $\mathrm{MHC}$ II ceases due to a the rapid silencing of MARCH-1 to prevent degradation of antigenic PMHC II complexes generated at the time and place of activation (De Gassart et al., 2008; Walseng et al., 2010a; Walseng et al., 2010b; Young et al., 2008). Another substrate of MARCH-1 is the costimulatory molecule CD86, so silencing this ligase also increases the expression of this co-stimulatory molecule required for $\mathrm{T}$ cell activation (Ohmura-Hoshino et al., 2009). Interestingly, MARCH-1 is upregulated in monocytes in response to $\mathrm{IL}-10$, indicating that regulating $\mathrm{MHC}$ II turn-over is an important immune regulatory mechanism, but whether this is the case also in other APCs remains to be established (Thibodeau et al., 2008).

\section{ANTIGEN UPTAKE AND TRANSPORT IN THE} ENDOCYTIC PATHWAY.

Antigens can enter the cell via diverse endocytic mechanisms, creating endosomal compartments with distinct composition and functional properties (Doherty and McMahon, 2009). Receptor mediated endocytosis involves the specific recognition of a ligand and subsequent internalization via specific adaptors and coats depending on the internalizing receptor. Classical examples of such receptors are the $B c R$, Dectin-1, the scavenger receptor $(S R)$ and the mannose receptor (MR). Phagocytosis is also initiated by receptor mediated recognition of invariant patterns and the activation of numerous cytoplasmic effectors, but involves actin driven membrane protrusion and particle engulfment (reviewed in (Underhill and Ozinsky, 2002)). The repertoire of receptors activated determines the functional maturation of the phagosome and the production and release of pro- or anti-inflammatory mediators (Blander and Medzhitov, 2006; Stuart and Ezekowitz, 2005). Macropinocytosis occurs without the need for prior recognition of cargo. Uptake of fluid phase antigens occurs as membrane protrusions fuse together, capturing any antigens trapped between them. This negates the necessity for specific receptor recognition, and allows for the presentation of peptides derived from previously unknown pathogenic entities (reviewed in (Norbury, 2006))

The manner in which a particular antigen is internalized can significantly affect the subsequent intracellular routing, and the nature of the endocytic compartment accessed can give varying outcomes with regard to subsequent antigen presentation. As such, antigen targeted to the MR supplies a species of early endosomes devoted to cross-presentation on MHC I, whereas the SR delivers antigen to 

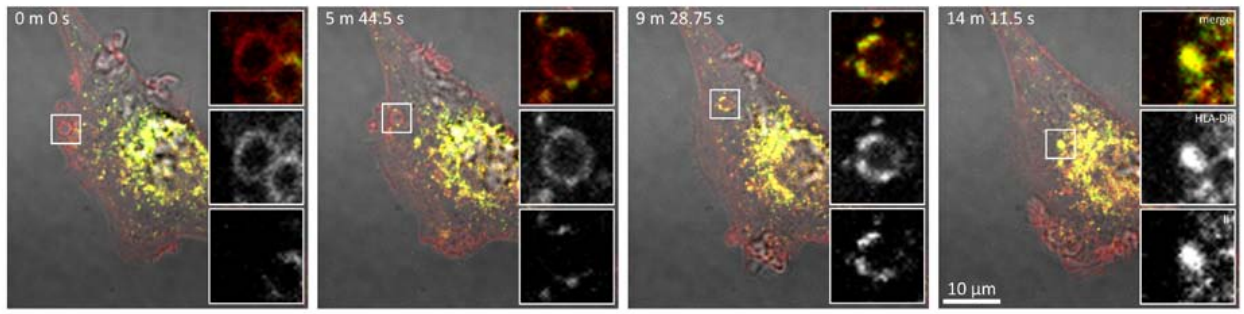

FIGURE 5 | MACROPINOCYTOSIS. Macropinocytosis occurs almost exclusively at sites of membrane ruffling. Actin driven protrusions enclose large volumes of the extracellular fluids and fuse together to form macropinosomes of up to $5 \mu \mathrm{m}$ in diameter (Norbury, 2006). In human moDCs, these macropinosomes can be seen to interact extensively with endosomes containing both li and MHC II from their biogenesis at the PM, through to their consumption in perinuclear compartments. Selected images from a time-lapse sequence are presented, the insets shows one single tracked macropinosome in high magnification. Cells were pulsed with an alexa fluor 488 (Invitrogen, Carlsbad, CA, USA) labeled antibody targeting lumenal li (M-B741, BD biosciences, Franklin Lakes, NJ, USA), washed in RPMI and an antibody specific for mature MHC II (L243, BD biosciences, Franklin Lakes, NJ, USA) conjugated to alexa fluor 555 was added to the cell medium imediately before imaging. Confocal images were acquired on an Olympus FluoView 1000 inverted microscope equipped with a PlanApo $60 / 1.10$ oil objective (Olympus, Hamburg, Germany). Constant temperature was set to $37^{\circ} \mathrm{C}$ and $\mathrm{CO}$ to $6 \%$ by an incubator enclosing the microscope stage. Images were processed in ImageJ ( $\mathrm{NIH}, \mathrm{USA}$ ) and assembled in Adobe Illustrator (Adobe systems Inc., San Jose, CA, USA).

endosomes facilitating direct presentation on MHC II

(Burgdorf et al., 2007). BcR internalized antigen transits via early endosomes to late endosomes, and end up in newly formed, BcR induced, multivesicular compartments (Lankar et al., 2002). As mentioned above, these events seem to be correlated with new MHC II-li trafficking. BcR ligation causes the activation of myosin II, which associates with $\mathrm{li}$, causing the convergence of endosomes containing $\mathrm{BcR}$ internalized antigen and $\mathrm{MHC}$ II (Vascotto et al., 2007). li can also direct MHC II to phagosomes where it can be degraded, and MHC II freed to bind peptides (Ramachandra et al., 1999), but whether this occurs prior to fusion with lysosomes and generation of a phagolysosome is not clear. Macropinocytosed cargo is certainly readily made available to MHC II (West et al., 2004), and in DCs endosomes accessed by li and MHC II can be seen to interact extensively with these vesicles from their biogenesis at the PM, through to their consumption in acidic perinuclear compartments (Landsverk OJB, unpublished, Figure 5).

\section{THE COMPARTMENT FOR PEPTIDE LOADING}

Compartments enriched in MHC II are collectively termed MHC II compartments (MIICs). They were first described in 1991 by Peters et al. as compartments related to lysosomes, containing LAMP1 and CD63, but less acidic and distinct from late endosomes due to lack of M6PR (Peters et al., 1991). MIICs have subsequently been characterized morphologically as being multi-vesicular, multilamellar or electron-dense (reviewed in (Stern et al., 2006)). In an early electron microscopy study Kleijmeer and colleagues describe the accessibility of various MIICs to endocytic markers in B cells, MOs, LCs and DCs from blood and spleen. They found that bovine serum albumin (BSA) was detectable in multivesicular MIICs within the first 10-30 minutes after uptake, and only appeared in multilamellar MIICs after 50 minutes. This led them to conclude that multivesicular MIICs were the precursors of multilamellar MIICs generated through maturation (Kleijmeer et al., 1997; Kleijmeer et al., 1996). This is highly reminiscent of the conventional endocytic pathway, however, lysosome related organelles 
generated through endosomal maturation are found in other specialized cells and function in the storage and/or secretion of cell type specific components (Raposo et al., 2007).

\section{MIIC MORPHOLOGY}

The defining characteristic of the otherwise heterogeneous MIICs is the presence of large amounts of MHC II. It has been reported that MHC II alone can induce the formation of multilamellar MIICs and that this is dependent on the transmembrane and cytoplasmic domains of MHC II (Calafat et al., 1994). In view of recent studies describing the ubiquitination of $\mathrm{MHC} \mathrm{II}$ and its role in the steady state turn-over of MHC II (Matsuki et al., 2007; van Niel et al., 2006; Walseng et al., 2010a), this indicates that ESCRT mediated sorting of MHC II onto internal membranes can generate the multivesicular/lamellar morphology of MIICs. As MHC II is necessarily relatively resistant to proteolysis due to its function to load peptides in proteolytic compartments, an intralumenal accumulation is to be expected, but how this promotes a multilamellar morphology is less clear. MHC II has, however, been shown to associate into both lipid and tetraspanin microdomains. In B lymphocytes the internal membranes of multivesicular MIICs are enriched in several tetraspanins (Escola et al., 1998; Hammond et al., 1998), and some of these are also present in MIICs from human moDCs and mouse BMDCs (Barois et al., 2002; Engering and Pieters, 2001; Vyas et al., 2007). The function of tetraspanins is thought to be linked to their ability to associate with one another and other proteins in an interacting network or 'tetraspanin web' (Charrin et al., 2009), and they might as such contribute to drive a multilamellar organization of internal membranes in the presence of $\mathrm{MHC}$ II. Interestingly one of these, CD63, is glucosylated during human moDC maturation, and this is accompanied by a change from multivesicular/multilamellar to densely packed membranes (Engering et al., 2003). However, the 'maintenance' of MIICs in B cells requires new protein synthesis, as incubation with cyclohexamide gradually decreases the number of MIICs (Calafat et al., 1994), and in moDCs maturation results in a decreased production of new MHC II and 'redistribution' of MHC II to the cell surface (Landmann et al., 2001)(Landsverk et al. paper II). The reduced amount of multilamellar MIICs could therefore be a consequence of less intracellular MHC II. Conversely, as monocytes differentiate to moDCs in response to IL- 4 there is an increase in multilamellar MIICs (Potolicchio et al., 2005), but whether this is due to the increased expression of $\mathrm{MHC}$ II or other DC specific factors is unknown.

\section{MIIC FUNCTION}

The significance of accumulated intralumenal MHC II and multivesicular/lamellar morphology is poorly understood. MIICs were for a long time considered as a temporary storage compartment for delivering MHC II to the cell surface in response to pathogenic stimuli (Murk et al., 2002). This was based on the observation that in immature DCs MHC II was mainly present in endosomes whereas after activation it was strongly expressed at the cell surface (Cella et al., 1997). However, the decrease in MHC II ubiquitination (De Gassart et al., 2008; Shin et al., 2006; van Niel et al., 2006; Walseng et al., 2010b) and transient increase in new MHC II production (Villadangos et al., 2001) (Landsverk et al. paper II), strongly argues that this increase is at least in part due to new MHC II not being degraded (Villadangos et al., 2005).

The clear link between ubiquitination and MHC II degradation suggests that in the steady state these 
compartments and their lumenal content are en route to lysosomal degradation. However, in human B cells multivesicular MIICs contain both CLIP associated- and peptide associated MHC II (Stang et al., 1998), and in human B cells and moDCs li is mainly present in MIICs with few internal vesicles, and barely detectable in multi-lamellar MIICs (Kleijmeer et al., 1996; Potolicchio et al., 2005). Thus, new MHC II clearly enters these same compartments in search for peptides. The essential peptide editing factor, HLA-DM, is present throughout the endocytic pathway, and the cell surface, but is particularly enriched in multivesicular, multilamellar and electron dense MIICs (Kleijmeer et al., 1997; Kleijmeer et al., 1996; Pierre et al., 1996), and HLA-DM assisted peptide loading has been shown in early compartments and even at the cell surface (Arndt et al., 2000; Santambrogio et al., 1999). However, open/empty MHC II and HLA-DM are predominantly detected in multilamellar compartments (Barois et al., 2002; Potolicchio et al., 2005), suggesting that peptide loading occurs primarily there. MHC II and HLA-DM are also strongly present on intralumenal membranes, and it has been suggested that intralumenal sorting of MHC II is an inherent part of the peptide loading process (Rocha and Neefjes, 2008). A fluorescence resonance energy transfer (FRET) based study found that HLA-DM and HLA-DR interact exclusively in the lumenal space of enlarged endosomes, and not in endosomes devoid of internal structures (Zwart et al., 2005). This entails the sorting of new MHC II into lumenal vesicles, HLA-DM assisted peptide loading and then back-fusion of lumenal vesicle with the limiting membrane. This poses an interesting problem, as the membrane topology and glycocalyx (carbohydrate parts of LAMPS and LIMPs, which serve to maintain the integrity of the limiting membrane), decreasing $\mathrm{pH}$ and increasingly proteolytic lumen of late compartments would require a novel machinery to drive back-fusion. Fusion of lumenal vesicles with the limiting membrane was proposed as early as 1988 (Griffiths et al., 1988), and has been proposed to contribute membrane for tubule formation in maturing DCs (Murk et al., 2002), but no factors capable of achieving this have been described so far, and in mice splenic DCs and human B cells HLA-DM is predominantly localized to the limiting membranes (Escola et al., 1998; Kleijmeer et al., 2001).

\section{MIIC FORMATION}

In most cells the endocytic pathway progresses rapidly from early endosomes, through late endosomes to lysosomes, whereas in B cells and DCs this pathway is delayed with accumulated late compartments (Kleijmeer et al., 1996). A likely scenario is that MIICs are diverted, albeit transiently, from the conventional rapidly maturing endocytic pathway. One potent candidate for contributing to MIIC diversion/biogenesis is the versatile li molecule (Stern et al., 2006). In paper I we show that in the presence of li mature MHC II accumulates in a slowly maturing endocytic compartment, and that this leads to a delayed degradation of membrane proteins sorted onto intralumenal membranes (Landsverk et al. paper I). Our lab has previously shown that li causes the delayed degradation of endocytosed cargo and proposed that this is due to a dramatic reorganization of the endocytic pathway induced by li (Gorvel et al., 1995a; Gregers et al., 2003c). In transfected human fibroblasts lacking MHC II, li induces the formation of enlarged endosomes which mature slowly from early endosomes through M6PR positive multivesicular endosomes and intermediate $\mathrm{M} 6 \mathrm{PR}^{\text {pos }} / \mathrm{LAMP}^{\text {low }}$ endosomes to dense $\mathrm{MPR}^{\text {neg }} / \mathrm{LAMP}^{\text {pos }}$ lysosomes 
(Stang and Bakke, 1997). Although these endosomes acquired intralumenal content, they did not to any great extent acquire the multilamellar morphology of classical MIICs, probably due to lack of MHC II, but were otherwise indistinguishable from the MIICs characterized by Kleijmeer and colleagues (Kleijmeer et al., 1996). These effects are dependent on the negative charges provided by acidic residues upstream of the leucine-based sorting signal in the cytosolic tail of Ii, and changing a single aspartic acid to arginine completely abolishes this effect (Nordeng et al., 2002). nuclear magnetic resonance studies followed by molecular dynamic simulations have shown that the $\alpha$-helical li tails form a trimeric updown-up or anti-parallel aggregate (Motta et al., 1997). It was therefore suggested that the cytosolic tails of li on opposing membranes could act as docking factors to promote endosome fusion, and this was demonstrated in a cell free endosome fusion assay (Nordeng et al., 2002).

The predominant presence of li in MIICs with few internal vesicles indicates that new $\mathrm{MHC}$ II-li enters endosomes at an early stage of MIIC formation (Kleijmeer et al., 1996; Potolicchio et al., 2005). As li is rapidly degraded in proteolytic compartments, and trimerization is necessary for the 'fusogenic properties' of li (Gedde-Dahl et al., 1997), the effect of $\mathrm{li}$ is probably restricted to the early events in MIIC formation. Indeed, in transfected cells, li induces the fusion of primarily early endosomes and fusion between late endosomes is rare (unpublished observations). Interestingly, these effects are not dependent on PtdIns(3)P and EEA1 (Nordeng et al., 2002)(Gregers et al. manuscript in preparation), factors normally required for early endosomal fusion (see above), suggesting that li alone can facilitate SNARE assembly. The generation of MIICs from early endosomes through endosomal fusion is not without precedence. In melanocytes, the biogenesis of melanosomes depends on factors which assemble SNAREs to drive early endosomal fusion, and these 'pre-melanosomes' subsequently mature and acquire late endosomal/lysosomal components such as LAMP1 and CD63 (Raposo et al., 2007). Intriguingly, the intracellular positioning (and proper functioning) of melanosomes depends on melanosome specific interactions with motor proteins for trafficking along microtubuli and the actin cytoskeleton (Raposo and Marks, 2007). Movement of MIICs along microtubules and actin filaments has also been observed, and the proper positioning of MIICs relative to $\mathrm{BcR}$ internalized antigen is critically dependent on an interaction between li and myosin II (Vascotto et al., 2007).

\section{MIIC MATURATION}

In paper I we show that li-induced enlarged early endosomes display a remarkably delayed maturation, with progression from early, Rab5 positive endosomes to late, Rab7a positive endosomes taking as long as 1-2 hours (Landsverk paper I). A similar enlargement of early endosomes can be induced by over expressing Rab5 or its GTPase deficient variant Rab5Q79L (Gorvel et al., 1991; Stenmark et al., 1994), but these endosomes mature rapidly, loosing Rab5 within 15-30 minutes, showing that increasing fusion alone does not delay maturation (Landsverk paper I). This delayed maturation is not dependent on the presence of MHC II, as a similar slow maturation is observed in cells not expressing MHC II (unpublished observations), suggesting that the presence of li alone diverts li-containing endosomes from the conventional endocytic pathway. How li achieves a delayed maturation is not clear. Conversion from early to late endosomes in the conventional 
endocytic pathway has been proposed to involve the displacement of the Rab5 guanine nucleotide exchange factor (GEF) Rabex 5 by SAND-1/Mon1, which also drives the recruitment of Rab7a, possibly by interacting with the Rab7a GEF HOPS. How SAND$1 /$ Mon1 is regulated is less clear, but has been proposed to involve sensing of endosomal size, the concentration of Ptdlns(3)P or a combination of the two (Poteryaev et al., 2010). In transfected cells, liinduced endosomes can grow to a large size and endosomes with a diameter of up to $5-10 \mu \mathrm{m}$ are frequently seen at high levels of expression (unpublished observations), and a Ptdlns sensor (2xFYVE) is strongly recruited to early li endosomes indicating that if the proposed mechanism of SAND$1 /$ Mon1 is valid, li must be preventing its recruitment. Alternatively, li might be influencing other processes potentially involved in endosomal maturation, such as the recruitment of Rabs, GEFs or GTPase activating proteins (GAPs), assembly of SNAREs, recruitment of acidifying proton pumps or alkalizing NADPH oxidases, membrane lipid flipases, LAMPs or LIMPs. The components involved in regulating maturation in the conventional endocytic pathway and which factors li influences clearly requires further investigation. However, it seems likely that $\mathrm{li}$ is one factor contributing to transiently diverting the endocytic pathway from a rapid to a slowly maturing pathway. Through the maturation, these compartments continue to exchange content and membranes with incoming endosomes from the cell surface, thus continuously receiving both old MHC II and antigen (Landsverk et al., 2010b). MHC IIli is also recruited to phagosomes and macropinosomes (Ramachandra et al., 1999; West et al., 2004), so it is likely that these compartments are similarly influenced by li. li could thereby serve not only to bring $\mathrm{MHC} \|$ and antigen together in an alternate endocytic pathway, but also contribute to the diversity of peptides generated and allow ample time for $\mathrm{MHC}$ II to sample them.

\section{MIIC DIVERSITY}

It should be noted, however, that the properties of MIICs will vary depending on the particular cell type in question and also within the single cell depending on other factors recruited to the specific MIIC. For example $\mathrm{M} \theta \mathrm{s}$ have a particularly aggressive endocytic environment due to their functions in non-inflammatory removal of debris, apoptotic cells and the destruction and clearance of invading pathogens. As such, MOs have low amounts of intracellular MHC II, possibly due to its rapid degradation in the steady state. Upon IFN- $\gamma /$ LPS induced activation however, $\mathrm{M} \theta$ s can decrease this proteolytic activity (Yates et al., 2007). IFN- $\gamma$ stimulation of $\mathrm{M} \theta \mathrm{s}$ also leads to increased expression of $\mathrm{Ii}$ and $\mathrm{MHC} \mathrm{II}$, through induction of CIITA pIV expression (Pai et al., 2002), thus potentially contributing to enhanced MIIC biogenesis and decreased proteolysis of both antigen and MHC II. DCs, in contrast, generally have a relatively mild proteolytic endocytic environment, but moDCs in particular exhibit increased levels of lysosomal proteolysis as compared to other human dendritic cell populations (McCurley and Mellman, 2010), indicating that there may be some subset specific variation. These variations reflect the activation induced or steady state recruitment of additional components to MIICs, such as proteolytic enzymes (Lautwein et al., 2002; Lennon-Dumenil et al., 2002), protease inhibitors (El-Sukkari et al., 2003; Kitamura et al., 2005; Pierre and Mellman, 1998), vacuolar proton pumps (Trombetta et al., 2003) or NADPH oxidase (NOX)-2, which produces reactive oxygen species leading to decreased acidification (Savina et al., 2006; Savina et al., 2009). Thus, a MIIC may vary 
significantly depending on the endocytic mechanism, the various additional components expressed/recruited and the APC type and activation stimuli. However, we propose that the underlying framework of MIIC biogenesis is, at least in part, undertaken by the endosome modulating functions of li.

\section{AdDITIONAL FUNCTIONS OF II}

\section{AND B CELL MATURATION}

It should be mentioned that li has been shown to have additional functions apparently unrelated to MHC II transport and MIIC biogenesis. A 42-44 amino-acid long fragment of the $\mathrm{N}$-terminal domain of li has been shown to be involved in $B$ cell maturation and survival (Matza et al., 2003; Matza et al., 2002; Shachar and Flavell, 1996). This fragment is generated through cleavage of the transmembrane segment of li by the $\gamma$-secretase/ presenelin complex (Becker-Herman et al., 2005), and has been shown to translocate to the nucleus and induce NF-KB activity through its effect on the trans-activation domain of p65/RelA (BeckerHerman et al., 2005; Matza et al., 2001).

\section{AS A CELL SURFACE RECEPTOR}

This was more recently linked to another function of li where it was shown to act as a cell surface receptor for macrophage migration inhibitory factor (MIF) (Gore et al., 2008; Leng et al., 2003), a cytokine involved in micro vascular and atherogenic recruitment of mononuclear cells (Noels et al., 2009). Signal transduction upon MIF binding to li requires CD44 (Meyer-Siegler et al., 2004; Shi et al., 2006), a cell-surface glycoprotein involved in cell-cell interactions and adhesion to the extracellular matrix (Johnson and Ruffell, 2009). MIF can also bind to chemokine receptors CXCR2 and CXCR4. CXCR2 has been co-immunoprecipitated with li, and both li and CXCR2 were found to be required for monocyte recruitment during inflammation (Bernhagen et al., 2007).

\section{AND CD1 TRANSPORT}

li has been implicated in the transport of MHC I-like CD1 family proteins which function to present lipid antigens to T cells (Salio et al., 2010). li has been coimmunoprecipitated with CD1a (and CD9 a tetraspanin involved in cell adhesion and migration) in immature moDCs, this association depends on lipid rafts and facilitates recycling of CD1a which lacks its own internalization motif (Sloma et al., 2008). However, CD1a has been shown to recycle in a Rab22a/ARF6 dependent pathway in Hela cells which do not express li, and also in these cells a fraction of CD1a partitions into lipid rafts (Barral et al., 2008). li has also been shown to associate with CD1d in B cells and this serves to direct CD1d into the endocytic system (Jayawardena-Wolf et al., 2001). In human moDCs li leads to enhanced presentation of exogenous (but not endogenous) antigens on CD1d (Chen et al., 2007). CD1d contains its own tyrosine based internalization motif for rapid recycling at the cell surface, and the enhanced antigen presentation in the presence of $\mathrm{li}$ presumably reflects a sorting into more proteolytic antigen processing compartments. Thus li might play a dual role in both sorting and MIIC biogenesis also for antigen presentation by CD1 proteins.

\section{AND CD70 CO-STIMULATION}

The stimulus provided by co-stimulatory molecules is essential for the activation of $\mathrm{MHC}$ reactive $\mathrm{T}$ cells. The B7 family molecules CD80 and CD86 interact with CD28 or CTLA-4, and act as positive or negative regulators of $T$ cell expansion, respectively (Greenwald et al., 2005). TNF receptor family 
molecules OX40 and CD27 interact with OX40L and CD70, respectively, and induce a distinct signaling pathway which may break tolerance and induce differentiation of memory $\mathrm{T}$ cells (Denoeud and Moser, 2010; Redmond et al., 2009). Intriguingly, CD70 seems to rely on li for its transport to late endocytic compartments. Co-immunoprecipitation experiments show that CD70 associates with $\mathrm{li}$ in Meljuso cells and transfected Hela cells, and this might serve to coordinate delivery of MHC II with costimulatory ligands to distinct membrane domains upon APC activation (Zwart et al., 2010). This is an enticing concept, as APCs express a plentitude of self peptides on their MHC II in the steady state, restricting co-stimulation to $\mathrm{MHC}$ II from MIICs delivered to the cell surface after activation might reduce the potential for activating escaped selfreactive $\mathrm{T}$ cell clones. Whether similar mechanisms exist for the B7 family members is not known, but in immature DCs ubiquitin ligases acting on $\mathrm{MHC}$ II also target CD86 (Ohmura-Hoshino et al., 2006a), this would presumably likewise deliver CD86 to the intralumenal vesicles of MIICs, and could after reception of a maturation stimuli similarly deliver CD86 to membrane domains.

\section{II, MHCI AND FCRN TRANSPORT}

li has also been found to associate with peptide free MHC I and somewhat surprisingly cause the increased cell surface expression of certain MHC I alleles (Powis, 2006; Reber et al., 2002). This is contrary to its action on all other partners and clearly requires further examination. li has also been co-immunoprecipitated with the MHC I related neonatal Fcy Receptor (FcRn) in transfected Hela cells, and this association apparently leads to the relocation of FcRn to LAMP-1 $^{+}$late endosomes/lysosomes (Ye et al., 2008).
II AND CANCER

li is not surprisingly expressed in a variety of hematopoietic cancers, but is also present in cancers of the bladder, prostate and stomach, in some cases without the coordinate expression of MHC II (MeyerSiegler et al., 2006; Meyer-Siegler et al., 2005; Tamori et al., 2005). The increased expression of li has been linked to poor clinical prognosis in patients with myeloid leukemia, multiple myeloma, nonHodgkin's lymphoma, sarcoma, colon and gastric cancers (Chamuleau et al., 2004; Clements et al., 1992; Cuthbert et al., 2009; Ishigami et al., 2001; Jiang et al., 1999; Stein et al., 2004). These procarcinogenic effects of li have been linked to its role as a cell surface receptor (se above), where MIF binding to CD44-li leads to the activation of intracellular signaling pathways leading to cell proliferation and survival (reviewed in (Berkova et al., 2010)). The gram-negative bacterium Helicobacter pylori is strongly associated with gastric cancers. $H$ pylori binds to li on gastric epithelial cells and induces MIF production, it might thereby contribute to enhanced survival of the hosting epithelial cells in infected mucosa (Beswick and Reyes, 2009). However, also the conventional properties of li could contribute to tumor development by promoting immune evasion of cancerous cells by preventing the presentation of endogenous tumor antigens (Humphreys et al., 2004).

\section{IN IMMUNOTHERAPY}

In accordance with its wide distribution in a range of tumors and its function in antigen presentation, li has become an attractive target for cancer therapy. SiRNA mediated knock down of li has been used as an approach to enhance anti-tumour immunity (Ke et al., 2007; Qiu et al., 1999; Xu et al., 2004), and 
antibody targeted cytotoxic drugs have proved highly effective in eliminating human tumor xenografts in monkeys and mice (Chang et al., 2005; Griffiths et al., 2003; Sapra et al., 2005). Milatuzumab, a humanized mouse-anti li antibody, is currently being evaluated in clinical trials for treating multiple myeloma, non-Hodgkin's lymphoma and chronic lymphocytic leukemia in humans (reviewed in (Berkova et al., 2010; Mark et al., 2009)). li is also being exploited as a targeting vector for delivering peptides to MHC II. Genetic exchange of CLIP with antigenic peptides has proven to be highly efficient in targeting peptides into the peptide binding groove of MHC II (Fujii et al., 1998; Malcherek et al., 1998;
Nakano et al., 1997; Van Bergen et al., 1997), and even low affinity peptides that do not efficiently bind to MHC II have been shown to be capable of activating CD4+ T cells (Carstens et al., 2000; Gregers et al., 2003a). DNA vaccines based on peptide/CLIP replaced li genes have been shown to elicit specific $T$ cell responses, induce protective immunity against infections (Nagata et al., 2002; Nagata et al., 2001; van Tienhoven et al., 2001), and anti-tumour responses in animal models (Brulet et al., 2007; Gao et al., 2006). Thus using li as a vehicle for loading peptides onto MHC II might be a promising approach to elicit pathogen/tumour specific responses in cases where the target sequence is known. 


\section{AIMS OF THE THESIS}

Presentation of exogenous antigen to naïve T cells requires the coordination of diverse intracellular events to achieve the uptake, processing and loading of peptides on MHC II molecules. In APCs in general and DCs in particular the endocytic pathway is adapted to serve this purpose, and exhibits dynamic alterations in response to pathogenic challenge. This thesis aims to characterize the role of li in modulating the endocytic pathway in the steady state to promote MHC II antigen presentation, and investigate the molecular basis for an li mediated modulation during DC maturation.

The presence of li causes a delayed degradation and processing of endocytosed antigens, and leads to the fusion of MHC class II containing vesicles (Gorvel et al., 1995b; Gregers et al., 2003c; Nordeng et al., 2002). When $\mathrm{li}$ is over-expressed in experimental systems these eventually form large endosomal vesicles and these properties have been shown to be dependant on particular domains within the cytosolic tail of li (Nordeng et al., 2002). In the steady state, APCs contain lysosome related organelles (MIICs) that are accessed by both old and newly synthesized MHC II (Landsverk et al., 2009). The role of Ii in directing new MHC II to MIICs is firmly established, but how old MHC II is sorted to MIICs is unknown. To compare and discriminate between the primary role of Ii in new MHC II assembly and transport, and a secondary role on mature MHC II, we designed a novel experimental system combining photo activation and induced expression. Our findings were recently published in Immunology and Cell Biology (Landsverk et al., 2010b) and confirm a role for li in the biogenesis of a compartment receiving both old and new MHC II.

DCs undergo remarkable phenotypical and functional changes upon pathogen or cytokine induced activation. The endosomal system undergoes severe re-organization, with modulated proteolytic capacity and dynamic tubule formation. Migration is transiently halted to accommodate antigen uptake (Faure-Andre et al., 2008) and $\mathrm{MHC}$ II loading and transport to the cell surface is enhanced. As li can affect all these processes we sought to determine the transcriptional/translational rational for a role for li in these processes. By quantitative realtime PCR and biochemical approaches we examined induced responses to pathogenic stimuli and inflammatory cytokines. Our findings presented in paper II indicate that the presumption that all CIITA controlled genes are equally affected upon maturation is not valid, and a large pool of functional li is maintained in mature DCs. 


\section{SUMMARY OF INCLUDED PAPERS}

PAPER I. INVARIANT CHAIN INCREASES THE HALFLIFE OF MHC II BY DELAYING ENDOSOMAL MATURATION. In steady state APCS MHC II is most often found accumulated in late endosomes containing LAMP1 and CD63. Within these compartments, MHC II is particularly accumulated on the intralumenal vesicles, several studies have confirmed a role for ubiquitin ligases in the degradation of MHC II (Matsuki et al., 2007; Ohmura-Hoshino et al., 2006b; Shin et al., 2006; van Niel et al., 2006; Walseng et al., 2010a), suggesting that mature MHC II is sorted onto intralumenal vesicles via the conventional ubiquitin-ESCRT pathway for degradation of membrane proteins. Importantly, li associated MHC II is not ubiquitinated (van Niel et al., 2006). During peptide loading MHC II is dissociated from li through proteolysis and the action of DM and mature MHC II is freed to traffic to the cell surface and present its antigenic peptides to $\mathrm{CD} 4+\mathrm{T}$ cells. Mature, cell surface MHC II can recycle into Arf6 and Rab35 positive tubular endosomes, and this internalization is independent of AP-2 and clathrin (Walseng et al., 2008). However, liassociated MHC II is dependent on AP-2 and clathrin for its trafficking to peptide loading compartments (Dugast et al., 2005; McCormick et al., 2005). In our studies of the role of Ii in MHC II trafficking we have consistently observed an accumulation of MHC ॥ into endosomes induced by li. In paper I we used a conformation specific antibody and disclosed that also mature MHC II is directed to these endosomes. Moreover, these compartments acquired a multivesicular morphology with abundant MHC ॥ present on intralumenal vesicles. To conclusively determine a role for $\mathrm{li}$ in the sorting of mature MHC II we designed a novel experimental system combining a photo-activable green fluorescent protein (PAGFP) attached to MHC II and an inducible expression system for li. This allowed us to image a sub-population of photo activated MHC II, and examine how they were distributed to endosomes in response to newly produced li. This redistribution was not dependent on a 'secondary' interaction of mature MHC II with new li, or the sorting/ubiquitination motifs in the cytosolic tails of MHC II, and did not affect the total amount of MHC II expressed at the cell surface. We did, however, find that in the presence of li, the half life of MHC II was increased and that this was due to a greatly delayed maturation of $\mathrm{li}$ containing endosomes. Thus we conclude that li induces an APC specific endocytic environment where endocytic cargo such as MHC II and antigen are converged and conserved in order to promote the proteolysis, loading and presentation of a diverse array of antigenic peptides to T cells (Landsverk et al., 2010b).

Paper II. Differential Regulation of MHC II AND INVARIANT CHAIN EXPRESSION DURING MATURATION OF MONOCYTE DERIVED DENTDRITIC CELLS. This study was initiated in order to examine the transcriptional and translational basis for diverse li functions during the maturation of DCs. Several studies have attributed functions to li during the activation of DCs. Fiebiger et al. found that a fragment of li p41 could stabilize extracellular cathepsin L, possibly to achieve the degradation of extracellular matrix and facilitate the influx of effector cells to inflammatory sites (Fiebiger et al., 2002), whereas a 1998 Cell paper attributed the regulation of cell surface MHC II to the efficiency of li processing by cathepsin $S$ and ultimately its inhibitor cystatin C (Pierre and Mellman, 1998). 
Most notably, Faure-André et al. in an elegant Science paper describe a pause in DC migration upon activation due to the transient binding up of myosin II by elevated li (Faure-Andre et al., 2008). In our pursuit of an understanding of the functions of li on the endomembrane system and its possible modulation during pathogen encounter, we wanted to examine in detail the regulation of li as compared to $\mathrm{MHC}$ II during DC maturation. Most previous studies have only examined the transcription of MHC II and presumed that li follows a similar course due to its mutual dependence on CIITA. Interestingly, we found that the regulation of li was not strictly correlated with that of MHC II. Ii mRNAs were significantly less upregulated at early timepoints after activation, and decreased more slowly at later time-points. This indicates that the turn-over of CIITA at li promoter binding sites was lower than at the MHC II loci and less influenced by external stimuli. Alternatively, li mRNA was more stable than that of MHC II. The levels of mRNA are not necessarily a good measure of gene output due to their differential stability and affinity for ribosomal proteins, we therefore performed metabolic labeling and chase experiments on immature and mature DCs to examine new protein synthesis and half-life. Our findings corroborated and expanded the qRTPCR data, showing that in mature cells there is an abundance of li, mostly non-associated with MHC II. Immunofluorescence microscopy indicated that the majority of this population resided in the ER, but biochemical assays showed that li gained access to endosomes and was degraded also in mature DCs. In view of our results presented in paper I and previous findings (Gregers et al., 2003c; Nordeng et al., 2002), this suggests that li could play a role in modulating the endocytic pathway in mature DCs. We find that there is a biosynthetic rational for diverse $\mathrm{Ii}$ functions also in mature DCs, and suggest that Ii could facilitate the modulation of endosomal compartments for preserving antigen for loading on recycling $\mathrm{MHC}$ II or transfer to lymph node resident DCs after entry into these organs.

\section{METHOdOLOGICAL CONSIDERATIONS}

\section{MICROSCOPY}

Microscopes have been vital tools for scientists since their development at the end of the sixteenth century and modern imaging technology has greatly expanded the scope of questions we can approach. At its core, microscopy is all about deriving an image from the interaction of light with matter. In fluorescent microscopy, fluorophores with distinct excitation and emission spectra can be distinguished within the same sample by applying light with specific wavelengths and collecting the emitted light (Lichtman and Conchello, 2005). Fluorescently labeled antibodies were first introduced in 1941 (Coons et al., 1942) and now fluorophores with a color spectrum ranging from ultra-violet to infra-red are available for labeling molecules and organelles. For sub-cellular imaging in real-time, fluorophoreconjugated antibodies have some limitations due to the large size (e.g. 150kDa for IgG) and membrane impermeability of antigen targeting moieties. The advent of fluorescent proteins revolutionized science by allowing the specific labeling of distinct proteins in vivo and their visualization in both space and time. The green fluorescent protein (GFP) was first used as a fluorescent probe in 1994 (Chalfie et al., 1994), and in 2008 Osamu Shimomura, Martin Chalfie and Roger Y. Tsien were awarded the Nobel prize in chemistry for its discovery and development. Today related fluorescent proteins covering nearly the entire visual spectrum are available (Chudakov et al., 2010), and their use extends beyond resolving 
molecular processes in space and time, to studies of protein function, dynamics and interactions (Wang et al., 2008).

In paper I (and (Bergeland et al., 2008)) we use a photo-activable GFP (PAGFP) which was designed to enhance the inherent photo-convertible properties of the original GFP (Patterson and LippincottSchwartz, 2002). PAGFP has a barely detectable absorbance of $488 \mathrm{~nm}$ light in its native state, but upon exposure to ultra-violet light, PAGFP gains a 100 -fold increase in fluorescence emission (517nm) upon 488nm excitation (Figure 6). The photoconversion involve an irreversible shift in the chromophore from a neutral phenolic form to an anionic phenolate form (Patterson and LippincottSchwartz, 2002). This enables the selective labeling in time and space of a population of PAGFP tagged molecules (figure 6), and allowed us to examine the effect of induced li on exclusively old MHC II (Landsverk et al., 2010b). However, although PAGFP is only 2 aa (S65T, T203H) removed from enhanced
GFP (EGFP), it has an almost three-fold reduced molar extinction coefficient $(\varepsilon)$ and barely half the brightness. Importantly, PAGFP is significantly less photo-stable and is rapidly photo-bleached, consequently, long time imaging requires a low intensity laser and low resolution scanning. In paper I (and (Landsverk et al., 2010a)), we also use the photo stabilized, enhanced, GFP (EGFP) and the monomeric (m-) Cherry. Although controls were performed for all the fusion constructs, it should be noted that attachment of a large (220-240 aa, $25 \mathrm{kDa}) \beta$-barrel to any protein could interfere with its normal function.

The use of microscopes and fluorescent probes has undoubtedly revolutionized life sciences, however, the acquisition, analysis and interpretation of microscopy data is challenging. Fluorophores have excitation and emission spectra which can absorb and emit light along its entire spectrum and this makes crosstalk (bleed-through) an issue. Equally problematic is the overlap of specific fluorescence
A

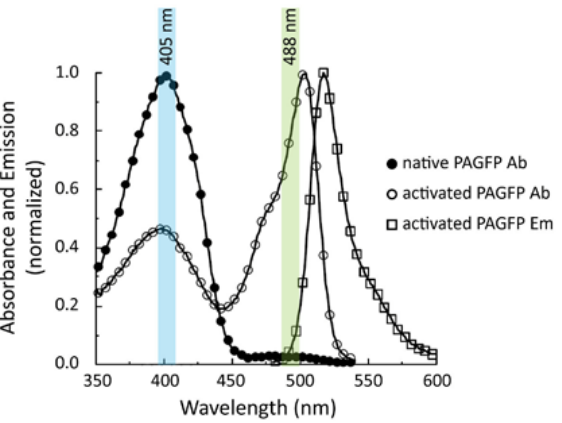

B

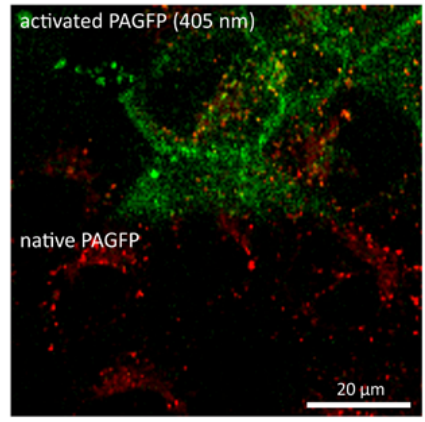

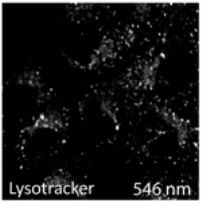

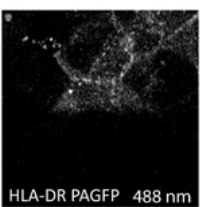

Figure 6 | PAGFP AbSorbance ANd Emission SPECtra. A) Native PAGFP optimally absorbs light of ca $400 \mathrm{~nm}$ wavelength (solid circles) and undergoes an irreversible photo-conversion to a GFP-like absorption spectrum (open circles) with a resulting 100 -fold increase in fluorescence emission (517nm, open squares) upon 488nm excitation. Graph from (Patterson and Lippincott-Schwartz, 2004). B) Madin Darby canine kidney cells stably transfected with HLA-DR1 alpha fused to PAGFP and HLA-DR1 beta (Lipofectamine 2000, Invitrogen, Carlsbad, CA, USA) were incubated with lysotracker red (Invitrogen), and PAGFP was activated in half the frame with a $405 \mathrm{~nm}$ laser pulse. Confocal images were acquired on an Olympus FluoView 1000 inverted microscope equipped with a PlanApo 60/1.10 oil objective (Olympus, Hamburg, Germany). Lysotracker red was excited with $546 \mathrm{~nm}$ and PAGFP with $488 \mathrm{~nm}$, excitation DM405/488/559/635, spectral emission filters SDM560 (500-545) and SDM640 (570-630). Constant temperature was set to $37^{\circ} \mathrm{C}$ and $\mathrm{CO} 2$ to $6 \%$ by an incubator enclosing the microscope stage. Images were processed in ImageJ (NIH, USA) and assembled in Adobe Illustrator (Adobe systems Inc., San Jose, CA, USA). One single image from a time-lapse sequence is shown, in red lysotracker, in green activated PAGFP. 
with background

autofluorescence.

Autofluorescence spectra are generally broad and encompass most of the visible spectral range, overlapping the excitation/emission wavelengths of GFP and its many derivatives, and this can lead to low signal-to-noise ratio. Unfortunately, autofluorescence is not uniformly distributed, and organelles such as mitochondria and lysosomes tend to have a higher autofluorescence than their surroundings. With increasingly sensitive detection systems (charge-coupled devices (CCDs), or photomultiplier tubes (PMTs)), these signals can easily be mistaken for specific. New fluorophores with narrow, non-overlapping excitation/emission spectra, fine-tuned lasers, excitation filters, spectral emission filters and sequential scanning can reduce such artifacts, but requires insight into the physical aspects of fluorophores, and microscope settings applied (North, 2006). In fluorescent microscopy, any acquired signal should be dissected in order to determine its correct origin.

In paper I we worked for a long time after the hypothesis that li might capture old MHC II at the cell surface and redirect it to MHC II compartments. This hypothesis, as many in our laboratory and elsewhere, was based on observations made at the microscope. We observed that with increasing levels of Ii, MHC II was mainly present in enlarged endosomes and apparently depleted from the cell surface. However, despite a large body of alternative experimental approaches, we could not detect any complexes formed between old MHC II and new li, nor a decrease in total surface MHC II. These findings eventually led to a revisal of the hypothesis and the story presented in paper I (Landsverk et al., 2010b). In our initial observations we were deceived by high intensity staining of endosomal MHC II in cells expressing li. To avoid over-exposure we adjusted our acquisition parameters and gained endosomal resolution, but concomitantly a weaker signal from the less concentrated cell surface pool of MHC II. Such is modern microscopy, biological events that alter the properties of our specimens can be compensated for (or disguised) by adjusting laser intensities, PMTs/CCDs and software to fit our predisposed conclusions. As visually predisposed beings we seek resolution and adjust our settings to resolve elements with high signal at the cost of elements with low intensity, but quite possibly of equal or greater relevance. Unbiased acquisition and analysis of microscopy data would be optimal, but the automated imaging systems need to overcome several obstacles before they be widely applied to produce reliable data. Analytical software struggles to distinguish the heterogeneous features and natural variation in biological specimens, and manual definition of acquisition and analysis parameters is still required.

The advances in fluorescent probes and microscope technology with better lasers, filters, PMTs/CCDs and software allows for manipulation of real and artifactual signals. Correct interpretation of visual data necessitates an in depth knowledge of the processes examined and the technical experience to evaluate the integrity of acquired data and its biological significance. Users and analysts should be aware of the pitfalls and exhibit critical judgment in the interpretation of any microscopy data, quantified or not. Seeing is believing, but your eyes (or software) may be deceiving you.

\section{CELL LINES AND IN VITRO GENERATION OF DCS}

In paper I we used human fibroblasts, melanoma cells and canine kidney cells to examine the impact of Ii on old MHC II. These cells lines are not APCs, and with the exception of the Meljuso cells, do not 
express endogenous MHC II, li nor other CIITA target genes or lineage specific genes induced during APC development. However, MHC II expression can be induced in various cell types, including fibroblasts, in response to IFN- $\gamma$ which leads to CIITA pIV expression, sufficient to achieve MHC II antigen presentation. CIITA regulates only a small number of genes, and apart from MHC II, HLA-DM, HLA-DO and li, only nine other genes are regulated. These include an ubiquitin E3 ligase (TRIM26), an alternative isoform of the early recycling Rab4 (Rab4b) and an immunoglobulin family member (MYBPC2) which can bind myosin and actin, as well as a lysosomal protease (TPP1) (Krawczyk et al., 2008). This suggests that the minimal requirement for $\mathrm{MHC}$ II antigen presentation involves few additional factors. The experimental system we have used with selective transfection of a few genes into non-APCs enable us to define the role of li in a setting where no other APC specific factors are present, and thereby avoids any 'contamination' of the results by unidentified/uncharacterized elements.

In paper II we examine the molecular basis for li function in maturing moDCs. The heterogeneity within the DC network and the development of DClike cells from monocyte precursors during inflammation is outlined in the theoretical discussion. However, the in vitro differentiation of DCs from human monocytes is far removed from moDC development during inflammation in vivo. Human, 'immature', moDCs differentiated in the presence of GM-CSF and IL-4 presumably represent an intermediate stage between monocytes and the inflammatory DCs observed in mice, with a full DC phenotype acquired upon activation with PRR ligands or inflammatory cytokines. Monocytes can also give rise to other functionally distinct moDC types depending on the cytokines they are exposed to during differentiation. For example culture in GMCSF and IL-15 generates moDCs which are superior at inducing cytotoxic T cell development and culture in GM-CSF and IL-10 generates moDCs which render T cells anergic and drive the expansion of suppressor T cells (reviewed in (Ueno et al., 2010a)). Clearly moDCs differentiated in vivo will encounter a vastly more complex environment, and how these, let alone the steady-state developed DCs, compare to the in vitro generated DCs is not well characterized. Most studies on the cell biology of human DCs rely on GM-CSF and IL-4 generated moDCs, and for paper II we sought to expand our knowledge of established moDC responses to determine whether there was a transcriptional/translational rationale for li function in established endosomal dynamics. Both the transcriptional transient increase and decrease of CIITA and MHC II (but not li or the total MHC II population), the MIIC tubulation and MHC II cell surface increase have previously been shown for moDCs and these correspond to events in the conventional DC subsets, but not pDCs, in vivo. We therefore reasoned that moDCs were an acceptable experimental model in which to examine these events.

\section{Relative quANTITATIVE REAL-TIME PCR}

In paper II we use quantitative real time polymerase chain reaction ( $q R T-P C R$ ) to examine the relative ratios of $\mathrm{MHC} I I$ and li isoform mRNA levels through DC maturation. As our moDCs were generated from monocytes isolated from several individuals with variable haplotypes, we needed primers which covered most allelic variants of the MHC II isotypes. Primers were consequently designed to target conserved loci on the MHC II alpha chain mRNAs which display less allelic diversity than the beta chains (Robinson et al., 2010). As li can form heterotrimers and associates with all $\mathrm{MHC}$ II isotypes 
we assessed the total MHC II population (HLA-DR, HLA-DP and HLA-DQ) to determine the ratio of total MHC II to the total Ii (p33/35 and p41/43). All primers were extensively tested for specificity and efficiency by melting curve analysis and ten-fold serial dilutions $\left(E=10^{-1 / \text { slope }}\right)$. For reference we used glyceraldehyde 3-phosphate dehydrogenase (GAPDH) due to its consistent, constant level in all donors examined. Another commonly used reference gene, $\beta$-actin, exhibited marked fluctuations after moDC activation, possibly due to the increased migratory capacity in this maturation state. SYBR ${ }^{\circledR}$ Green was used as fluorescent reporter to monitor amplification of specific targets and threshold cycle $(\mathrm{Ct})$ values were corrected for primer efficiency according to equation:

$$
R=\frac{\left(E_{\text {target }}\right)^{\Delta C t \text { target }(\text { control-sample })}}{\left(E_{\text {reference }}\right)^{\Delta C t \text { reference }(\text { control-sample })}}
$$

Relative qRT-PCR is, like microscopy above, fraught with potential for error in sample preparation, running and analysis. In our analysis we have consistently used the same protocols, reagents and instruments in our data-acquisition and the same normalization and analytical procedures in order to be able to compare our different data sets. We have to the extent possible tried to adhere to the most rigid experimental and analytical guidelines (Bustin et al., 2009). Working with moDCs generated from different individuals will necessarily include some deviation, however despite these premonitions our samples displayed a surprisingly low variation and consistent regulation in all donors examined.

An aspect which requires some consideration is the extent to which the respective mRNAs result from transcription or other mechanisms. The $3^{\prime}$ and $5^{\prime}$ ends of mRNAs are protected by the poly A tail and the 7-methyl-guanosine cap, respectively, and the removal of any of these initiates mRNA degradation by exonucleases. The target of the majority of mammalian micro-RNAs are located in the $3^{\prime}$ UTR (un-translated region) of mRNAs, and adenineuridine rich elements (AREs) located in the $3^{\prime}$ ends can confer constitutive instability on mRNAs containing them (Anderson, 2010), no such elements have been identified in the MHC II or li transcripts, although CIITA is a specific target of miRNAs (Asirvatham et al., 2008). Despite this we cannot exclude that the mRNA species examined have variable half-lives through maturation. Translational regulation of several mRNA species has been shown in moDCs after activation with LPS, but neither the li or MHC II isotypes have been found to be differentially translated (Ceppi et al., 2009). However, the steady state affinity of these mRNAs for ribosomes, and the consequent translational activity is unknown, so a correlation between mRNA levels and translation products, beyond the crude biochemical assays presented in paper II, could not be established. Post-transcriptional mechanisms that modify mRNA stability and/or translation could consequently influence the levels of mRNA and the translation efficiency (for a review see (Anderson, 2010)).

\section{CONCLUSIONS AND FUTURE PERSPECTIVES}

In this thesis we have examined the role of $\mathrm{li}$ in modulating the endosomal system to promote an APC specific endocytic environment devoted to antigen presentation on MHC II. Our findings presented in paper I (Landsverk et al., 2010b) clearly show that li is involved in the generation of a slowly maturing endocytic pathway that is accessed not only by new, li-associated MHC II, but also mature MHC II. We show that this increases the half-life of 
MHC II, but also of the epidermal growth factor (EGF) receptor which is sorted onto intralumenal vesicles after EGF stimulation. Placed in the context of the large body of research generated over the past three decades (as discussed in the theoretical introduction and (Landsverk et al., 2009)), our results strongly suggest that li plays a major role in the biogenesis of an alternate endocytic pathway devoted to MHC II peptide loading. This Ii induced pathway exhibits all the characteristics of the MIICs observed in B cells and steady state DCs, and allows for the accumulation of intracellular MHC II for exosome release or tubule mediated delivery of MHC II upon DC activation. In paper II we examine the molecular basis for a role for $\mathrm{li}$ in the endomembrane dynamics occurring during DC maturation and find that there is a sustained production of $\mathrm{li}$ in mature moDCs. This surplus of $\mathrm{li}$ is predominantly present in the ER, but a fraction traffics to the endocytic pathway despite the reduced availability of new MHC II. This provides a biosynthetic rationale for a role for $\mathrm{li}$ in modulating the endocytic pathway also in mature moDCs.

The multitude of li-interacting partners described has shown that this molecule is intimately involved in multiple aspects of antigen presentation and beyond. How many of these partners benefit from the endosome modulating capacity of $\mathrm{li}$ is poorly examined so far, but presumably CD1 molecules and MHC I could gain the same benefits as MHC II with regard to antigen loading. For $\mathrm{MHC} \mathrm{I}$, this suggests that li may play a role in the cross-presentation of exogenous antigens to $C D 8+T$ cells. The delayed proteolysis of antigen and early endosomes are essential to achieve the loading of peptides on MHC I, and li might thereby facilitate both proteasome/TAP (Transporter associated with antigen processing) dependent and independent pathways for peptide loading of MHC I in endosomes (for reviews on cross-presentation see (Amigorena and Savina, 2010; Ramachandra et al., 2009)). In this context it is interesting to note that one of the major cross presenting DC subsets, the pDCs, maintain CIITA activity and new MHC II/li production after activation (Young et al., 2008). Signaling receptors, such as TLR4, can maintain signaling from early, but not late endosomes (Palsson-McDermott et al., 2009). It is possible that li-associated chemokine receptors might receive similar benefits from an expanded early endosomal phase provided by li (Landsverk et al., 2010b). Alternatively, as $\mathrm{Ii}$ associated $\mathrm{MHC} \mathrm{II}$ is not a substrate for ubiquitin E3 ligases (van Niel et al., 2006), interactions with li might influence signaling by delaying receptor ubiquitination and degradation.

The function of li in intracellular trafficking and endosomal modulation in many ways resembles the role of small GTPases in membrane fusion and motility. Which factors li influences to achieve these profound effects on endosomes are so far unknown, but their identification will undoubtedly provide information, not only on the particulars of the APC specific endosomal system, but also on the general properties of the endocytic pathway common to all cell types. No SNAREs have so far been isolated with $\mathrm{li}$, but the rapid processing of $\mathrm{li}$ in the endocytic pathway, implies that any such interaction would be fleeting and difficult to isolate. The association with myosin II is intriguing, and could possibly serve additional purposes apart from controlling convergence of $B c R$ internalized antigen and $D C$ motility. Actin has been shown to play multiple roles in the endocytic pathway (Girao et al., 2008), and myosin II mediated recruitment of actin to li endosomes might play some hitherto unknown function here. An intriguing aspect is how this 
function curtailed in APCs. Enlarged endosomes are not usually present in DCs or B cells, and despite a high expression, li does not produce a visible enlarged morphology in human moDCs. In humans, ii p35 and li p43 contain an ER retention motif, and li trimers containing one or more of these exhibit impaired ER export in the absence of MHC II. In transfected cell lines lacking MHC II, the presence of li p35 seems to restrict the generation of enlarged endosomes by li p33 (Sand and Gregers, unpublished). However, as the ER retention motifs are absent in li isoforms from mice, other factors must also be involved. Potential factors could be caspases which cleave the cytoplasmic tail of li. A putative caspase cleavage site has been identified in the cytoplasmic tail of li (Huang et al., 2008), and cleavage in this motif (DQRD) would remove the negative charge required for the induction of enlarged endosomes (Nordeng et al., 2002) (se also figure 3 in introduction). Interestingly, this cleavage might be developmentally regulated. In mice, nitricoxide Synthase 2 (NOS2) was coimmunoprecipitated with li from BMDCs and MOs after LPS activation, but not from immature cells, and the proximal production of nitric oxide was proposed to inhibit caspase mediated cleavage of li (Huang et al., 2008). Alternatively, the morphological effect of li could be compensated for by the presence of other APC specific factors such as rabs and/or ubiquitin ligases. Retrieval of membrane (vesicles) from early endosomes could be achieved through elevated recycling through CIITA induced Rab4b (Krawczyk et al., 2007), li-myosin II recruitment of actin for recycling microdomains (Puthenveedu et al., 2010), or enhanced membrane invagination and intralumenal packing through APC specific ubiquitin ligases acting on MHC II.
To our knowledge li is the only factor not specifically devoted to endo-membrane dynamics which can exert such profound effects on the endocytic pathway. This function is remarkably conserved, li cloned from humans, mice (Gedde-Dahl et al., 1997), chicken (Bremnes et al., 2000), and even Salmo salar (McAdam and Gregers, unpublished) all maintain the capacity to generate enlarged endosomes. This strongly argues for an evolutionary drive to maintain this property, however despite a sustained effort by our lab over many years, and several publications, this function of li has received little notice in the immunological community. For the future it should be a goal to separate the primary function of li on MHC II trafficking from its secondary profound effects on the endosomal system, and determine its impact on the diversity of peptide-MHC II combinations presented to T cells. The tools to do this are at our disposal, and the future should provide conclusive evidence to verify or discard this property of $\mathrm{Ii}$ in $\mathrm{MHC}$ II antigen presentation.

In conclusion, although the three decades that have passed since the discovery of li have greatly increased our knowledge of the function of li in $\mathrm{MHC}$ II assembly and transport in the endocytic pathway, there still remain many unsolved questions, and additional roles are still being discovered for this versatile molecule. Further insight into these mechanisms might provide us with a better chance of manipulating them in order to find new approaches to combat cancers, autoimmunity and infectious diseases. 


\section{REFERENCES}

Aderem, A., and D.M. Underhill. 1999. Mechanisms of phagocytosis in macrophages. Annu Rev Immunol. 17:593-623.

Akhmanova, A., and J.A. Hammer, 3rd. 2010. Linking molecular motors to membrane cargo. Curr Opin Cell Biol. 22:479-487.

Allan, R.S., C.M. Smith, G.T. Belz, A.L. van Lint, L.M. Wakim, W.R. Heath, and F.R. Carbone. 2003. Epidermal viral immunity induced by CD8alpha+ dendritic cells but not by Langerhans cells. Science. 301:1925-1928.

Allan, R.S., J. Waithman, S. Bedoui, C.M. Jones, J.A. Villadangos, Y. Zhan, A.M. Lew, K. Shortman, W.R. Heath, and F.R. Carbone. 2006. Migratory dendritic cells transfer antigen to a lymph noderesident dendritic cell population for efficient CTL priming. Immunity. 25:153-162.

Amigorena, S., J.R. Drake, P. Webster, and I. Mellman. 1994. Transient accumulation of new class II MHC molecules in a novel endocytic compartment in B lymphocytes. Nature. 369:113-120.

Amigorena, S., and A. Savina. 2010. Intracellular mechanisms of antigen cross presentation in dendritic cells. Curr Opin Immunol. 22:109-117.

Anderson, H.A., D.T. Bergstralh, T. Kawamura, A. Blauvelt, and P.A. Roche. 1999. Phosphorylation of the invariant chain by protein kinase $C$ regulates MHC class II trafficking to antigen-processing compartments. J Immunol. 163:5435-5443.

Anderson, K.S., and P. Cresswell. 1994. A role for calnexin (IP90) in the assembly of class II MHC molecules. EMBO J. 13 (3):675-682.

Anderson, M.S., and J. Miller. 1992. Invariant chain can function as a chaperone protein for class II major histocompatibility complex molecules. Proc.Natl.Acad.Sci.USA. 89:2282-2286.

Anderson, P. 2010. Post-transcriptional regulons coordinate the initiation and resolution of inflammation. Nat Rev Immunol. 10:24-35.

Andoniou, C.E., S.L. van Dommelen, V. Voigt, D.M. Andrews, G. Brizard, C. Asselin-Paturel, T. Delale, K.J. Stacey, G. Trinchieri, and M.A. Degli-Esposti. 2005. Interaction between conventional dendritic cells and natural killer cells is integral to the activation of effective antiviral immunity. Nat Immunol. 6:1011-1019.

Arndt, S.O., A.B. Vogt, S. Markovic-Plese, R. Martin, G. Moldenhauer, A. Wolpl, Y. Sun, D. Schadendorf, G.J. Hammerling, and H. Kropshofer. 2000. Functional HLA-DM on the surface of $B$ cells and immature dendritic cells. Embo J. 19:1241-1251.

Arunachalam, B., C.A. Lamb, and P. Cresswell. 1994. Transport properties of free and MHC class IIassociated oligomers containing different isoforms of human invariant chain. Int Immunol. 6:439-451.
Ashman, J.B., and J. Miller. 1999. A role for the transmembrane domain in the trimerization of the MHC class II-associated invariant chain. J.Immunol. 163:2704-2712.

Asirvatham, A.J., C.J. Gregorie, Z. Hu, W.J. Magner, and T.B. Tomasi. 2008. MicroRNA targets in immune genes and the Dicer/Argonaute and ARE machinery components. Mol Immunol. 45:19952006.

Bachem, A., S. Guttler, E. Hartung, F. Ebstein, M. Schaefer, A. Tannert, A. Salama, K. Movassaghi, C. Opitz, H.W. Mages, V. Henn, P.M. Kloetzel, S. Gurka, and R.A. Kroczek. 2010. Superior antigen crosspresentation and XCR1 expression define human CD11c+CD141+ cells as homologues of mouse CD8+ dendritic cells. J Exp Med. 207:1273-1281.

Bakke, O., and B. Dobberstein. 1990. MHC class IIassociated invariant chain contains a sorting signal for endosomal compartments. Cell. 63:707-716.

Banchereau, J., F. Briere, C. Caux, J. Davoust, S. Lebecque, Y.J. Liu, B. Pulendran, and K. Palucka. 2000. Immunobiology of dendritic cells. Annu Rev Immunol. 18:767-811.

Barois, N., B. de Saint-Vis, S. Lebecque, H.J. Geuze, and M.J. Kleijmeer. 2002. MHC class II compartments in human dendritic cells undergo profound structural changes upon activation. Traffic. 3:894-905.

Barral, D.C., M. Cavallari, P.J. McCormick, S. Garg, A.I. Magee, J.S. Bonifacino, G. De Libero, and M.B. Brenner. 2008. CD1a and MHC class I follow a similar endocytic recycling pathway. Traffic. 9:1446-1457.

Becker-Herman, S., G. Arie, H. Medvedovsky, A. Kerem, and I. Shachar. 2005. CD74 is a member of the regulated intramembrane proteolysis-processed protein family. Mol Biol Cell. 16:5061-5069.

Bedoui, S., P.G. Whitney, J. Waithman, L. Eidsmo, L. Wakim, I. Caminschi, R.S. Allan, M. Wojtasiak, K. Shortman, F.R. Carbone, A.G. Brooks, and W.R. Heath. 2009. Cross-presentation of viral and self antigens by skin-derived CD103+ dendritic cells. Nat Immunol. 10:488-495.

Behnia, R., and S. Munro. 2005. Organelle identity and the signposts for membrane traffic. Nature. 438:597-604.

Bellemare-Pelletier, A., J. Tremblay, S. Beaulieu, M.R. Boulassel, J.P. Routy, B. Massie, R. Lapointe, and J. Thibodeau. 2005. HLA-DO transduced in human monocyte-derived dendritic cells modulates $\mathrm{MHC}$ class II antigen processing. J Leukoc Biol. 78:95-105.

Bénaroch, P., M. Yilla, G. Raposo, K. Ito, K. Miwa, H.J. Geuze, and H.L. Ploegh. 1995. How MHC class II molecules reach the endocytic pathway. EMBO J. 14:37-49. 
Benoist, C., and D. Mathis. 1990. Regulation of major histocompatibility complex class-II genes: $X, Y$ and other letters of the alphabet. Annu Rev Immunol. 8:681-715.

Bergeland, T., L. Haugen, O.J. Landsverk, H. Stenmark, and O. Bakke. 2008. Cell-cycle-dependent binding kinetics for the early endosomal tethering factor EEA1. EMBO Rep. 9:171-178.

Berkova, Z., R.H. Tao, and F. Samaniego. 2010. Milatuzumab - a promising new immunotherapeutic agent. Expert Opin Investig Drugs. 19:141-149.

Bernhagen, J., R. Krohn, H. Lue, J.L. Gregory, A. Zernecke, R.R. Koenen, M. Dewor, I. Georgiev, A. Schober, L. Leng, T. Kooistra, G. Fingerle-Rowson, P. Ghezzi, R. Kleemann, S.R. McColl, R. Bucala, M.J. Hickey, and C. Weber. 2007. MIF is a noncognate ligand of CXC chemokine receptors in inflammatory and atherogenic cell recruitment. Nat Med. 13:587-596.

Beswick, E.J., and V.E. Reyes. 2009. CD74 in antigen presentation, inflammation, and cancers of the gastrointestinal tract. World J Gastroenterol. 15:2855-2861.

Bevec, T., V. Stoka, G. Pungercic, I. Dolenc, and V. Turk. 1996. Major histocompatibility complex class IIassociated p41 invariant chain fragment is a strong inhibitor of lysosomal cathepsin L. J.Exp.Med. 183:1331-1338.

Bijlmakers, M.E., P. Benaroch, and H.L. Ploegh. 1994. Mapping functional regions in the lumenal domain of the class II-associated invariant chain. J.Exp.Med. 180:623-629.

Bikoff, E.K., L.Y. Huang, V. Episkopou, J. van Meerwijk, R.N. Germain, and E.J. Robertson. 1993. Defective major histocompatibility complex class II assembly, transport, peptide acquisition, and $\mathrm{CD} 4+\mathrm{T}$ cell selection in mice lacking invariant chain expression. J.Exp.Med. 177:1699-1712.

Bikoff, E.K., G. Kenty, and L. Van Kaer. 1998. Distinct peptide loading pathways for MHC class II molecules associated with alternative li chain isoforms. J.Immunol. 160:3101-3110.

Blander, J.M., and R. Medzhitov. 2006. On regulation of phagosome maturation and antigen presentation. Nat Immunol. 7:1029-1035.

Blott, E.J., and G.M. Griffiths. 2002. Secretory lysosomes. Nat Rev Mol Cell Biol. 3:122-131.

Boes, M., N. Bertho, J. Cerny, M. Op den Brouw, T. Kirchhausen, and H. Ploegh. 2003. T cells induce extended class II MHC compartments in dendritic cells in a Toll-like receptor-dependent manner. J Immunol. 171:4081-4088.

Boes, M., J. Cerny, R. Massol, M. Op den Brouw, T. Kirchhausen, J. Chen, and H.L. Ploegh. 2002. Tcell engagement of dendritic cells rapidly rearranges MHC class II transport. Nature. 418:983-988.

Bonifacino, J.S., and L.M. Traub. 2003. Signals for sorting of transmembrane proteins to endosomes and lysosomes. Annu Rev Biochem. 72:395-447.

Brasel, K., T. De Smedt, J.L. Smith, and C.R. Maliszewski. 2000. Generation of murine dendritic cells from flt3-ligand-supplemented bone marrow cultures. Blood. 96:3029-3039.

Bremnes, B., T. Madsen, M. Gedde-Dahl, and O. Bakke. 1994. An LI and ML motif in the cytoplasmic tail of the MHC-associated invariant chain mediate rapid internalization. J.Cell Sci. 107:2021-2032.

Bremnes, B., M. Rode, M. Gedde-Dahl, T.W. Nordeng, J. Jacobsen, S.A. Ness, and O. Bakke. 2000. The MHC Class II-Associated Chicken Invariant Chain Shares Functional Properties with Its Mammalian Homologs. Exp Cell Res. 259:360369.

Brocke, P., N. Garbi, F. Momburg, and G.J. Hammerling. 2002. HLA-DM, HLA-DO and tapasin: functional similarities and differences. Curr Opin Immunol. 14:22-29.

Brulet, J.M., F. Maudoux, S. Thomas, K. Thielemans, A. Burny, O. Leo, F. Bex, and S. Hallez. 2007. DNA vaccine encoding endosome-targeted human papillomavirus type 16 E7 protein generates CD4+ $\mathrm{T}$ cell-dependent protection. Eur J Immunol. 37:376-384.

Burgdorf, S., A. Kautz, V. Bohnert, P.A. Knolle, and C. Kurts. 2007. Distinct pathways of antigen uptake and intracellular routing in CD4 and CD8 $\mathrm{T}$ cell activation. Science. 316:612-616.

Bursch, L.S., L. Wang, B. Igyarto, A. Kissenpfennig, B. Malissen, D.H. Kaplan, and K.A. Hogquist. 2007. Identification of a novel population of Langerin+ dendritic cells. J Exp Med. 204:3147-3156.

Busch, R., C.H. Rinderknecht, S. Roh, A.W. Lee, J.J. Harding, T. Burster, T.M. Hornell, and E.D. Mellins. 2005. Achieving stability through editing and chaperoning: regulation of MHC class II peptide binding and expression. Immunol Rev. 207:242260.

Bustin, S.A., V. Benes, J.A. Garson, J. Hellemans, J. Huggett, M. Kubista, R. Mueller, T. Nolan, M.W. Pfaffl, G.L. Shipley, J. Vandesompele, and C.T. Wittwer. 2009. The MIQE guidelines: minimum information for publication of quantitative realtime PCR experiments. Clin Chem. 55:611-622.

Cai, H., K. Reinisch, and S. Ferro-Novick. 2007. Coats, tethers, Rabs, and SNAREs work together to mediate the intracellular destination of a transport vesicle. Dev Cell. 12:671-682.

Calafat, J., M. Nijenhuis, H. Janssen, A. Tulp, S. Dusseljee, R. Wubbolts, and J. Neefjes. 1994. Major histocompatibility complex class II molecules induce the formation of endocytic MIIC-like structures. J.Cell Biol. 126:967-977.

Callaghan, J., S. Nixon, C. Bucci, B.H. Toh, and H. Stenmark. 1999a. Direct interaction of EEA1 with Rab5b. Eur J Biochem. 265:361-366.

Callaghan, J., A. Simonsen, J.M. Gaullier, B.H. Toh, and H. Stenmark. 1999b. The endosome fusion regulator early-endosomal autoantigen 1 (EEA1) is a dimer. Biochem J. 338 ( Pt 2):539-543.

Caplan, S., E.C. Dell'Angelica, W.A. Gahl, and J.S. Bonifacino. 2000. Trafficking of major histocompatibility complex class II molecules in human B-lymphoblasts deficient in the AP-3 adaptor complex. Immunol Lett. 72:113-117. 
Carlsson, S.R., and M. Fukuda. 1992. The lysosomal membrane glycoprotein lamp-1 is transported to lysosomes by two alternative pathways. Arch.Biochem.Biophys. 296:630-639.

Carroll, K.S., J. Hanna, I. Simon, J. Krise, P. Barbero, and S.R. Pfeffer. 2001. Role of Rab9 GTPase in facilitating receptor recruitment by TIP47. Science. 292:1373-1376.

Carstens, C., D.K. Newman, H. Bohlen, A. Konig, and N. Koch. 2000. Invariant chains with the class II binding site replaced by a sequence from influenza virus matrix protein constrain lowaffinity sequences to MHC II presentation. Int Immunol. 12:1561-1568.

Castellino, F., R. Han, and R.N. Germain. 2001. The transmembrane segment of invariant chain mediates binding to MHC class II molecules in a CLIP-independent manner. Eur J Immunol. 31:841-850.

Cella, M., A. Engering, V. Pinet, J. Pieters, and A. Lanzavecchia. 1997. Inflammatory stimuli induce accumulation of MHC class II complexes on dendritic cells. Nature. 388:782-787.

Cella, M., M. Salio, Y. Sakakibara, H. Langen, I. Julkunen, and A. Lanzavecchia. 1999. Maturation, activation, and protection of dendritic cells induced by double-stranded RNA. J Exp Med. 189:821-829.

Ceppi, M., G. Clavarino, E. Gatti, E.K. Schmidt, A. de Gassart, D. Blankenship, G. Ogola, J. Banchereau, D. Chaussabel, and P. Pierre. 2009. Ribosomal protein mRNAs are translationally-regulated during human dendritic cells activation by LPS. Immunome Res. 5:5.

Chalfie, M., Y. Tu, G. Euskirchen, W.W. Ward, and D.C. Prasher. 1994. Green fluorescent protein as a marker for gene expression. Science. 263:802805.

Chamuleau, M.E., Y. Souwer, S.M. Van Ham, A. Zevenbergen, T.M. Westers, J. Berkhof, C.J. Meijer, A.A. van de Loosdrecht, and G.J. Ossenkoppele. 2004. Class II-associated invariant chain peptide expression on myeloid leukemic blasts predicts poor clinical outcome. Cancer research. 64:5546-5550.

Chang, C.H., P. Sapra, S.S. Vanama, H.J. Hansen, I.D. Horak, and D.M. Goldenberg. 2005. Effective therapy of human lymphoma xenografts with a novel recombinant ribonuclease/anti-CD74 humanized IgG4 antibody immunotoxin. Blood. 106:43084314.

Charrin, S., F. le Naour, O. Silvie, P.E. Milhiet, C. Boucheix, and $E$. Rubinstein. 2009. Lateral organization of membrane proteins: tetraspanins spin their web. Biochem J. 420:133-154.

Chen, X., X. Wang, J.M. Keaton, F. Reddington, P.A. Illarionov, G.S. Besra, and J.E. Gumperz. 2007. Distinct endosomal trafficking requirements for presentation of autoantigens and exogenous lipids by human CD1d molecules. I Immunol. 178:6181-6190.

Cheong, C., I. Matos, J.H. Choi, D.B. Dandamudi, E. Shrestha, M.P. Longhi, K.L. Jeffrey, R.M.
Anthony, C. Kluger, G. Nchinda, H. Koh, A. Rodriguez, J. Idoyaga, M. Pack, K. Velinzon, C.G. Park, and R.M. Steinman. 2010. Microbial Stimulation Fully Differentiates Monocytes to DC-SIGN/CD209(+) Dendritic Cells for Immune T Cell Areas. Cell. 143:416-429.

Chow, A., D. Toomre, W. Garrett, and I. Mellman. 2002. Dendritic cell maturation triggers retrograde MHC class II transport from lysosomes to the plasma membrane. Nature. 418:988-994.

Chudakov, D.M., M.V. Matz, S. Lukyanov, and K.A. Lukyanov. 2010. Fluorescent proteins and their applications in imaging living cells and tissues. Physiol Rev. 90:1103-1163.

Claesson, L., D. Larhammar, L. Rask, and P.A. Peterson. 1983. cDNA clone for the human invariant gamma chain of class II histocompatibility antigens and its implications for the protein structure. Proc.Natl.Acad.Sci.USA. 80:73957399.

Clements, V.K., S. Baskar, T.D. Armstrong, and S. OstrandRosenberg. 1992. Invariant chain alters the malignant phenotype of MHC class II+ tumor cells. J.Immunol. 149:2391-2396.

Colonna, M., G. Trinchieri, and Y.J. Liu. 2004. Plasmacytoid dendritic cells in immunity. Nat Immunol. 5:1219-1226.

Conibear, E. 2010. Converging views of endocytosis in yeast and mammals. Curr Opin Cell Biol. 22:513518.

consortium, T.M.s. 1999. Complete sequence and gene map of a human major histocompatibility complex. Nature. 401:921-923.

Coons, A.H., H.J. Creech, R.N. Jones, and E. Berliner. 1942. The demonstration of pneumococcal antigen in tissues by the use of fluorescent antibody. J Immunol. 45:159-170.

Cosson, P., and J.S. Bonifacino. 1992. Role of transmembrane domain interactions in the assembly of class II MHC molecules. Science. 258:659-662.

Crozat, K., R. Guiton, V. Contreras, V. Feuillet, C.A. Dutertre, E. Ventre, T.P. Vu Manh, T. Baranek, A.K. Storset, J. Marvel, P. Boudinot, A. Hosmalin, I. Schwartz-Cornil, and M. Dalod. 2010. The XC chemokine receptor 1 is a conserved selective marker of mammalian cells homologous to mouse CD8alphat dendritic cells. J Exp Med. 207:1283-1292.

Cuthbert, R.J., J.M. Wilson, N. Scott, P.L. Coletta, and M.A. Hull. 2009. Differential CD74 (major histocompatibility complex Class II invariant chain) expression in mouse and human intestinal adenomas. European Journal of Cancer.

De Gassart, A., V. Camosseto, J. Thibodeau, M. Ceppi, N. Catalan, P. Pierre, and E. Gatti. 2008. MHC class Il stabilization at the surface of human dendritic cells is the result of maturation-dependent MARCH I down-regulation. Proc Natl Acad Sci U S A. 105:3491-3496.

De Matteis, M.A., and A. Godi. 2004. PI-loting membrane traffic. Nat Cell Biol. 6:487-492. 
Denoeud, J., and M. Moser. 2010. Role of CD27/CD70 pathway of activation in immunity and tolerance. J Leukoc Biol.

Denzin, L.K., D.B. Sant'Angelo, C. Hammond, M.J. Surman, and P. Cresswell. 1997. Negative regulation by HLA-DO of MHC class II-restricted antigen processing. Science. 278:106-109.

Derbinski, J., and B. Kyewski. 2010. How thymic antigen presenting cells sample the body's self-antigens. Curr Opin Immunol.

Dixon, A.M., B.J. Stanley, E.E. Matthews, J.P. Dawson, and D.M. Engelman. 2006. Invariant chain transmembrane domain trimerization: a step in MHC class II assembly. Biochemistry. 45:52285234.

Doherty, G.J., and H.T. McMahon. 2009. Mechanisms of Endocytosis. Annu Rev Biochem.

Donaldson, J.G. 2003. Multiple roles for Arf6: sorting, structuring, and signaling at the plasma membrane. J Biol Chem. 278:41573-41576.

Dorhoi, A., and S.H. Kaufmann. 2009. Fine-tuning of T cell responses during infection. Curr Opin Immunol. 21:367-377.

Driessen, C., R.A. Bryant, A.M. Lennon-Dumenil, J.A. Villadangos, P.W. Bryant, G.P. Shi, H.A. Chapman, and H.L. Ploegh. 1999. Cathepsin S controls the trafficking and maturation of $\mathrm{MHC}$ class II molecules in dendritic cells. J Cell Biol. 147:775-790.

Dudziak, D., A.O. Kamphorst, G.F. Heidkamp, V.R. Buchholz, C. Trumpfheller, S. Yamazaki, C. Cheong, K. Liu, H.W. Lee, C.G. Park, R.M. Steinman, and M.C. Nussenzweig. 2007. Differential antigen processing by dendritic cell subsets in vivo. Science. 315:107-111.

Dugast, M., H. Toussaint, C. Dousset, and P. Benaroch. 2005. AP2 clathrin adaptor complex, but not AP1, controls the access of the major histocompatibility complex (MHC) class II to endosomes. J Biol Chem. 280:19656-19664.

Duncan, L.M., S. Piper, R.B. Dodd, M.K. Saville, C.M. Sanderson, J.P. Luzio, and P.J. Lehner. 2006. Lysine-63-linked ubiquitination is required for endolysosomal degradation of class I molecules. Embo J. 25:1635-1645.

Edwards, J.P., X. Zhang, K.A. Frauwirth, and D.M. Mosser. 2006. Biochemical and functional characterization of three activated macrophage populations. J Leukoc Biol. 80:1298-1307.

El-Sukkari, D., N.S. Wilson, K. Hakansson, R.J. Steptoe, A. Grubb, K. Shortman, and J.A. Villadangos. 2003. The protease inhibitor cystatin C is differentially expressed among dendritic cell populations, but does not control antigen presentation. J Immunol. 171:5003-5011.

Elliott, E.A., J.R. Drake, S. Amigorena, J. Elsemore, P. Webster, I. Mellman, and R.A. Flavell. 1994. The invariant chain is required for intracellular transport and function of major histocompatibility complex class II molecules. J.Exp.Med. 179:681-694.

Engering, A., L. Kuhn, D. Fluitsma, E. Hoefsmit, and J. Pieters. 2003. Differential post-translational modification of $\mathrm{CD} 63$ molecules during maturation of human dendritic cells. Eur $J$ Biochem. 270:2412-2420.

Engering, A., and J. Pieters. 2001. Association of distinct tetraspanins with MHC class II molecules at different subcellular locations in human immature dendritic cells. Int Immunol. 13:127134.

Escola, J.M., M.J. Kleijmeer, W. Stoorvogel, J.M. Griffith, O. Yoshie, and H.J. Geuze. 1998. Selective enrichment of tetraspan proteins on the internal vesicles of multivesicular endosomes and on exosomes secreted by human B- lymphocytes. J Biol Chem. 273:20121-20127.

Faure-Andre, G., P. Vargas, M.I. Yuseff, M. Heuze, J. Diaz, D. Lankar, V. Steri, J. Manry, S. Hugues, F. Vascotto, J. Boulanger, G. Raposo, M.R. Bono, M. Rosemblatt, M. Piel, and A.M. Lennon-Dumenil. 2008. Regulation of dendritic cell migration by CD74, the MHC class II-associated invariant chain. Science. 322:1705-1710.

Ferlazzo, G., M. Pack, D. Thomas, C. Paludan, D. Schmid, T. Strowig, G. Bougras, W.A. Muller, L. Moretta, and C. Munz. 2004. Distinct roles of IL-12 and IL15 in human natural killer cell activation by dendritic cells from secondary lymphoid organs. Proc Natl Acad Sci U S A. 101:16606-16611.

Fiebiger, E., R. Maehr, J. Villadangos, E. Weber, A. Erickson, E. Bikoff, H.L. Ploegh, and A.M. LennonDumenil. 2002. Invariant chain controls the activity of extracellular cathepsin L. J Exp Med. 196:1263-1269.

Fineschi, B., K. Sakaguchi, E. Appella, and J. Miller. 1996. The proteolytic environment involved in MHC class II-restricted antigen presentation can be modulated by the p41 form of invariant chain. J.Immunol. 157:3211-3215.

Frauwirth, K., and N. Shastri. 2001. Mutation of the invariant chain transmembrane region inhibits II degradation, prolongs association with $\mathrm{MHC}$ class II, and selectively disrupts antigen presentation. Cell Immunol. 209:97-108.

Freisewinkel, I.M., K. Schenck, and N. Koch. 1993. The segment of invariant chain that is critical for association with major histocompatibility complex class II molecules contains the sequence of a peptide eluted from class II polypeptides. Proc.Natl.Acad.Sci.USA. 90:9703-9706.

Fujii, S., S. Senju, Y.Z. Chen, M. Ando, S. Matsushita, and Y. Nishimura. 1998. The CLIP-substituted invariant chain efficiently targets an antigenic peptide to HLA class II pathway in L cells. Hum.Immunol. 59:607-614.

Gao, M., H.P. Wang, Y.N. Wang, Y. Zhou, and Q.L. Wang. 2006. HCV-NS3 Th1 minigene vaccine based on invariant chain CLIP genetic substitution enhances $\mathrm{CD} 4(+)$ Th1 cell responses in vivo. Vaccine. 24:5491-5497.

Gaullier, J.M., A. Simonsen, A. D'Arrigo, B. Bremnes, H. Stenmark, and R. Aasland. 1998. FYVE fingers bind Ptdlns(3)P. Nature. 394:432-433. 
Gedde-Dahl, M., I. Freisewinkel, M. Staschewski, K. Schenck, N. Koch, and O. Bakke. 1997. Exon 6 is essential for invariant chain trimerization and induction of large endosomal structures. $J$ Biol Chem. 272:8281-8287.

Geissmann, F., S. Gordon, D.A. Hume, A.M. Mowat, and G.J. Randolph. 2010a. Unravelling mononuclear phagocyte heterogeneity. Nat Rev Immunol. 10:453-460.

Geissmann, F., M.G. Manz, S. Jung, M.H. Sieweke, M. Merad, and K. Ley. 2010b. Development of monocytes, macrophages, and dendritic cells. Science. 327:656-661.

Germain, R.N., and L.R. Hendrix. 1991. MHC class II structure, occupancy and surface expression determined by post-endoplasmic reticulum antigen binding. Nature. 353:134-139.

Gerosa, F., B. Baldani-Guerra, L.A. Lyakh, G. Batoni, S. Esin, R.T. Winkler-Pickett, M.R. Consolaro, M. De Marchi, D. Giachino, A. Robbiano, M. Astegiano, A. Sambataro, R.A. Kastelein, G. Carra, and G. Trinchieri. 2008. Differential regulation of interleukin 12 and interleukin 23 production in human dendritic cells. J Exp Med. 205:14471461.

Gerosa, F., A. Gobbi, P. Zorzi, S. Burg, F. Briere, G. Carra, and G. Trinchieri. 2005. The reciprocal interaction of NK cells with plasmacytoid or myeloid dendritic cells profoundly affects innate resistance functions. J Immunol. 174:727-734.

Ghosh, P., M. Amaya, E. Mellins, and D.C. Wiley. 1995. The structure of an intermediate in class II MHC maturation: CLIP bound to HLA-DR3. Nature. 378:457-462.

Ginhoux, F., M.P. Collin, M. Bogunovic, M. Abel, M. Leboeuf, J. Helft, J. Ochando, A. Kissenpfennig, B. Malissen, M. Grisotto, H. Snoeck, G. Randolph, and M. Merad. 2007. Blood-derived dermal langerin+ dendritic cells survey the skin in the steady state. J Exp Med. 204:3133-3146.

Girao, H., M.I. Geli, and F.Z. Idrissi. 2008. Actin in the endocytic pathway: from yeast to mammals. FEBS Lett. 582:2112-2119.

Girolomoni, G., C. Caux, S. Lebecque, C. DezutterDambuyant, and P. Ricciardi-Castagnoli. 2002. Langerhans cells: still a fundamental paradigm for studying the immunobiology of dendritic cells. Trends Immunol. 23:6-8.

Glimcher, L.H., and C.J. Kara. 1992. Sequences and factors: a guide to MHC class-II transcription. Annu Rev Immunol. 10:13-49.

Gordon, S. 2002. Pattern recognition receptors: doubling up for the innate immune response. Cell. 111:927-930.

Gordon, S., and P.R. Taylor. 2005. Monocyte and macrophage heterogeneity. Nat Rev Immunol. 5:953-964.

Gore, Y., D. Starlets, N. Maharshak, S. Becker-Herman, U. Kaneyuki, L. Leng, R. Bucala, and I. Shachar. 2008. Macrophage Migration Inhibitory Factor Induces B Cell Survival by Activation of a CD74CD44 Receptor Complex. J Biol Chem. 283:27842792.
Gorvel, J.-P., P. Chavrier, M. Zerial, and J. Gruenberg. 1991. rab5 controls early endosome fusion in vitro. Cell. 64:915-925.

Gorvel, J.-P., J.-M. Escola, E. Stang, and O. Bakke. 1995a. Invariant chain induces a delayed transport from early to late endosomes. J.Biol.Chem. 270:27412746.

Gorvel, J.P., J.M. Escola, E. Stang, and O. Bakke. 1995b. Invariant chain induces a delayed transport from early to late endosomes. J Biol Chem. 270:27412746.

Greenwald, R.J., G.J. Freeman, and A.H. Sharpe. 2005. The B7 family revisited. Annu Rev Immunol. 23:515548.

Gregers, T.F., B. Fleckenstein, F. Vartdal, P. Roepstorff, O. Bakke, and I. Sandlie. 2003a. MHC class II loading of high or low affinity peptides directed by li/peptide fusion constructs: implications for $\mathrm{T}$ cell activation. Int Immunol. 15:1291-1299.

Gregers, T.F., T.W. Nordeng, and O. Bakke. 2003b. MHC class II antigen presentation. In Intracellular pathogens in membrane interactions and vacuolar biogenesis. J.-P. Gorvel, editor. Landes Bioscience, Georgetown, Texas. 250-277.

Gregers, T.F., T.W. Nordeng, H.C. Birkeland, I. Sandlie, and O. Bakke. 2003c. The cytoplasmic tail of invariant chain modulates antigen processing and presentation. Eur J Immunol. 33:277-286.

Griffiths, G., B. Hoflack, K. Simons, I. Mellman, and S. Kornfeld. 1988. The mannose 6-phosphate receptor and the biogenesis of lysosomes. Cell. 52:329-341.

Griffiths, G.L., M.J. Mattes, R. Stein, S.V. Govindan, I.D. Horak, H.J. Hansen, and D.M. Goldenberg. 2003. Cure of SCID mice bearing human B-lymphoma xenografts by an anti-CD74 antibodyanthracycline drug conjugate. Clin Cancer Res. 9:6567-6571.

Hales, C.M., J.P. Vaerman, and J.R. Goldenring. 2002. Rab11 family interacting protein 2 associates with Myosin $\mathrm{Vb}$ and regulates plasma membrane recycling. J Biol Chem. 277:50415-50421.

Hammer, J.A., 3rd, and X.S. Wu. 2002. Rabs grab motors: defining the connections between Rab GTPases and motor proteins. Curr Opin Cell Biol. 14:6975.

Hammond, C., L.K. Denzin, M. Pan, J.M. Griffith, H.J. Geuze, and P. Cresswell. 1998. The tetraspan protein CD82 is a resident of MHC class II compartments where it associates with HLA-DR, -DM, and -DO molecules. J Immunol. 161:32823291.

Harter, C., and I. Mellman. 1992. Transport of the lysosomal membrane glycoprotein Igp120 (IgpA) to lysosomes does not require appearance on the plasma membrane. J.Cell Biol. 117:311-325.

Harton, J.A., and J.P. Ting. 2000. Class II transactivator: mastering the art of major histocompatibility complex expression. Mol Cell Biol. 20:6185-6194.

Heath, W.R., and F.R. Carbone. 2009. Dendritic cell subsets in primary and secondary $T$ cell responses at body surfaces. Nat Immunol. 10:1237-1244. 
Henne, C., F. Schwenk, N. Koch, and P. Möller. 1995. Surface expression of the invariant chain (CD74) is independent of concomitant expression of major histocompatibility complex class II antigens. Immunology. 84:177-182.

Henri, S., L.F. Poulin, S. Tamoutounour, L. Ardouin, M. Guilliams, B. de Bovis, E. Devilard, C. Viret, H. Azukizawa, A. Kissenpfennig, and B. Malissen. 2010. CD207+ CD103+ dermal dendritic cells cross-present keratinocyte-derived antigens irrespective of the presence of Langerhans cells. J Exp Med. 207:189-206.

Hochrein, H., K. Shortman, D. Vremec, B. Scott, P. Hertzog, and M. O'Keeffe. 2001. Differential production of IL-12, IFN-alpha, and IFN-gamma by mouse dendritic cell subsets. J Immunol. 166:54485455.

Hofmann, M.W., S. Honing, D. Rodionov, B. Dobberstein, K. von Figura, and O. Bakke. 1999. The Leucinebased Sorting Motifs in the Cytoplasmic Domain of the Invariant Chain Are Recognized by the Clathrin Adaptors AP1 and AP2 and their Medium Chains. J. Biol. Chem. 274:36153-36158.

Honey, K., and A.Y. Rudensky. 2003. Lysosomal cysteine proteases regulate antigen presentation. Nat Rev Immunol. 3:472-482.

Hornell, T.M., T. Burster, F.L. Jahnsen, A. Pashine, M.T. Ochoa, J.J. Harding, C. Macaubas, A.W. Lee, R.L. Modlin, and E.D. Mellins. 2006. Human dendritic cell expression of HLA-DO is subset specific and regulated by maturation. J Immunol. 176:35363547.

Hsing, L.C., and A.Y. Rudensky. 2005. The lysosomal cysteine proteases in MHC class II antigen presentation. Immunol Rev. 207:229-241.

Huang, D., D.T. Cai, R.Y. Chua, D.M. Kemeny, and S.H. Wong. 2008. Nitric-oxide synthase 2 interacts with CD74 and inhibits its cleavage by caspase during dendritic cell development. J Biol Chem. 283:1713-1722.

Humphreys, R.E., G.G. Hillman, E. von Hofe, and M. Xu. 2004. Forcing tumor cells to present their own tumor antigens to the immune system: a necessary design for an efficient tumor immunotherapy. Cell Mol Immunol. 1:180-185.

Hurley, J.H. 2008. ESCRT complexes and the biogenesis of multivesicular bodies. Curr Opin Cell Biol. 20:411.

Hurley, J.H., and P.I. Hanson. 2010. Membrane budding and scission by the ESCRT machinery: it's all in the neck. Nat Rev Mol Cell Biol. 11:556-566.

Inaba, K., M. Inaba, N. Romani, H. Aya, M. Deguchi, S. Ikehara, S. Muramatsu, and R.M. Steinman. 1992. Generation of large numbers of dendritic cells from mouse bone marrow cultures supplemented with granulocyte/macrophage colony-stimulating factor. J Exp Med. 176:16931702.

Ishigami, S., S. Natsugoe, K. Tokuda, A. Nakajo, H. Iwashige, K. Aridome, S. Hokita, and T. Aikou. 2001. Invariant chain expression in gastric cancer. Cancer letters. 168:87-91.
Iyoda, T., S. Shimoyama, K. Liu, Y. Omatsu, Y. Akiyama, Y. Maeda, K. Takahara, R.M. Steinman, and K. Inaba. 2002. The CD8+ dendritic cell subset selectively endocytoses dying cells in culture and in vivo. J Exp Med. 195:1289-1302.

Jahn, R., and R.H. Scheller. 2006. SNAREs--engines for membrane fusion. Nat Rev Mol Cell Biol. 7:631643.

Jasanoff, A., G. Wagner, and D.C. Wiley. 1998. Structure of a trimeric domain of the MHC class II-associated chaperonin and targeting protein li. EMBO J. 17:6812-6818.

Jayawardena-Wolf, J., K. Benlagha, Y.H. Chiu, R. Mehr, and A. Bendelac. 2001. CD1d endosomal trafficking is independently regulated by an intrinsic CD1dencoded tyrosine motif and by the invariant chain. Immunity. 15:897-908.

Jiang, Z., M. Xu, L. Savas, P. LeClair, and B.F. Banner. 1999. Invariant chain expression in colon neoplasms. Virchows Archiv. 435:32-36.

Johnson, K.F., and S. Kornfeld. 1992. A His-Leu-Leu sequence near the carboxyl terminus of the cytoplasmic domain of the cation-dependent mannose 6-phosphate receptor is necessary for the lysosomal enzyme sorting function. J.Biol.Chem. 267:17110-17115.

Johnson, P., and B. Ruffell. 2009. CD44 and its role in inflammation and inflammatory diseases. Inflamm Allergy Drug Targets. 8:208-220.

Jones, P.P., D.B. Murphy, D. Hewgill, and H.O. McDevitt. 1979. Detection of a common polypeptide chain in I--A and I--E sub-region immunoprecipitates. Mol Immunol. 16:51-60.

Jongbloed, S.L., A.J. Kassianos, K.J. McDonald, G.J. Clark, X. Ju, C.E. Angel, C.J. Chen, P.R. Dunbar, R.B. Wadley, V. Jeet, A.J. Vulink, D.N. Hart, and K.J. Radford. 2010. Human CD141+ (BDCA-3)+ dendritic cells (DCs) represent a unique myeloid DC subset that cross-presents necrotic cell antigens. J Exp Med. 207:1247-1260.

Kang, S.J., H.E. Liang, B. Reizis, and R.M. Locksley. 2008. Regulation of hierarchical clustering and activation of innate immune cells by dendritic cells. Immunity. 29:819-833.

Kaplan, D.H., A. Kissenpfennig, and B.E. Clausen. 2008. Insights into Langerhans cell function from Langerhans cell ablation models. Eur J Immunol. 38:2369-2376.

Karlsson, L., C.D. Surh, J. Sprent, and P.A. Peterson. 1991. A novel class II MHC molecule with unusual tissue distribution. Nature. 351:485-488.

Kaufman, J.F., C. Auffray, A.J. Korman, D.A. Shackelford, and J. Strominger. 1984. The class II molecules of the human and murine major histocompatibility complex. Cell. 36:1-13.

Ke, S., X.H. Chen, H. Li, J.F. Li, Q.L. Gu, B.Y. Liu, and Z.G. Zhu. 2007. Silencing invariant chain of DCs enhances Th1 response using small interfering RNA. Cell Biol Int. 31:663-671.

Kelly, A.P., J.J. Monaco, S.G. Cho, and J. Trowsdale. 1991. A new human HLA class II-related locus, DM. Nature. 353:571-573. 
Khalil, H., A. Brunet, I. Saba, R. Terra, R.P. Sekaly, and J. Thibodeau. 2003. The MHC class II beta chain cytoplasmic tail overcomes the invariant chain p35-encoded endoplasmic reticulum retention signal. Int Immunol. 15:1249-1263.

Khalil, H., F. Deshaies, A. Bellemare-Pelletier, A. Brunet, A. Faubert, G.A. Azar, and J. Thibodeau. 2002. Class II transactivator-induced expression of HLADO(beta) in HeLa cells. Tissue Antigens. 60:372382.

King, C., S.G. Tangye, and C.R. Mackay. 2008. T follicular helper (TFH) cells in normal and dysregulated immune responses. Annu Rev Immunol. 26:741766.

Kissenpfennig, A., S. Henri, B. Dubois, C. Laplace-Builhe, P. Perrin, N. Romani, C.H. Tripp, P. Douillard, L. Leserman, D. Kaiserlian, S. Saeland, J. Davoust, and B. Malissen. 2005. Dynamics and function of Langerhans cells in vivo: dermal dendritic cells colonize lymph node areas distinct from slower migrating Langerhans cells. Immunity. 22:643654.

Kitamura, H., H. Kamon, S. Sawa, S.J. Park, N. Katunuma, K. Ishihara, M. Murakami, and T. Hirano. 2005. IL-6STAT3 controls intracellular MHC class II alphabeta dimer level through cathepsin S activity in dendritic cells. Immunity. 23:491-502.

Kjær-Nielsen, L., J.D. Perera, L.F. Boyd, D.H. Margulies, and J. McCluskey. 1990. The extracellular domains of MHC class II molecules determine their processing requirements for antigen presentation. J.Immunol. 144:2915-2924.

Klechevsky, E., R. Morita, M. Liu, Y. Cao, S. Coquery, L. Thompson-Snipes, F. Briere, D. Chaussabel, G. Zurawski, A.K. Palucka, Y. Reiter, J. Banchereau, and $\mathrm{H}$. Ueno. 2008. Functional specializations of human epidermal Langerhans cells and CD14+ dermal dendritic cells. Immunity. 29:497-510.

Kleijmeer, M., G. Ramm, D. Schuurhuis, J. Griffith, M. Rescigno, P. Ricciardi-Castagnoli, A.Y. Rudensky, F. Ossendorp, C.J. Melief, W. Stoorvogel, and H.J. Geuze. 2001. Reorganization of multivesicular bodies regulates MHC class II antigen presentation by dendritic cells. J Cell Biol. 155:53-63.

Kleijmeer, M.J., S. Morkowski, J.M. Griffith, A.Y. Rudensky, and H.J. Geuze. 1997. Major histocompatibility complex class II compartments in human and mouse B lymphoblasts represent conventional endocytic compartments. J Cell Biol. 139:639649.

Kleijmeer, M.J., G. Raposo, and H.J. Geuze. 1996. Characterization of MHC Class II Compartments by Immunoelectron Microscopy. Methods. 10:191-207.

Koch, N., W. Lauer, J. Habicht, and B. Dobberstein. 1987. Primary structure of the gene for the murine la antigen-associated invariant chains (li). An alternatively spliced exon encodes a cysteinerich domain highly homologous to a repetitive sequence of thyroglobulin. EMBO J. 6:16771683.
Kouranti, I., M. Sachse, N. Arouche, B. Goud, and A. Echard. 2006. Rab35 regulates an endocytic recycling pathway essential for the terminal steps of cytokinesis. Curr Biol. 16:1719-1725.

Krawczyk, M., E. Leimgruber, Q. Seguin-Estevez, I. DunandSauthier, E. Barras, and W. Reith. 2007. Expression of RAB4B, a protein governing endocytic recycling, is co-regulated with $\mathrm{MHC}$ class II genes. Nucleic Acids Res. 35:595-605.

Krawczyk, M., Q. Seguin-Estevez, E. Leimgruber, P. Sperisen, C. Schmid, P. Bucher, and W. Reith. 2008. Identification of CIITA regulated genetic module dedicated for antigen presentation. PLOS Genet. 4:e1000058.

Kropshofer, H., A.B. Vogt, and G.J. Hämmerling. 1995a. Structural features of the invariant chain fragment CLIP controlling rapid release from HLA-DR molecules and inhibition of peptide binding. Proc.Natl.Acad.Sci.USA. 92:83138317.

Kropshofer, H., A.B. Vogt, L.J. Stern, and G.J. Hämmerling. 1995b. Self-release of CLIP in peptide loading of HLA-DR molecules. Science. 270:1357-1359.

Kukol, A., J. Torres, and I.T. Arkin. 2002. A structure for the trimeric MHC class II-associated invariant chain transmembrane domain. J Mol Biol. 320:11091117.

Kuwana, T., P.A. Peterson, and L. Karlsson. 1998. Exit of major histocompatibility complex class IIinvariant chain p35 complexes from the endoplasmic reticulum is modulated by phosphorylation. Proc.Natl.Acad.Sci.USA. 95:1056-1061.

Lamb, C.A., and P. Cresswell. 1992. Assembly and transport properties of invariant chain trimers and HLA-DR-invariant chain complexes. J.Immunol. 148:3478-3482.

Landmann, S., A. Muhlethaler-Mottet, L. Bernasconi, T. Suter, J.M. Waldburger, K. Masternak, J.F. Arrighi, C. Hauser, A. Fontana, and W. Reith. 2001. Maturation of dendritic cells is accompanied by rapid transcriptional silencing of class II transactivator (CIITA) expression. J Exp Med. 194:379-391.

Landsverk, H.B., F. Mora-Bermudez, O.J. Landsverk, G. Hasvold, S. Naderi, O. Bakke, J. Ellenberg, P. Collas, R.G. Syljuasen, and T. Kuntziger. 2010a. The protein phosphatase 1 regulator PNUTS is a new component of the DNA damage response. EMBO Rep. 11:868-875.

Landsverk, O.J., O. Bakke, and T.F. Gregers. 2009. MHC II and the endocytic pathway: regulation by invariant chain. Scand J Immunol. 70:184-193.

Landsverk, O.J., N. Barois, T.F. Gregers, and O. Bakke. 2010b. Invariant chain increases the half-life of MHC II by delaying endosomal maturation. Immunol Cell Biol.

Lankar, D., H. Vincent-Schneider, V. Briken, T. Yokozeki, G. Raposo, and C. Bonnerot. 2002. Dynamics of major histocompatibility complex class II compartments during B cell receptor-mediated cell activation. J Exp Med. 195:461-472. 
Lapierre, L.A., R. Kumar, C.M. Hales, J. Navarre, S.G. Bhartur, J.O. Burnette, D.W. Provance, Jr., J.A. Mercer, M. Bahler, and J.R. Goldenring. 2001. Myosin vb is associated with plasma membrane recycling systems. Mol Biol Cell. 12:1843-1857.

Lautwein, A., T. Burster, A.M. Lennon-Dumenil, H.S. Overkleeft, E. Weber, H. Kalbacher, and C. Driessen. 2002. Inflammatory stimuli recruit cathepsin activity to late endosomal compartments in human dendritic cells. Eur J Immunol. 32:3348-3357.

Lee, C.z., and H.M. McConnell. 1995. A general model of invariant chain association with class II major histocompatibility complex proteins. Proc.Natl.Acad.Sci.USA. 92:8269-8273.

Leng, L., C.N. Metz, Y. Fang, J. Xu, S. Donnelly, J. Baugh, T. Delohery, Y. Chen, R.A. Mitchell, and R. Bucala. 2003. MIF signal transduction initiated by binding to CD74. J Exp Med. 197:1467-1476.

Lennon-Dumenil, A.M., A.H. Bakker, R. Maehr, E. Fiebiger, H.S. Overkleeft, M. Rosemblatt, H.L. Ploegh, and C. Lagaudriere-Gesbert. 2002. Analysis of protease activity in live antigen-presenting cells shows regulation of the phagosomal proteolytic contents during dendritic cell activation. J Exp Med. 196:529-540.

Lennon-Dumenil, A.M., R.A. Roberts, K. Valentijn, C. Driessen, H.S. Overkleeft, A. Erickson, P.J. Peters, E. Bikoff, H.L. Ploegh, and P. Wolf Bryant. 2001. The p41 isoform of invariant chain is a chaperone for cathepsin L. EMBO J. 20:40554064.

Leon, B., M. Lopez-Bravo, and C. Ardavin. 2007. Monocytederived dendritic cells formed at the infection site control the induction of protective $T$ helper 1 responses against Leishmania. Immunity. 26:519-531.

Lichtman, J.W., and J.A. Conchello. 2005. Fluorescence microscopy. Nat Methods. 2:910-919.

Lipp, J., B. Dobberstein, and M.T. Haeuptle. 1987. Signal recognition particle arrests elongation of nascent secretory and membrane proteins at multiple sites in a transient manner. J.Biol.Chem. 262:1680-1684.

Liu, K., C. Waskow, X. Liu, K. Yao, J. Hoh, and M. Nussenzweig. 2007. Origin of dendritic cells in peripheral lymphoid organs of mice. Nat Immunol. 8:578-583.

Liu, S.H., M.S. Marks, and F.M. Brodsky. 1998. A dominantnegative clathrin mutant differentially affects trafficking of molecules with distinct sorting motifs in the class II major histocompatibility complex (MHC) pathway. J.Cell Biol. 140:10231037.

Liu, Y.J. 2005. IPC: professional type 1 interferonproducing cells and plasmacytoid dendritic cell precursors. Annu Rev Immunol. 23:275-306.

Lotteau, V., L. Teyton, A. Peleraux, T. Nilsson, L. Karlsson, S.L. Schmid, V. Quaranta, and P.A. Peterson. 1990. Intracellular transport of class II MHC molecules directed by invariant chain. Nature. 348:600-605.
Luber, C.A., J. Cox, H. Lauterbach, B. Fancke, M. Selbach, J. Tschopp, S. Akira, M. Wiegand, H. Hochrein, M. O'Keeffe, and M. Mann. 2010. Quantitative proteomics reveals subset-specific viral recognition in dendritic cells. Immunity. 32:279289.

Lutz, M.B., N. Kukutsch, A.L. Ogilvie, S. Rossner, F. Koch, N. Romani, and G. Schuler. 1999. An advanced culture method for generating large quantities of highly pure dendritic cells from mouse bone marrow. J Immunol Methods. 223:77-92.

Luzio, J.P., P.R. Pryor, and N.A. Bright. 2007. Lysosomes: fusion and function. Nat Rev Mol Cell Biol. 8:622632.

Machamer, C.E., and P. Cresswell. 1984. Monensin prevents terminal glycosylation of the $\mathrm{N}$ - and $\mathrm{O}$ linked oligosaccharides of the HLA-DR-associated invariant chain and inhibits its dissociation from the alpha-beta chain complex. Proc Natl Acad Sci U S A. 81:1287-1291.

MacMicking, J.D., G.A. Taylor, and J.D. McKinney. 2003. Immune control of tuberculosis by IFN-gammainducible LRG-47. Science. 302:654-659.

Magalhaes, J.G., J.H. Fritz, L. Le Bourhis, G. Sellge, L.H. Travassos, T. Selvanantham, S.E. Girardin, J.L. Gommerman, and D.J. Philpott. 2008. Nod2dependent Th2 polarization of antigen-specific immunity. J Immunol. 181:7925-7935.

Malcherek, G., V. Gnau, G. Jung, H.G. Rammensee, and A. Melms. 1995. Supermotifs enable natural invariant chain-derived peptides to interact with many major histocompatibility complex-class II molecules. J Exp Med. 181:527-536.

Malcherek, G., C. Wirblich, N. Willcox, H.G. Rammensee, J. Trowsdale, and A. Melms. 1998. MHC class IIassociated invariant chain peptide replacement by $T$ cell epitopes: engineered invariant chain as a vehicle for directed and enhanced MHC class II antigen processing and presentation. Eur.J.Immunol. 28:1524-1533.

Maldonado-Lopez, R., T. De Smedt, P. Michel, J. Godfroid, B. Pajak, C. Heirman, K. Thielemans, O. Leo, J. Urbain, and M. Moser. 1999. CD8alphat and CD8alpha- subclasses of dendritic cells direct the development of distinct $\mathrm{T}$ helper cells in vivo. $J$ Exp Med. 189:587-592.

Manickasingham, S.P., A.D. Edwards, O. Schulz, and C. Reis e Sousa. 2003. The ability of murine dendritic cell subsets to direct $\mathrm{T}$ helper cell differentiation is dependent on microbial signals. Eur J Immunol. 33:101-107.

Mark, T., P. Martin, J.P. Leonard, and R. Niesvizky. 2009. Milatuzumab: a promising new agent for the treatment of lymphoid malignancies. Expert Opin Investig Drugs. 18:99-104.

Matsuki, Y., M. Ohmura-Hoshino, E. Goto, M. Aoki, M. Mito-Yoshida, M. Uematsu, T. Hasegawa, H. Koseki, O. Ohara, M. Nakayama, K. Toyooka, K. Matsuoka, H. Hotta, A. Yamamoto, and S. Ishido. 2007. Novel regulation of MHC class II function in B cells. Embo J. 26:846-854. 
Matza, D., A. Kerem, and I. Shachar. 2003. Invariant chain, a chain of command. Trends Immunol. 24:264268.

Matza, D., F. Lantner, Y. Bogoch, L. Flaishon, R. Hershkoviz, and I. Shachar. 2002. Invariant chain induces B cell maturation in a process that is independent of its chaperonic activity. Proc Natl Acad Sci U S A. 99:3018-3023.

Matza, D., O. Wolstein, R. Dikstein, and I. Shachar. 2001. Invariant chain induces $B$ cell maturation by activating a TAF(II)105-NF-kappaB-dependent transcription program. J Biol Chem. 276:2720327206.

McBride, H.M., V. Rybin, C. Murphy, A. Giner, R. Teasdale, and M. Zerial. 1999. Oligomeric complexes link Rab5 effectors with NSF and drive membrane fusion via interactions between EEA1 and syntaxin 13. Cell. 98:377-386.

McCormick, P.J., J.A. Martina, and J.S. Bonifacino. 2005. Involvement of clathrin and AP-2 in the trafficking of $\mathrm{MHC}$ class II molecules to antigenprocessing compartments. Proc Natl Acad Sci U S A. 102:7910-7915.

McCurley, N., and I. Mellman. 2010. Monocyte-derived dendritic cells exhibit increased levels of lysosomal proteolysis as compared to other human dendritic cell populations. PLoS One. 5:e11949.

McGeachy, M.J., Y. Chen, C.M. Tato, A. Laurence, B. JoyceShaikh, W.M. Blumenschein, T.K. McClanahan, J.J. O'Shea, and D.J. Cua. 2009. The interleukin 23 receptor is essential for the terminal differentiation of interleukin 17-producing effector $\mathrm{T}$ helper cells in vivo. Nat Immunol. 10:314-324.

Megjugorac, N.J., H.A. Young, S.B. Amrute, S.L. Olshalsky, and P. Fitzgerald-Bocarsly. 2004. Virally stimulated plasmacytoid dendritic cells produce chemokines and induce migration of $\mathrm{T}$ and $\mathrm{NK}$ cells. J Leukoc Biol. 75:504-514.

Merad, M., M.G. Manz, H. Karsunky, A. Wagers, W. Peters, I. Charo, I.L. Weissman, J.G. Cyster, and E.G. Engleman. 2002. Langerhans cells renew in the skin throughout life under steady-state conditions. Nat Immunol. 3:1135-1141.

Meyer-Siegler, K.L., K.A. Iczkowski, L. Leng, R. Bucala, and P.L. Vera. 2006. Inhibition of macrophage migration inhibitory factor or its receptor (CD74) attenuates growth and invasion of DU-145 prostate cancer cells. J Immunol. 177:8730-8739.

Meyer-Siegler, K.L., K.A. Iczkowski, and P.L. Vera. 2005. Further evidence for increased macrophage migration inhibitory factor expression in prostate cancer. BMC Cancer. 5:73.

Meyer-Siegler, K.L., E.C. Leifheit, and P.L. Vera. 2004. Inhibition of macrophage migration inhibitory factor decreases proliferation and cytokine expression in bladder cancer cells. BMC Cancer. $4: 34$.

Mihelic, M., A. Dobersek, G. Guncar, and D. Turk. 2008. Inhibitory fragment from the p41 form of invariant chain can regulate activity of cysteine cathepsins in antigen presentation. J Biol Chem. 283:14453-14460.

Milner, J.D., J.M. Brenchley, A. Laurence, A.F. Freeman, B.J. Hill, K.M. Elias, Y. Kanno, C. Spalding, H.Z. Elloumi, M.L. Paulson, J. Davis, A. Hsu, A.I. Asher, J. O'Shea, S.M. Holland, W.E. Paul, and D.C. Douek. 2008. Impaired $\mathrm{T}(\mathrm{H}) 17$ cell differentiation in subjects with autosomal dominant hyper-IgE syndrome. Nature. 452:773776.

Moller, P., C. Henne, and G. Moldenhauer. 1995. CD74 Workshop panel report. In Leukocyte Typing V: White Cell Differentiation Antigens. S. S., editor. Oxford University Press. 568-571.

Mosser, D.M., and J.P. Edwards. 2008. Exploring the full spectrum of macrophage activation. Nat Rev Immunol. 8:958-969.

Motta, A., P. Amodeo, P. Fucile, M.A. Castiglione Morelli, B. Bremnes, and O. Bakke. 1997. A new triplestranded alpha-helical bundle in solution: the assembly of the cytosolic tail of MHC-associated invariant chain. Structure. 5:1453-1464.

Muhlethaler-Mottet, A., L.A. Otten, V. Steimle, and B. Mach. 1997. Expression of MHC class II molecules in different cellular and functional compartments is controlled by differential usage of multiple promoters of the transactivator CIITA. Embo J. 16:2851-2860.

Murk, J.L., W. Stoorvogel, M.J. Kleijmeer, and H.J. Geuze. 2002. The plasticity of multivesicular bodies and the regulation of antigen presentation. Semin Cell Dev Biol. 13:303-311.

Nagarajan, U.M., J. Lochamy, X. Chen, G.W. Beresford, R. Nilsen, P.E. Jensen, and J.M. Boss. 2002. Class II transactivator is required for maximal expression of HLA-DOB in B cells. J Immunol. 168:17801786.

Nagata, T., T. Aoshi, M. Suzuki, M. Uchijima, Y.H. Kim, Z. Yang, and Y. Koide. 2002. Induction of protective immunity to Listeria monocytogenes by immunization with plasmid DNA expressing a helper T-cell epitope that replaces the class IIassociated invariant chain peptide of the invariant chain. Infect Immun. 70:2676-2680.

Nagata, T., T. Higashi, T. Aoshi, M. Suzuki, M. Uchijima, and Y. Koide. 2001. Immunization with plasmid DNA encoding MHC class II binding peptide/CLIPreplaced invariant chain (Ii) induces specific helper T cells in vivo: the assessment of li p31 and p41 isoforms as vehicles for immunization. Vaccine. 20:105-114.

Naik, S.H., D. Metcalf, A. van Nieuwenhuijze, I. Wicks, L. Wu, M. O'Keeffe, and K. Shortman. 2006. Intrasplenic steady-state dendritic cell precursors that are distinct from monocytes. Nat Immunol. 7:663-671.

Naik, S.H., A.I. Proietto, N.S. Wilson, A. Dakic, P. Schnorrer, M. Fuchsberger, M.H. Lahoud, M. O'Keeffe, Q.X. Shao, W.F. Chen, J.A. Villadangos, K. Shortman, and L. Wu. 2005. Cutting edge: generation of splenic CD8+ and CD8-dendritic cell equivalents in Fms-like tyrosine kinase 3 ligand bone marrow cultures. J Immunol. 174:6592-6597. 
Nakagawa, T.Y., W.H. Brissette, P.D. Lira, R.J. Griffiths, N. Petrushova, J. Stock, J.D. McNeish, S.E. Eastman, E.D. Howard, S.R. Clarke, E.F. Rosloniec, E.A. Elliott, and A.Y. Rudensky. 1999. Impaired invariant chain degradation and antigen presentation and diminished collagen-induced arthritis in cathepsin S null mice. Immunity. 10:207-217.

Nakano, N., R. Rooke, C. Benoist, and D. Mathis. 1997. Positive selection of $T$ cells induced by viral delivery of neopeptides to the thymus. Science. 275:678-683.

Neefjes, J.J., and H.L. Ploegh. 1992. Inhibition of endosomal proteolytic activity by leupeptin blocks surface expression of MHC class II molecules and their conversion to SDS resistance alpha beta heterodimers in endosomes. EMBO J. 11:411-416.

Neumann, J., and N. Koch. 2006. A novel domain on HLADRbeta chain regulates the chaperone role of the invariant chain. J Cell Sci. 119:4207-4214.

Nielsen, E., F. Severin, J.M. Backer, A.A. Hyman, and M. Zerial. 1999. Rab5 regulates motility of early endosomes on microtubules. Nat Cell Biol. 1:376-382.

Noels, H., J. Bernhagen, and C. Weber. 2009. Macrophage migration inhibitory factor: a noncanonical chemokine important in atherosclerosis. Trends Cardiovasc Med. 19:76-86.

Norbury, C.C. 2006. Drinking a lot is good for dendritic cells. Immunology. 117:443-451.

Nordeng, T.W., T.F. Gregers, T.L. Kongsvik, S. Meresse, J.P. Gorvel, F. Jourdan, A. Motta, and O. Bakke. 2002. The cytoplasmic tail of invariant chain regulates endosome fusion and morphology. Mol Biol Cell. 13:1846-1856.

North, A.J. 2006. Seeing is believing? A beginners' guide to practical pitfalls in image acquisition. $J$ Cell Biol. 172:9-18.

O'Kelly, I., M.H. Butler, N. Zilberberg, and S.A. Goldstein. 2002. Forward transport. 14-3-3 binding overcomes retention in endoplasmic reticulum by dibasic signals. Cell. 111:577-588.

O'Sullivan, D.M., D. Noonan, and V. Quaranta. 1987. Four la invariant chain forms derive from a single gene by alternate splicing and alternate initiation of transcription/translation. J.Exp.Med. 166:444-460.

Ogrinc, T., I. Dolenc, A. Ritonja, and V. Turk. 1993. Purification of the complex of cathepsin $\mathrm{L}$ and the MHC class II-associated invariant chain fragment from human kidney. FEBS Lett. 336:555-559.

Ohmura-Hoshino, M., E. Goto, Y. Matsuki, M. Aoki, M. Mito, M. Uematsu, H. Hotta, and S. Ishido. 2006a. A novel family of membrane-bound E3 ubiquitin ligases. J Biochem (Tokyo). 140:147154.

Ohmura-Hoshino, M., Y. Matsuki, M. Aoki, E. Goto, M. Mito, M. Uematsu, T. Kakiuchi, H. Hotta, and S. Ishido. 2006b. Inhibition of MHC class II expression and immune responses by c-MIR. J Immunol. 177:341-354.
Ohmura-Hoshino, M., Y. Matsuki, M. Mito-Yoshida, E. Goto, M. Aoki-Kawasumi, M. Nakayama, O. Ohara, and S. Ishido. 2009. Cutting edge: requirement of MARCH-I-mediated MHC II ubiquitination for the maintenance of conventional dendritic cells. J Immunol. 183:6893-6897.

Ong, G.L., D.M. Goldenberg, H.J. Hansen, and M.J. Mattes. 1999. Cell surface expression and metabolism of major histocompatibility complex class II invariant chain (CD74) by diverse cell lines. Immunology. 98:296-302.

Pai, R.K., D. Askew, W.H. Boom, and C.V. Harding. 2002. Regulation of class II MHC expression in APCs: roles of types I, III, and IV class II transactivator. J Immunol. 169:1326-1333.

Palsson-McDermott, E.M., S.L. Doyle, A.F. McGettrick, M. Hardy, H. Husebye, K. Banahan, M. Gong, D. Golenbock, T. Espevik, and L.A. O'Neill. 2009. TAG, a splice variant of the adaptor TRAM, negatively regulates the adaptor MyD88independent TLR4 pathway. Nat Immunol. 10:579-586

Palucka, K., H. Ueno, G. Zurawski, J. Fay, and J. Banchereau. 2010. Building on dendritic cell subsets to improve cancer vaccines. Curr Opin Immunol. 22:258-263.

Papadopoulos, E.J., C. Sassetti, H. Saeki, N. Yamada, T. Kawamura, D.J. Fitzhugh, M.A. Saraf, T. Schall, A. Blauvelt, S.D. Rosen, and S.T. Hwang. 1999. Fractalkine, a CX3C chemokine, is expressed by dendritic cells and is up-regulated upon dendritic cell maturation. Eur J Immunol. 29:2551-2559.

Parker, D.C. 1993. T cell-dependent B cell activation. Annu Rev Immunol. 11:331-360.

Pathak, S.S., J.D. Lich, and J.S. Blum. 2001. Cutting edge: editing of recycling class II:peptide complexes by HLA-DM. J Immunol. 167:632-635.

Pattenden, S.G., R. Klose, E. Karaskov, and R. Bremner. 2002. Interferon-gamma-induced chromatin remodeling at the CIITA locus is BRG1 dependent. Embo J. 21:1978-1986.

Patterson, G.H., and J. Lippincott-Schwartz. 2002. A photoactivatable GFP for selective photolabeling of proteins and cells. Science. 297:1873-1877.

Patterson, G.H., and J. Lippincott-Schwartz. 2004. Selective photolabeling of proteins using photoactivatable GFP. Methods. 32:445-450.

Perret, E., A. Lakkaraju, S. Deborde, R. Schreiner, and E. Rodriguez-Boulan. 2005. Evolving endosomes: how many varieties and why? Curr Opin Cell Biol. 17:423-434.

Peters, P.J., J.J. Neefjes, V. Oorschot, H.L. Ploegh, and H.J. Geuze. 1991. Segregation of MHC class II molecules from MHC class I molecules in the Golgi complex for transport to lysosomal compartments. Nature. 349:669-676.

Pierre, P., L.K. Denzin, C. Hammond, J.R. Drake, S. Amigorena, P. Cresswell, and I. Mellman. 1996. HLA-DM is localized to conventional and unconventional MHC class II-containing endocytic compartments. Immunity. 4:229-239. 
Pierre, P., and I. Mellman. 1998. Developmental regulation of invariant chain proteolysis controls MHC class II trafficking in mouse dendritic cells. Cell. 93:1135-1145

Pinet, V.M., and E.O. Long. 1998. Peptide loading onto recycling HLA-DR molecules occurs in early endosomes. Eur.J.Immunol. 28:799-804.

Pober, J.S., T. Collins, M.A. Gimbrone, Jr., R.S. Cotran, J.D. Gitlin, W. Fiers, C. Clayberger, A.M. Krensky, S.J. Burakoff, and C.S. Reiss. 1983. Lymphocytes recognize human vascular endothelial and dermal fibroblast la antigens induced by recombinant immune interferon. Nature. 305:726-729.

Poteryaev, D., S. Datta, K. Ackema, M. Zerial, and A. Spang. 2010. Identification of the switch in early-to-late endosome transition. Cell. 141:497-508.

Potolicchio, I., S. Chitta, X. Xu, D. Fonseca, G. Crisi, V. Horejsi, J.L. Strominger, L.J. Stern, G. Raposo, and L. Santambrogio. 2005. Conformational variation of surface class II MHC proteins during myeloid dendritic cell differentiation accompanies structural changes in lysosomal MIIC. J Immunol. 175:4935-4947.

Poulin, L.F., S. Henri, B. de Bovis, E. Devilard, A. Kissenpfennig, and B. Malissen. 2007. The dermis contains langerin+ dendritic cells that develop and function independently of epidermal Langerhans cells. J Exp Med. 204:3119-3131.

Poulin, L.F., M. Salio, E. Griessinger, F. Anjos-Afonso, L. Craciun, J.L. Chen, A.M. Keller, O. Joffre, S. Zelenay, E. Nye, A. Le Moine, F. Faure, V. Donckier, D. Sancho, V. Cerundolo, D. Bonnet, and C. Reis e Sousa. 2010. Characterization of human DNGR-1+ BDCA3+ leukocytes as putative equivalents of mouse CD8alpha+ dendritic cells. J Exp Med. 207:1261-1271.

Powis, S.J. 2006. CLIP-region mediated interaction of Invariant chain with $\mathrm{MHC}$ class I molecules. FEBS Lett. 580:3112-3116.

Proietto, A.I., M. O'Keeffe, K. Gartlan, M.D. Wright, K. Shortman, L. Wu, and M.H. Lahoud. 2004. Differential production of inflammatory chemokines by murine dendritic cell subsets. Immunobiology. 209:163-172.

Pulendran, B., J.L. Smith, G. Caspary, K. Brasel, D. Pettit, E. Maraskovsky, and C.R. Maliszewski. 1999. Distinct dendritic cell subsets differentially regulate the class of immune response in vivo. Proc Natl Acad Sci U S A. 96:1036-1041.

Pulendran, B., H. Tang, and S. Manicassamy. 2010. Programming dendritic cells to induce $\mathrm{T}(\mathrm{H}) 2$ and tolerogenic responses. Nat Immunol. 11:647655.

Puthenveedu, M.A., B. Lauffer, P. Temkin, R. Vistein, P. Carlton, K. Thorn, J. Taunton, O.D. Weiner, R.G. Parton, and M. von Zastrow. 2010. Sequencedependent sorting of recycling proteins by actinstabilized endosomal microdomains. Cell. 143:761-773.

Qiu, G., J. Goodchild, R.E. Humphreys, and M. Xu. 1999. Cancer immunotherapy by antisense suppression of li protein in MHC-class-II-positive tumor cells. Cancer Immunol Immunother. 48:499-506.

Raiborg, C., K.G. Bache, D.J. Gillooly, I.H. Madshus, E. Stang, and H. Stenmark. 2002. Hrs sorts ubiquitinated proteins into clathrin-coated microdomains of early endosomes. Nat Cell Biol. 4:394-398.

Ramachandra, L., D. Simmons, and C.V. Harding. 2009. MHC molecules and microbial antigen processing in phagosomes. Curr Opin Immunol. 21:98-104.

Ramachandra, L., R. Song, and C.V. Harding. 1999. Phagosomes are fully competent antigenprocessing organelles that mediate the formation of peptide:class II MHC complexes. J Immunol. 162:3263-3272.

Raposo, G., and M.S. Marks. 2007. Melanosomes--dark organelles enlighten endosomal membrane transport. Nat Rev Mol Cell Biol. 8:786-797.

Raposo, G., M.S. Marks, and D.F. Cutler. 2007. Lysosomerelated organelles: driving post-Golgi compartments into specialisation. Curr Opin Cell Biol. 19:394-401.

Raposo, G., H.W. Nijman, W. Stoorvogel, R. Liejendekker, C.V. Harding, C.J. Melief, and H.J. Geuze. 1996. B lymphocytes secrete antigen-presenting vesicles. J.Exp.Med. 183:1161-1172.

Reber, A.J., H.R. Turnquist, H.J. Thomas, C.T. Lutz, and J.C. Solheim. 2002. Expression of invariant chain can cause an allele-dependent increase in the surface expression of $\mathrm{MHC}$ class I molecules. Immunogenetics. 54:74-81.

Redmond, W.L., C.E. Ruby, and A.D. Weinberg. 2009. The role of OX40-mediated co-stimulation in T-cell activation and survival. Crit Rev Immunol. 29:187-201.

Reis e Sousa, C. 2006. Dendritic cells in a mature age. Nat Rev Immunol. 6:476-483.

Reis e Sousa, C., S. Hieny, T. Scharton-Kersten, D. Jankovic, H. Charest, R.N. Germain, and A. Sher. 1997. In vivo microbial stimulation induces rapid $\mathrm{CD} 40$ ligand-independent production of interleukin 12 by dendritic cells and their redistribution to $T$ cell areas. J Exp Med. 186:1819-1829.

Reith, W., S. LeibundGut-Landmann, and J.M. Waldburger. 2005. Regulation of MHC class II gene expression by the class II transactivator. Nat Rev Immunol. 5:793-806.

Reith, W., and B. Mach. 2001. The bare lymphocyte syndrome and the regulation of $\mathrm{MHC}$ expression. Annu Rev Immunol. 19:331-373.

Robinson, J., K. Mistry, H. McWilliam, R. Lopez, P. Parham, and S.G. Marsh. 2010. The IMGT/HLA database. Nucleic Acids Res.

Rocha, N., and J. Neefjes. 2008. MHC class II molecules on the move for successful antigen presentation. Embo J. 27:1-5.

Roche, P.A., M.S. Marks, and P. Cresswell. 1991. Formation of a nine-subunit complex by HLA class II glycoproteins and the invariant chain. Nature. 354:392-394. 
Roche, P.A., C.L. Teletski, E. Stang, O. Bakke, and E.O. Long. 1993. Cell surface HLA-DR-invariant chain complexes are targeted to endosomes by rapid internalization. Proc.Natl.Acad.Sci.USA. 90:8581-8585

Rodionov, D.G., and O. Bakke. 1998. Medium chains of adaptor complexes AP-1 and AP-2 recognize leucine-based sorting signals from the invariant chain. J.Biol.Chem. 273:6005-6008.

Rodriguez-Pinto, D. 2005. B cells as antigen presenting cells. Cell Immunol. 238:67-75.

Rodriguez-Pinto, D., and J. Moreno. 2005. B cells can prime naive $\mathrm{CD} 4+\mathrm{T}$ cells in vivo in the absence of other professional antigen-presenting cells in a CD154-CD40-dependent manner. Eur J Immunol. 35:1097-1105.

Romagnoli, P., and R.N. Germain. 1994. The CLIP region of invariant chain plays a critical role in regulating major histocompatibility complex class II folding, transport, and peptide occupancy. J.Exp.Med. 180:1107-1113.

Romani, N., B.E. Clausen, and P. Stoitzner. 2010. Langerhans cells and more: langerin-expressing dendritic cell subsets in the skin. Immunol Rev. 234:120-141.

Sadegh-Nasseri, S., and R.N. Germain. 1991. A role for peptide in determining MHC class II structure. Nature. 353:167-170.

Saftig, P., and J. Klumperman. 2009. Lysosome biogenesis and lysosomal membrane proteins: trafficking meets function. Nat Rev Mol Cell Biol. 10:623635.

Salio, M., J.D. Silk, and V. Cerundolo. 2010. Recent advances in processing and presentation of CD1 bound lipid antigens. Curr Opin Immunol. 22:8188.

Sallusto, F., and A. Lanzavecchia. 1994. Efficient presentation of soluble antigen by cultured human dendritic cells is maintained by granulocyte/macrophage colony-stimulating factor plus interleukin 4 and downregulated by tumor necrosis factor alpha. J Exp Med. 179:1109-1118.

Sandoval, I.V., and O. Bakke. 1994. Targeting of membrane proteins to endosomes and lysosomes. Trends Cell Biol. 4:292-297.

Santambrogio, L., I. Potolicchio, S.P. Fessler, S.H. Wong, G. Raposo, and J.L. Strominger. 2005. Involvement of caspase-cleaved and intact adaptor protein 1 complex in endosomal remodeling in maturing dendritic cells. Nat Immunol. 6:1020-1028.

Santambrogio, L., A.K. Sato, G.J. Carven, S.L. Belyanskaya, J.L. Strominger, and L.J. Stern. 1999. Extracellular antigen processing and presentation by immature dendritic cells. Proc Natl Acad Sci U S A. 96:15056-15061

Santic, M., M. Molmeret, and Y. Abu Kwaik. 2005. Modulation of biogenesis of the Francisella tularensis subsp. novicida-containing phagosome in quiescent human macrophages and its maturation into a phagolysosome upon activation by IFN-gamma. Cell Microbiol. 7:957967.
Sapra, P., R. Stein, J. Pickett, Z. Qu, S.V. Govindan, T.M. Cardillo, H.J. Hansen, I.D. Horak, G.L. Griffiths, and D.M. Goldenberg. 2005. Anti-CD74 antibody-doxorubicin conjugate, IMMU-110, in a human multiple myeloma xenograft and in monkeys. Clin Cancer Res. 11:5257-5264.

Savina, A., C. Jancic, S. Hugues, P. Guermonprez, P. Vargas, I.C. Moura, A.M. Lennon-Dumenil, M.C. Seabra, G. Raposo, and S. Amigorena. 2006. NOX2 controls phagosomal $\mathrm{pH}$ to regulate antigen processing during crosspresentation by dendritic cells. Cell. 126:205-218.

Savina, A., A. Peres, I. Cebrian, N. Carmo, C. Moita, N. Hacohen, L.F. Moita, and S. Amigorena. 2009. The small GTPase Rac2 controls phagosomal alkalinization and antigen crosspresentation selectively in $\mathrm{CD} 8(+)$ dendritic cells. Immunity. 30:544-555.

Schaiff, W.T., K.A. Hruska, Jr., C. Bono, S. Shuman, and B.D. Schwartz. 1991. Invariant chain influences posttranslational processing of HLA-DR molecules. J.Immunol. 147:603-608.

Schnorrer, P., G.M. Behrens, N.S. Wilson, J.L. Pooley, C.M. Smith, D. El-Sukkari, G. Davey, F. Kupresanin, M. Li, E. Maraskovsky, G.T. Belz, F.R. Carbone, K. Shortman, W.R. Heath, and J.A. Villadangos. 2006. The dominant role of CD8+ dendritic cells in cross-presentation is not dictated by antigen capture. Proc Natl Acad Sci U S A. 103:1072910734.

Schuler, G., and R.M. Steinman. 1985. Murine epidermal Langerhans cells mature into potent immunostimulatory dendritic cells in vitro. J Exp Med. 161:526-546.

Schulze, H., T. Kolter, and K. Sandhoff. 2009. Principles of lysosomal membrane degradation: Cellular topology and biochemistry of lysosomal lipid degradation. Biochim Biophys Acta. 1793:674683.

Schutze, M.-P., P.A. Peterson, and M.R. Jackson. 1994. An $\mathrm{N}$-terminal double-arginine motif maintains type II membrane proteins in the endoplasmic reticulum. EMBO J. 13:1696-1705.

Serbina, N.V., T.P. Salazar-Mather, C.A. Biron, W.A. Kuziel, and E.G. Pamer. 2003. TNF/iNOS-producing dendritic cells mediate innate immune defense against bacterial infection. Immunity. 19:59-70.

Sette, A., S. Southwood, J. Miller, and E. Appella. 1995. Binding of major histocompatibility complex class II to the invariant chain-derived peptide, CLIP, is regulated by allelic polymorphism in class II. J.Exp.Med. 181:677-683.

Sevilla, L.M., S.S. Richter, and J. Miller. 2001. Intracellular transport of MHC class II and associated invariant chain in antigen presenting cells from AP-3-deficient mocha mice. Cell Immunol. 210:143-153.

Shachar, I., and R.A. Flavell. 1996. Requirement for invariant chain in B cell maturation and function. Science. 274:106-108.

Shi, X., L. Leng, T. Wang, W. Wang, X. Du, J. Li, C. McDonald, Z. Chen, J.W. Murphy, E. Lolis, P. Noble, W. Knudson, and R. Bucala. 2006. CD44 is 
the signaling component of the macrophage migration inhibitory factor-CD74 receptor complex. Immunity. 25:595-606.

Shin, J.S., M. Ebersold, M. Pypaert, L. Delamarre, A. Hartley, and I. Mellman. 2006. Surface expression of MHC class II in dendritic cells is controlled by regulated ubiquitination. Nature. 444:115-118.

Shortman, K., and W.R. Heath. 2010. The CD8+ dendritic cell subset. Immunol Rev. 234:18-31.

Shortman, K., and S.H. Naik. 2007. Steady-state and inflammatory dendritic-cell development. Nat Rev Immunol. 7:19-30.

Siebenkotten, I.M., C. Carstens, and N. Koch. 1998. Identification of a sequence that mediates promiscuous binding of invariant chain to $\mathrm{MHC}$ class II allotypes. J Immunol. 160:3355-3362.

Siegal, F.P., N. Kadowaki, M. Shodell, P.A. FitzgeraldBocarsly, K. Shah, S. Ho, S. Antonenko, and Y.J. Liu. 1999. The nature of the principal type 1 interferon-producing cells in human blood. Science. 284:1835-1837.

Simonsen, A., J.M. Gaullier, A. D'Arrigo, and H. Stenmark. 1999a. The Rab5 effector EEA1 interacts directly with syntaxin-6. J Biol Chem. 274:28857-28860.

Simonsen, A., K.W. Pedersen, T.W. Nordeng, A. von der Lippe, E. Stang, E.O. Long, and O. Bakke. 1999b. Polarized transport of $\mathrm{MHC}$ class II molecules in Madin-Darby canine kidney cells is directed by a leucine-based signal in the cytoplasmic tail of the beta-chain. J Immunol. 163:2540-2548.

Sixt, M., N. Kanazawa, M. Selg, T. Samson, G. Roos, D.P. Reinhardt, R. Pabst, M.B. Lutz, and L. Sorokin. 2005. The conduit system transports soluble antigens from the afferent lymph to resident dendritic cells in the $T$ cell area of the lymph node. Immunity. 22:19-29.

Sloma, I., M.T. Zilber, T. Vasselon, N. Setterblad, M. Cavallari, L. Mori, G. De Libero, D. Charron, N. Mooney, and C. Gelin. 2008. Regulation of CD1a Surface Expression and Antigen Presentation by Invariant Chain and Lipid Rafts. I Immunol. 180:980-987.

Stang, E., and O. Bakke. 1997. MHC class II associated invariant chain induced enlarged endosomal structures. A morphological study. Exp.Cell Res. 235:79-82.

Stang, E., C.B. Guerra, M. Amaya, Y. Paterson, O. Bakke, and E.D. Mellins. 1998. DR/CLIP (class IIassociated invariant chain peptides) and $\mathrm{DR} /$ peptide complexes colocalize in prelysosomes in human B lymphoblastoid cells. J Immunol. 160:4696-4707.

Starr, T.K., S.C. Jameson, and K.A. Hogquist. 2003. Positive and negative selection of T cells. Annu Rev Immunol. 21:139-176.

Stein, R., Z. Qu, T.M. Cardillo, S. Chen, A. Rosario, I.D. Horak, H.J. Hansen, and D.M. Goldenberg. 2004. Antiproliferative activity of a humanized antiCD74 monoclonal antibody, hLL1, on B-cell malignancies. Blood. 104:3705-3711.
Steinman, R.M., D. Hawiger, and M.C. Nussenzweig. 2003. Tolerogenic dendritic cells. Annu Rev Immunol. 21:685-711.

Stenmark, H. 2009. Rab GTPases as coordinators of vesicle traffic. Nat Rev Mol Cell Biol. 10:513-525.

Stenmark, H., R.G. Parton, O. Steele-Mortimer, A. Lütcke, J. Gruenberg, and M. Zerial. 1994. Inhibition of rab5 GTPase activity stimulates membrane fusion in endocytosis. EMBO J. 13:1287-1296.

Stern, L.J., I. Potolicchio, and L. Santambrogio. 2006. MHC class II compartment subtypes: structure and function. Curr Opin Immunol. 18:64-69.

Stockinger, B., U. Pessara, R.H. Lin, J. Habicht, M. Grez, and N. Koch. 1989. A role of la-associated invariant chains in antigen processing and presentation. Cell. 56:683-689.

Stoitzner, P., C.H. Tripp, A. Eberhart, K.M. Price, J.Y. Jung, L. Bursch, F. Ronchese, and N. Romani. 2006. Langerhans cells cross-present antigen derived from skin. Proc Natl Acad Sci U S A. 103:77837788.

Stoorvogel, W., G.J. Strous, H.J. Geuze, V. Oorschot, and A.L. Schwartz. 1991. Late endosomes derive from early endosomes by maturation. Cell. 65:417-427.

Strubin, M., C. Berte, and B. Mach. 1986a. Alternative splicing and alternative initiation of translation explain the four forms of the la antigenassociated invariant chain. EMBO J. 5:34833488.

Strubin, M., E.O. Long, and B. Mach. 1986b. Two forms of the la antigen-associated invariant chain result from alternative initiations at two in-phase AUGs. Cell. 47:619-625.

Stuart, L.M., and R.A. Ezekowitz. 2005. Phagocytosis: elegant complexity. Immunity. 22:539-550.

Stumptner, P., and P. Benaroch. 1997. Interaction of MHC class II molecules with the invariant chain: role of the invariant chain (81-90) region. EMBO J. 16:5807-5818.

Takaesu, N.T., J.A. Lower, E.J. Robertson, and E.K. Bikoff. 1995. Major histocompatibility class II peptide occupancy, antigen presentation, and CD4+ T cell function in mice lacking the p41 isoform of invariant chain. Immunity. 3:385-396.

Takaesu, N.T., J.A. Lower, D. Yelon, E.J. Robertson, and E.K. Bikoff. 1997. In vivo functions mediated by the p41 isoform of the MHC class II-associated invariant chain. J.Immunol. 158:187-199.

Tamori, Y., X. Tan, K. Nakagawa, E. Takai, J. Akagi, T. Kageshita, H. Egami, and M. Ogawa. 2005. Clinical significance of MHC class II-associated invariant chain expression in human gastric carcinoma. Oncol Rep. 14:873-877.

Taxman, D.J., D.E. Cressman, and J.P. Ting. 2000. Identification of class II transcriptional activatorinduced genes by representational difference analysis: discoordinate regulation of the DN alpha/DO beta heterodimer. I Immunol. 165:1410-1416.

Tezuka, H., Y. Abe, M. Iwata, H. Takeuchi, H. Ishikawa, M. Matsushita, T. Shiohara, S. Akira, and T. Ohteki. 2007. Regulation of IgA production by naturally 
occurring TNF/iNOS-producing dendritic cells. Nature. 448:929-933.

Thayer, W.P., L. Ignatowicz, D.A. Weber, and P.E. Jensen. 1999. Class II-associated invariant chain peptideindependent binding of invariant chain to class II MHC molecules. J.Immunol. 162:1502-1509.

Thery, C., V. Brachet, A. Regnault, M. Rescigno, P. Ricciardi-Castagnoli, C. Bonnerot, and S. Amigorena. 1998. MHC class II transport from lysosomal compartments to the cell surface is determined by stable peptide binding, but not by the cytosolic domains of the alpha- and betachains. J Immunol. 161:2106-2113.

Thibodeau, J., M.C. Bourgeois-Daigneault, G. Huppe, J. Tremblay, A. Aumont, M. Houde, E. Bartee, A. Brunet, M.E. Gauvreau, A. de Gassart, E. Gatti, M. Baril, M. Cloutier, S. Bontron, K. Fruh, D. Lamarre, and V. Steimle. 2008. Interleukin-10induced MARCH1 mediates intracellular sequestration of MHC class II in monocytes. Eur J Immunol. 38:1225-1230.

Thilo, L., E. Stroud, and T. Haylett. 1995. Maturation of early endosomes and vesicular traffic to lysosomes in relation to membrane recycling. J Cell Sci. 108 ( Pt 4):1791-1803.

Trombetta, E.S., M. Ebersold, W. Garrett, M. Pypaert, and I. Mellman. 2003. Activation of lysosomal function during dendritic cell maturation. Science. 299:1400-1403.

Trombetta, E.S., and I. Mellman. 2005. Cell biology of antigen processing in vitro and in vivo. Annu Rev Immunol. 23:975-1028.

Trowsdale, J., J. Ragoussis, and R.D. Campbell. 1991. Map of the human MHC. Immunol Today. 12:443-446.

Turley, S.J., K. Inaba, W.S. Garrett, M. Ebersold, J. Unternaehrer, R.M. Steinman, and I. Mellman. 2000. Transport of peptide-MHC class II complexes in developing dendritic cells. Science. 288:522-527.

Ueno, H., N. Schmitt, E. Klechevsky, A. Pedroza-Gonzalez, T. Matsui, G. Zurawski, S. Oh, J. Fay, V. Pascual, J. Banchereau, and K. Palucka. 2010a. Harnessing human dendritic cell subsets for medicine. Immunol Rev. 234:199-212.

Ueno, H., N. Schmitt, A.K. Palucka, and J. Banchereau. 2010b. Dendritic cells and humoral immunity in humans. Immunol Cell Biol. 88:376-380.

Underhill, D.M., and A. Ozinsky. 2002. Phagocytosis of microbes: complexity in action. Annu Rev Immunol. 20:825-852.

Van Bergen, J., S.P. Schoenberger, F. Verreck, R. Amons, R. Offringa, and F. Koning. 1997. Efficient loading of HLA-DR with a T helper epitope by genetic exchange of CLIP. Proc.Natl.Acad.Sci.USA. 94:7499-7502.

van Ham, S.M., E.P. Tjin, B.F. Lillemeier, U. Gruneberg, K.E. van Meijgaarden, L. Pastoors, D. Verwoerd, A. Tulp, B. Canas, D. Rahman, T.H. Ottenhoff, D.J. Pappin, J. Trowsdale, and J. Neefjes. 1997. HLADO is a negative modulator of HLA-DMmediated MHC class II peptide loading. Curr Biol. 7:950-957. van Niel, G., R. Wubbolts, T. Ten Broeke, S.I. Buschow, F.A. Ossendorp, C.J. Melief, G. Raposo, B.W. van Balkom, and W. Stoorvogel. 2006. Dendritic cells regulate exposure of $\mathrm{MHC}$ class II at their plasma membrane by oligoubiquitination. Immunity. 25:885-894.

van Tienhoven, E.A., C.T. ten Brink, J. van Bergen, F. Koning, W. van Eden, and C.P. Broeren. 2001. Induction of antigen specific $\mathrm{CD} 4+\mathrm{T}$ cell responses by invariant chain based DNA vaccines. Vaccine. 19:1515-1519.

Vascotto, F., D. Lankar, G. Faure-Andre, P. Vargas, J. Diaz, D. Le Roux, M.I. Yuseff, J.B. Sibarita, M. Boes, G. Raposo, E. Mougneau, N. Glaichenhaus, C. Bonnerot, B. Manoury, and A.M. LennonDumenil. 2007. The actin-based motor protein myosin II regulates MHC class II trafficking and BCR-driven antigen presentation. I Cell Biol. 176:1007-1019.

Villadangos, J.A., M. Cardoso, R.J. Steptoe, D. van Berkel, J. Pooley, F.R. Carbone, and K. Shortman. 2001. $\mathrm{MHC}$ class II expression is regulated in dendritic cells independently of invariant chain degradation. Immunity. 14:739-749.

Villadangos, J.A., and P. Schnorrer. 2007. Intrinsic and cooperative antigen-presenting functions of dendritic-cell subsets in vivo. Nat Rev Immunol. 7:543-555.

Villadangos, J.A., P. Schnorrer, and N.S. Wilson. 2005. Control of MHC class II antigen presentation in dendritic cells: a balance between creative and destructive forces. Immunol Rev. 207:191-205.

Villadangos, J.A., and L. Young. 2008. Antigen-presentation properties of plasmacytoid dendritic cells. Immunity. 29:352-361.

Viville, S., J. Neefjes, V. Lotteau, A. Dierich, M. Lemeur, H. Ploegh, C. Benoist, and D. Mathis. 1993. Mice lacking the MHC class II-associated invariant chain. Cell. 72:635-648.

Vyas, J.M., Y.M. Kim, K. Artavanis-Tsakonas, J.C. Love, A.G. Van der Veen, and H.L. Ploegh. 2007. Tubulation of class II MHC compartments is microtubule dependent and involves multiple endolysosomal membrane proteins in primary dendritic cells. $J$ Immunol. 178:7199-7210.

Wakeham, D.E., C.Y. Chen, B. Greene, P.K. Hwang, and F.M. Brodsky. 2003. Clathrin self-assembly involves coordinated weak interactions favorable for cellular regulation. Embo J. 22:4980-4990.

Walseng, E., O. Bakke, and P.A. Roche. 2008. Major histocompatibility complex class II-peptide complexes internalize using a clathrin- and dynamin-independent endocytosis pathway. J Biol Chem. 283:14717-14727.

Walseng, E., K. Furuta, B. Bosch, K.A. Weih, Y. Matsuki, O. Bakke, S. Ishido, and P.A. Roche. 2010a. Ubiquitination regulates MHC class II-peptide complex retention and degradation in dendritic cells. Proc Natl Acad Sci U SA.

Walseng, E., K. Furuta, R.S. Goldszmid, K.A. Weih, A. Sher, and P.A. Roche. 2010b. Dendritic cell activation prevents MHC class II ubiquitination and 
promotes MHC class II survival regardless of the activation stimulus. J Biol Chem.

Wang, K., P.A. Peterson, and L. Karlsson. 1997. Decreased endosomal delivery of major histocompatibility complex class II-invariant chain complexes in dynamin-deficient cells. J.Biol.Chem. 272:1705517060.

Wang, Y., J.Y. Shyy, and S. Chien. 2008. Fluorescence proteins, live-cell imaging, and mechanobiology: seeing is believing. Annu Rev Biomed Eng. 10:138.

Warmerdam, P.A.M., E.O. Long, and P.A. Roche. 1996. Isoforms of the invariant chain regulate transport of MHC class II molecules to antigen processing compartments. J.Cell Biol. 133:281291.

Watts, C. 2004. The exogenous pathway for antigen presentation on major histocompatibility complex class II and CD1 molecules. Nat Immunol. 5:685-692.

West, M.A., R.P. Wallin, S.P. Matthews, H.G. Svensson, R. Zaru, H.G. Ljunggren, A.R. Prescott, and C. Watts. 2004. Enhanced dendritic cell antigen capture via toll-like receptor-induced actin remodeling. Science. 305:1153-1157.

Westerheide, S.D., P. Louis-Plence, D. Ping, X.F. He, and J.M. Boss. 1997. HLA-DMA and HLA-DMB gene expression functions through the conserved S-X$Y$ region. J Immunol. 158:4812-4821.

Wettstein, D.A., J.J. Boniface, P.A. Reay, H. Schild, and M.M. Davis. 1991. Expression of a class II major histocompatibility complex (MHC) heterodimer in a lipid-linked form with enhanced peptide/soluble MHC complex formation at low pH. J.Exp.Med. 174:219-228.

Wilson, N.S., and J.A. Villadangos. 2004. Lymphoid organ dendritic cells: beyond the Langerhans cells paradigm. Immunol Cell Biol. 82:91-98.

Wollert, T., C. Wunder, J. Lippincott-Schwartz, and J.H. Hurley. 2009. Membrane scission by the ESCRTIII complex. Nature. 458:172-177.

Wright, K.L., and J.P. Ting. 2006. Epigenetic regulation of MHC-II and CIITA genes. Trends Immunol. 27:405-412.

Wubbolts, R., M. Fernandez-Borja, I. Jordens, E. Reits, S. Dusseljee, C. Echeverri, R.B. Vallee, and J. Neefjes. 1999. Opposing motor activities of dynein and kinesin determine retention and transport of $\mathrm{MHC}$ class II-containing compartments. J Cell Sci. 112 ( Pt 6):785-795.

Wubbolts, R., M. Fernandez-Borja, L. Oomen, D. Verwoerd, H. Janssen, J. Calafat, A. Tulp, S. Dusseljee, and J. Neefjes. 1996. Direct vesicular transport of $\mathrm{MHC}$ class II molecules from lysosomal structures to the cell surface. J.Cell Biol. 135:611-622.

Xu, M., X. Lu, N.L. Kallinteris, Y. Wang, S. Wu, E. von Hofe, J.V. Gulfo, R.E. Humphreys, and G.G. Hillman. 2004. Immunotherapy of cancer by antisense inhibition of li protein, an immunoregulator of antigen selection by MHC class II molecules. Curr Opin Mol Ther. 6:160-165.

Xu, Y., C. Jagannath, X.D. Liu, A. Sharafkhaneh, K.E. Kolodziejska, and N.T. Eissa. 2007. Toll-like receptor 4 is a sensor for autophagy associated with innate immunity. Immunity. 27:135-144.

Yamazaki, S., and R.M. Steinman. 2009. Dendritic cells as controllers of antigen-specific Foxp3+ regulatory T cells. J Dermatol Sci. 54:69-75.

Yates, R.M., A. Hermetter, G.A. Taylor, and D.G. Russell. 2007. Macrophage activation downregulates the degradative capacity of the phagosome. Traffic. 8:241-250.

Ye, L., X. Liu, S.N. Rout, Z. Li, Y. Yan, L. Lu, T. Kamala, N.K. Nanda, W. Song, S.K. Samal, and X. Zhu. 2008. The MHC class II-associated invariant chain interacts with the neonatal Fc gamma receptor and modulates its trafficking to endosomal/lysosomal compartments. J Immunol. 181:2572-2585.

Young, L.J., N.S. Wilson, P. Schnorrer, A. Proietto, T. ten Broeke, Y. Matsuki, A.M. Mount, G.T. Belz, M. O'Keeffe, M. Ohmura-Hoshino, S. Ishido, W. Stoorvogel, W.R. Heath, K. Shortman, and J.A. Villadangos. 2008. Differential MHC class II synthesis and ubiquitination confers distinct antigen-presenting properties on conventional and plasmacytoid dendritic cells. Nat Immunol. 9:1244-1252.

Zhao, X., E. Deak, K. Soderberg, M. Linehan, D. Spezzano, J. Zhu, D.M. Knipe, and A. Iwasaki. 2003. Vaginal submucosal dendritic cells, but not Langerhans cells, induce protective Th1 responses to herpes simplex virus-2. J Exp Med. 197:153-162.

Zhong, G., P. Romagnoli, and R.N. Germain. 1997. Related leucine-based cytoplasmic targeting signals in invariant chain and major histocompatibility complex class II molecules control endocytic presentation of distinct determinants in a single protein. J Exp Med. 185:429-438.

Zimmermann, V.S., P. Rovere, J. Trucy, K. Serre, P. Machy, F. Forquet, L. Leserman, and J. Davoust. 1999. Engagement of $\mathrm{B}$ cell receptor regulates the invariant chain-dependent MHC class II presentation pathway. J.Immunol. 162:24952502.

Zwart, W., A. Griekspoor, C. Kuijl, M. Marsman, J. van Rheenen, H. Janssen, J. Calafat, M. van Ham, L. Janssen, M. van Lith, K. Jalink, and J. Neefjes. 2005. Spatial separation of HLA-DM/HLA-DR interactions within MIIC and phagosomeinduced immune escape. Immunity. 22:221-233.

Zwart, W., V. Peperzak, E. de Vries, A.M. Keller, G. van der Horst, E.A. Veraar, U. Geumann, H. Janssen, L. Janssen, S.H. Naik, J. Neefjes, and J. Borst. 2010. The invariant chain transports TNF family member CD70 to MHC class II compartments in dendritic cells. J Cell Sci. 123:3817-3827. 
PAPERS

PAPER I

Invariant chain increases the half-life of MHC II by delaying endosomal maturation

Landsverk, O. J. B., Barois, N., Gregers, T. F., Bakke, O. Immunol Cell Biol. 2010 Nov 30.

PAPER II

Regulation of invariant chain through monocyte derived dendritic cell maturation

Landsverk, O. J. B., Ottesen, A. H., Berg-Larsen, A., Appel, S., Bakke, O. Manuscript. 

I 



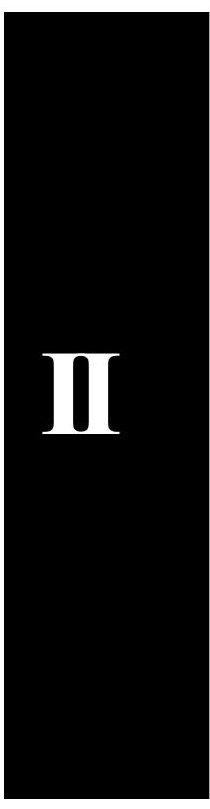


